\title{
Monoaminergic and Histaminergic Strategies and Treatments in Brain Diseases
}

\author{
Giuseppe Di Giovanni ${ }^{1}$, Dubravka Svob Strac ${ }^{2}$, Montse Sole ${ }^{3}$, Mercedes Unzeta ${ }^{3}$, \\ Keith F. Tipton ${ }^{4}$, Dorotea Mück-Šeler ${ }^{2}$, Irene Bolea ${ }^{3}$, Laura Della Corte ${ }^{5}$, \\ Matea Nikolac Perkovic ${ }^{2}$, Nela Pivac ${ }^{2}$, Ilse J. Smolders ${ }^{6}$, Anna Stasiak $^{7}$, \\ Wieslawa A. Fogel ${ }^{7}$ and Philippe De Deurwaerdère ${ }^{8 *}$

\begin{abstract}
${ }^{1}$ Department of Physiology and Biochemistry, University of Malta, Msida, Malta, ${ }^{2}$ Division of Molecular Medicine, Rudjer Boskovic Institute, Zagreb, Croatia, ${ }^{3}$ Departament de Bioquímica i Biologia Molecular, Facultat de Medicina, Institut de Neurociències, Universitat Autònoma de Barcelona, Barcelona, Spain, ${ }^{4}$ School of Biochemistry and Immunology, Trinity College Dublin, Dublin, Ireland, ${ }^{5}$ Department of Neuroscience, University of Florence, Florence, Italy, ${ }^{6}$ Department of Pharmaceutical Chemistry and Drug Analysis, Vrije Universiteit Brussel, Brussels, Belgium, ${ }^{7}$ Department of Hormone Biochemistry, Medical University of Lodz, Lodz, Poland, ${ }^{8}$ Centre National de la Recherche Scientifique (Unité Mixte de Recherche 5293), Institut of Neurodegenerative Diseases, Bordeaux Cedex, France
\end{abstract}

OPEN ACCESS

Edited by:

Arjan Blokland,

Maastricht University, Netherlands

Reviewed by:

Grzegorz Kreiner,

Polish Academy of Sciences, Poland

John Finberg

Technion - Israel Institute of

Technology, Israel

*Correspondence:

Philippe De Deurwaerdère

deurwaer@u-bordeaux.fr

Specialty section

This article was submitted to

Neuropharmacology,

a section of the journal

Frontiers in Neuroscience

Received: 31 July 2016 Accepted: 07 November 2016 Published: 24 November 2016

Citation:

Di Giovanni G, Svob Strac D, Sole M Unzeta M, Tipton KF, Mück-Šeler D, Bolea I, Della Corte L, Nikolac

Perkovic M, Pivac N, Smolders IJ,

Stasiak A, Fogel WA and De

Deurwaerdère $P$ (2016)

Monoaminergic and Histaminergic Strategies and Treatments in Brain Diseases. Front. Neurosci. 10:541. doi: 10.3389/fnins.2016.00541
The monoaminergic systems are the target of several drugs for the treatment of mood, motor and cognitive disorders as well as neurological conditions. In most cases, advances have occurred through serendipity, except for Parkinson's disease where the pathophysiology led almost immediately to the introduction of dopamine restoring agents. Extensive neuropharmacological studies first showed that the primary target of antipsychotics, antidepressants, and anxiolytic drugs were specific components of the monoaminergic systems. Later, some dramatic side effects associated with older medicines were shown to disappear with new chemical compounds targeting the origin of the therapeutic benefit more specifically. The increased knowledge regarding the function and interaction of the monoaminergic systems in the brain resulting from in vivo neurochemical and neurophysiological studies indicated new monoaminergic targets that could achieve the efficacy of the older medicines with fewer side-effects. Yet, this accumulated knowledge regarding monoamines did not produce valuable strategies for diseases where no monoaminergic drug has been shown to be effective. Here, we emphasize the new therapeutic and monoaminergic-based strategies for the treatment of psychiatric diseases. We will consider three main groups of diseases, based on the evidence of monoamines involvement (schizophrenia, depression, obesity), the identification of monoamines in the diseases processes (Parkinson's disease, addiction) and the prospect of the involvement of monoaminergic mechanisms (epilepsy, Alzheimer's disease, stroke). In most cases, the clinically available monoaminergic drugs induce widespread modifications of amine tone or excitability through neurobiological networks and exemplify the overlap between therapeutic approaches to psychiatric and neurological conditions. More recent developments that have resulted in improved drug specificity and responses will be discussed in this review.

Keywords: antipsychotic, antidepressant, monoamine oxidase inhibitor, multi-target pharmacology, neurodegenerative diseases, stroke, antiparkinsonian treatments, drug addiction 


\section{INTRODUCTION}

Monoaminergic systems are important cellular targets in a variety of neuropsychiatric and neurological conditions. Improved knowledge of these systems, in terms of function and molecular organization, has confirmed their roles in the efficacy of older medications. Medicinal chemistry has detected some newer compounds that affect identified molecular targets and additional monoaminergic targets are still being investigated. Although monoaminergic systems have a pivotal role in the effect of many existing medicines, there is a need for further developments, as additional targets have been identified that could be as interesting as monoamines (Millan et al., 2015b).

Monoaminergic systems, involving dopamine (DA), serotonin (5-HT), noradrenaline (NA) and histamine are involved in virtually all cerebral functions and modification of their activity has been identified in most, if not all, neuropsychiatric and neurological diseases. Some of these diseases, including schizophrenia, depression and Parkinson's disease (PD) benefit from monoaminergic-based treatments, but there is still scope for therapeutic improvement. In spite of clear monoaminergic disturbances in other devastating diseases, including Alzheimer's disease, addiction and epilepsy, no approved monoamine-based treatments are yet available. The discovery of the most pertinent drugs in numerous psychiatric diseases was serendipitous while the causal implication of monoaminergic systems in several diseases is still unclear. In this context, the identification of drug targets as well as more detailed neuropharmacological analysis should allow for the improvement of existing drugs.

The complexity of the organization of monoaminergic systems in the brain limits the likelihood of drugs acting on a single target to correct a disease selectively, although recent examples suggest that this strategy might be worth continuing (Meltzer and Roth, 2013). Moreover, specific targets for a neurotransmitter are often distributed in numerous neurobiological circuits so that a selective compound may produce a plethora of distinct effects, some of which may be undesirable. Such a situation may occur in the treatment of diseases like schizophrenia where the use of DA receptor antagonists is associated with undesirable side effects, as discussed below. The complexity of these circuits may lead to the proposed use of either agonists or antagonists for correcting the same diseases (Di Giovanni and De Deurwaerdère, 2016). There is a growing body of evidence demonstrating that most neuropsychiatric disorders are multifactorial and that an action on a single target is elusive both in terms of

\footnotetext{
Abbreviations: COMT, catechol-O-methyl transferase; DA, dopamine; 5-HT, serotonin; NA, noradrenaline; MAO, monoamine oxidase; MAO-I, monoamine oxidase inhibitor; SSRI, selective serotonin reuptake inhibitor; SNRI, serotonin noradrenaline reuptake inhibitor; AD, Alzheimer's disease; PD, Parkinson's disease; VTA, ventral tegmental area; SNc, substantia nigra pars compacta; LC, locus coeruleus; L-DOPA, L-3,4-dihydroxyphenylalanine; AADC, aromatic Lamino acid decarboxylase; DBH, dopamine $\beta$-hydroxylase; TPH, tryptophan hydroxylase; VMAT2, vesicular monoamine transporter; SERT, 5-HT transporter; DAT, DA transporter; NET, NA transporter; OCT, organic cation transporters; PMAT, plasma membrane monoamine transporter; EPS, extrapyramidal sideeffects; TCA, tricyclic antidepressant; AChEI, acetylcholinesterase inhibitor; VAP1 , vascular adhesion protein 1 .
}

symptomatic and curative treatments (Millan et al., 2015a,b). Increased understanding of the mechanisms involved in such diseases led to the use of combinations of drugs targeting distinct receptors/enzymes or to the development of multi-target drugs. Finally, it is clear that the action on one target of one monoaminergic system will have repercussion on the activity of the other systems, which can affect the efficacy of medicines and may also introduce unwanted side-effects.

Therapeutic approaches that target monoaminergic systems are completely different and depend on the disease. The aim of this review is to present the development of new chemical compounds and therapeutic strategies aimed at modulating monoaminergic function in various brain disorders. We used the angle depicted in Figure $\mathbf{1}$ arbitrarily categorizing three groups of diseases. Thus, after briefly presenting the physiology of the four main monoamine systems in the brain, this review will summarize past and current developments in the treatment of neuropsychiatric diseases that have monoaminergic-based medication (schizophrenia, depression, obesity) without a clear pathophysiological picture. Thereafter, we will present therapeutic strategies for brain diseases where the cause of the disease has been identified but with distinct success regarding the treatments and their amelioration (PD, drug addiction). The review will finish by presenting some strategies aimed at ameliorating the symptoms of brain diseases that still do not benefit from monoaminergic-based treatments in spite of the numerous evidence that it could be beneficial (epilepsy, $\mathrm{AD}$, and ischemic stroke). The choice has been also driven by the involvement of the various researchers in the COST action CM1103, which was dedicated to drug design in the field of monoamines. The overall picture should give a clearer indication of the neuropharmacological significance of targeting monoaminergic systems in neuropsychiatric diseases and the need for future research.

\section{MONOAMINERGIC SYSTEMS IN THE BRAIN}

Pathways of monoaminergic systems project from the brainstem to different brain areas and the spinal cord, and they include dopaminergic neurons, located in the ventral tegmental area (VTA) and the substantia nigra pars compacta (SNc), noradrenergic neurons, arising from locus coeruleus (LC), serotonergic neurons, originating from median and dorsal raphe nuclei (Hale and Lowry, 2011) and histaminergic neurons arriving from tuberomamillary nucleus of the hypothalamus (Taylor, 1975). Figure 2 illustrates approximately the, still limited, knowledge of the pharmacological and biochemical identities for each of these systems. DA is a catecholamine synthesized by the enzyme tyrosine hydroxylase (TH), which catalyzes the conversion of the amino acid L-tyrosine to L3,4-dihydroxyphenylalanine (L-DOPA), and by the aromatic Lamino acid decarboxylase (AADC) which converts L-DOPA into DA (Cooper et al., 2003). DA can be metabolized by dopamine $\beta$-hydroxylase (DBH) into NA. DBH is mainly present in vesicles and can be found in the cytosol (Gagnon et al., 1976). 5-HT is 


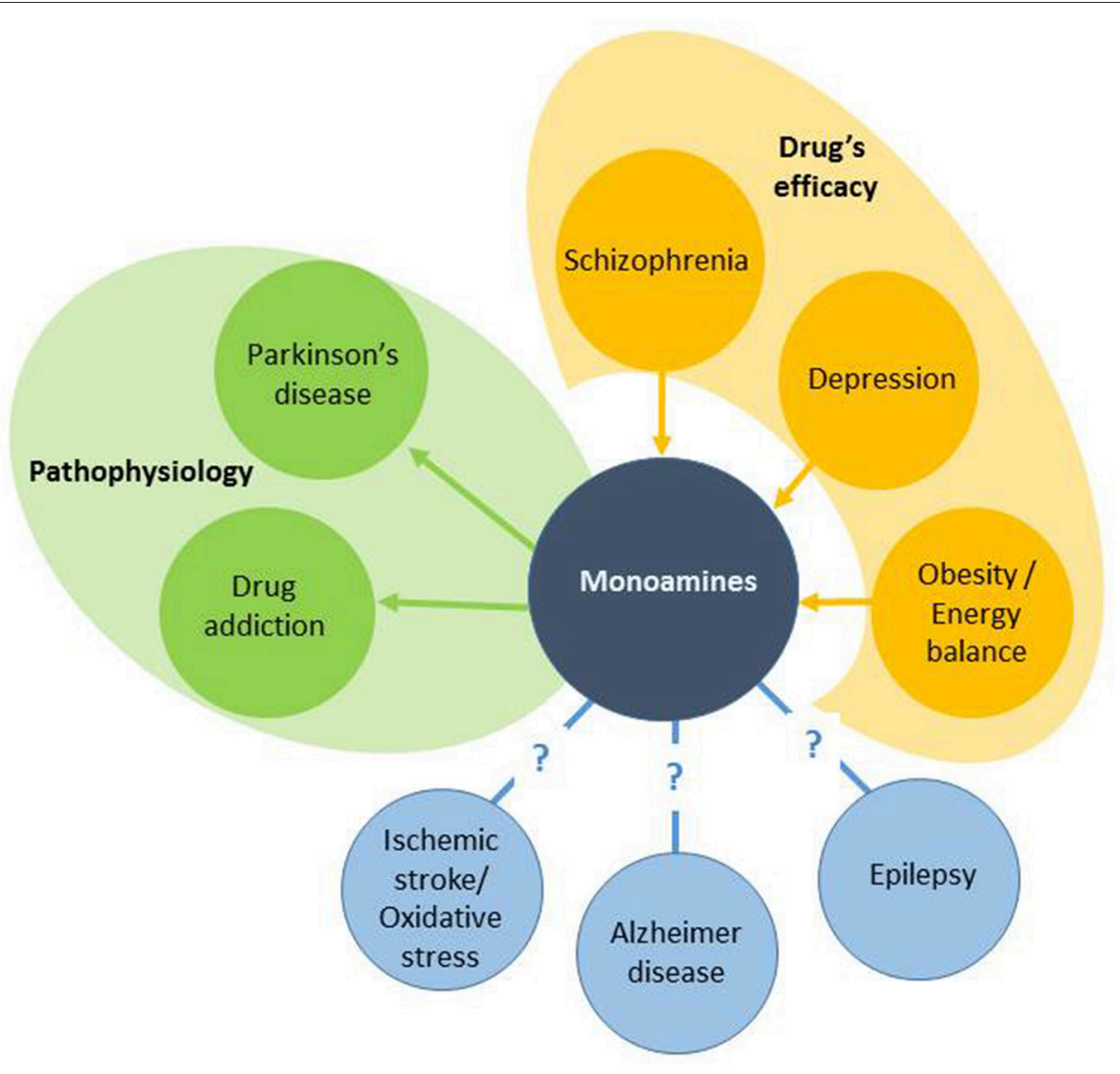

FIGURE 1 | Relationships between brain diseases and monoamines. We artificially separate three groups of diseases. The first group is based on the discovery of the involvement of monoamines in drug's efficacy (the arrows go from the drugs to monoamines in a disease). The second group includes diseases where monoamines have been causally involved in the disease, leading to development of monoaminergic drugs (L-DOPA for instance; the arrows go from the disease to the drugs). The third group has no monoamine-based treatments implying an open research.

produced from L-tryptophan by tryptophan hydroxylase (TPH) and AADC. Unlike in the case of the catecholamines and 5HT, the decarboxylase involved in the synthesis of histamine is L-histidine decarboxylase (Taylor, 1975).

The degradation of biogenic amines is a complex mechanism that is not fully understood because it involves several enzymes and cell types. The monoamine oxidases (MAO) are a family of flavin adenine dinucleotide (FAD)-containing enzymes that catalyze the oxidative deamination of primary, secondary or tertiary amines. They produce hydrogen peroxide, ammonia and the corresponding aldehyde. There are two isoforms of MAO present in mammals: MAO-A and MAO$B$, which share approximately $70 \%$ sequence identity and are encoded by separate genes located on the $\mathrm{X}$ chromosome (Youdim et al., 2006). The anatomical distribution of MAO isoforms in human brains was confirmed by positron-emission topography (PET) using intravenous ${ }^{11} \mathrm{C}$-labeled irreversible inhibitors (Fowler et al., 1987). Autoradiographic and in situ hybridization studies have revealed that histaminergic and serotonergic neurons as well as astrocytes are rich in MAO$\mathrm{B}$ whereas catecholaminergic neurons mainly contain MAO-A (Saura et al., 1992, 1996). DA, NA and 5-HT can be degraded by MAO-A (Youdim et al., 2006; Finberg, 2014). The aldehyde derivatives, which are more toxic than the parent compounds, are catabolized by aldehyde dehydrogenase/reductase (Eisenhofer et al., 2004). MAO-B is involved in the glial metabolism of catecholamines and can affect the metabolism of biogenic amines in diverse conditions including PD (Youdim et al., 2006; Riederer and Laux, 2011). It is also involved in the metabolism of other amines, including 2-phenylethylamine and $\mathrm{N}$ (tele)-methylhistamine.

Catechol-O-methyltransferase (COMT) can also metabolize DA and NA (Eisenhofer et al., 2004). Two isoforms have been described (soluble COMT, S-COMT; membrane-bound COMT, MB-COMT) having different subcellular compartmentation. In the brain, S-COMT is found in the cytosol of glial cells, whereas MB-COMT is bound to the endoplasmic reticulum and present in neurons. MB-COMT mainly inactivates catecholamines and derivatives originating from DA and NA neurotransmission, whereas S-COMT preferentially transforms exogenous catecholamines (Myohanen et al., 2010; Tammimäki et al., 2010). COMT is not present in DA terminals (Schendzielorz et al., 2013), implying that glial cells or other neurons reuptake extracellular DA in tissues where the clearance 


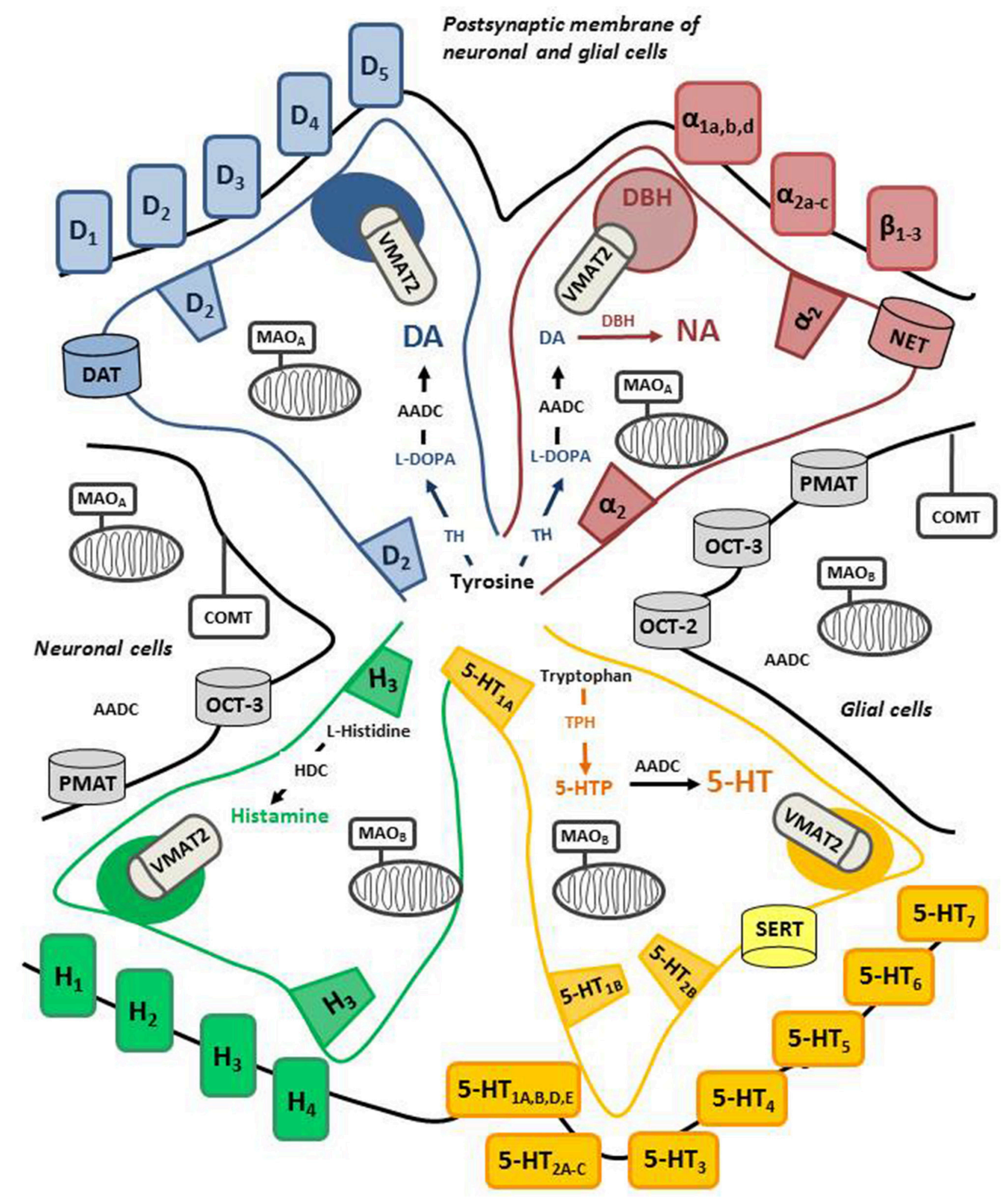

FIGURE 2 | Cellular and molecular organization of central monoaminergic systems. The figure depicts each monoamine system (dopamine, DA; noradrenaline, NA; serotonin, 5-HT; histamine) the biosynthesis, metabolism, the receptors and transporters. The color is used to identify the proteins that are selective for each system while the black color is used for non-specific proteins. The terminals of each monoaminergic neurons contact post-synaptic elements that express a variety of receptors which are more or less specific for each monoamine. Autoreceptors can be located at terminals and cell bodies for most systems. In the 
FIGURE 2 | Continued

case of serotonergic cells, $5-\mathrm{HT}_{1 \mathrm{~A}}$ autoreceptors are expressed at cell bodies and $5-\mathrm{H} \mathrm{T}_{1 \mathrm{~B}}$ autoreceptors are expressed at terminals The post-synaptic elements (neurons, glial cells) also express enzymes involved in their metabolism (MAO-A/B, COMT, AADC) as well as non-specific transporters. Of note, the distribution of $\mathrm{MAO}-\mathrm{B}$ in the serotoninergic cells is rather located at the level of cell bodies. DBH is mainly expressed in vesicles of exocytosis in noradrenergic terminals. AADC, aromatic L-amino acid decarboxylase; DBH, dopamine $\beta$-hydroxylase; TPH, tryptophan hydroxylase; VMAT2, vesicular monoamine transporter; SERT, 5-HT transporter, DAT, DA transporter; NET, NA transporter; OCT, organic cation transporters; PMAT, plasma membrane monoamine transporter; HDC, L-histidine decarboxylase; MAO, monoamine oxidase (A or B); COMT, catechol-O-methyl transferase.

of DA is low. COMT is also involved in the degradation of metabolites generated by MAO activities. The final products from these two distinct catabolic pathways is homovanillic acid for DA metabolism and either vanillylmandelic acid or a conjugated form of 3-methoxy-4-hydroxyphenylglycol for NA metabolism (Eisenhofer et al., 2004). Histamine follows distinct pathways. It is converted in the brain by histamine $\mathrm{N}$ methyltransferase to $\mathrm{N}$ (tele)-methylhistamine, which undergoes degradation by MAO-B followed by the aldehyde oxidation to $\mathrm{N}$ (tele)-methylimidazole acetic acid, while in periphery histamine is degraded by diamine oxidase (Taylor, 1975; Morisset et al., 2000).

Once synthesized, all monoamines are concentrated in the vesicular compartment by the vesicular monoamine transporter or VMAT2 (Wimalasena, 2011). Regarding the extracellular space, various transporters are involved in the clearance of monoamines. Three major classes of monoamine transporters, 5-HT transporter (SERT), DA transporter (DAT), and NA transporter (NET), are responsible for the reuptake of 5HT, DA and NA, respectively, from the synaptic cleft back to pre-synaptic neuron (Torres et al., 2003). Of note, the reuptake of DA occurs physiologically through the NET in extrastriatal tissues (Di Chiara et al., 1992). The reuptake of these monoamines is not totally selective and there are also several low affinity/high capacitance transporters including the organic cation transporters (OCT1-3 subtypes) and the plasma membrane monoamine transporter (PMAT) (Daws, 2009; Hensler et al., 2013; De Deurwaerdère et al., 2016). These systems, which are expressed by glial cells and other types of neurons, are involved in the reuptake of histamine (no preferential transporter) and the other monoamines. Thus, while the first step of synthesis can be selective, most of the other steps are overlapping and the catabolism involves cells other than monoaminergic neurons (Figure 2). Furthermore, the enzymes of biogenic amine catabolism are involved in several additional processes.

The main selectivity regarding these systems, although limited to some extent, is conferred by the receptors; two families for DA ( $D_{1}$-like including $D_{1}$ and $D_{5} R$ and $D_{2}$-like including $D_{2} L$, $\mathrm{D}_{2} \mathrm{~S}, \mathrm{D}_{3}, \mathrm{D}_{4}$ receptor subtypes) (Emilien et al., 1999; Beaulieu and Gainetdinov, 2011), three families also for NA $\left(\alpha_{1 a, b, d}\right.$ or $\alpha_{2 \mathrm{a}-\mathrm{d}}$ receptor subtypes, and $\beta$ receptor subtypes including $\left.\beta_{1-3}\right)$ (Andersson, 1980; Ahles and Engelhardt, 2014; Ghanemi and Hu, 2015), four for histamine $\left(\mathrm{H}_{1-4}\right)$ (Panula et al., 2015) and seven for 5-HT (5-HT $1-7$ ) (Barnes and Sharp, 1999; Hoyer et al., 2002). They are mostly G-protein-coupled receptors (GPCR), except for the $5-\mathrm{HT}_{3}$ receptor subtypes which are channel receptors. The cerebral distribution is distinct for each receptor. The differential distribution in some brain regions for a subtype can be a hint with regards to its participation in some specific functions. Details related to brain expression of monoamine receptors are found in the above-cited authoritative reviews. In any case, most of them are expressed in several neurobiological networks. Moreover, several subtypes may directly, as autoreceptors (see below), or indirectly modify the activity of monoaminergic neurons, thereby altering neurobiological networks beyond their specific distribution.

Each monoaminergic neuronal system has its own autoreceptor(s). Thus, adrenergic cells express the $\alpha_{2 c}$ receptor while histaminergic neurons express $\mathrm{H}_{3}$ receptors. Dopaminergic and serotonergic neurons express $\mathrm{D}_{2} / \mathrm{D}_{3}$ receptors and $5-\mathrm{HT}_{1 \mathrm{~A}}$, $5-\mathrm{HT}_{1 \mathrm{~B} / 1 \mathrm{D}}$ and $5-\mathrm{HT}_{2 \mathrm{~B}}$ receptors, respectively. The function of these autoreceptors located at both cell bodies and/or neuron terminals is usually to inhibit the electrical activity, excitability, synthesis and/or release. They also regulate the activity of the transporters presumably via intracellular signaling pathways. As illustrated in Figure 2, these autoreceptors are also expressed by other cell types (heteroreceptors).

The last point to consider when dealing with neuropharmacology of monoaminergic systems is that, either by acting on non-selective enzymes such as MAO, or by selectively targeting one receptor, the biological responses likely involve all systems due to their interaction throughout the brain (Fitoussi et al., 2013; Hensler et al., 2013). The complex interaction between these systems overwhelms the single target and the integrative views of the newer monoaminergic treatments must clearly include this dimension (De Deurwaerdère and Di Giovanni, 2016).

\section{FROM THE DRUGS TO MONOAMINES}

\section{Treatments of Schizophrenia Historical Perspectives}

It is logical to start the overview of the monoaminergic potentials in psychiatry by the discovery of neuroleptic drugs (antipsychotic drugs), which may be considered as the birth of biological psychiatry. Schizophrenia is a complex neuropsychiatric disorder with high prevalence (Owen et al., 2016). In the early 1950s, chlorpromazine was initially used by the French physicians Laborit and Charpentier for its antihistaminic properties, to calm down patients before anesthesia. The effect of chlorpromazine was spectacular and it was transposed successfully to the treatment of schizophrenia by Deniker and Delay (López-Muñoz et al., 2005). Other drugs from different chemical classes were found to mimic the antipsychotic action of chlorpromazine, but it was several years before the understanding that dopaminergic 
system could be involved (Carlsson and Lindqvist, 1963), and that the DA $\left(\mathrm{D}_{2}\right)$ receptor subtype was a common target of all antipsychotic drugs (Seeman et al., 1975, 1976). Nowadays, central $\mathrm{D}_{2}$ receptors, among other receptor types, remain an essential target in drug design of newer antipsychotic drugs (Butini et al., 2016).

\section{Mechanisms of Action of Antipsychotic Drugs}

All antipsychotic drugs block the $\mathrm{D}_{2}$ receptor subtype and the antipsychotic efficacy depends on the proportion of occupied $\mathrm{D}_{2}$ receptors, which is directly related to the affinity of the compound at $\mathrm{D}_{2}$ receptor and the free plasma concentration of the antipsychotic drug. Most of these drugs including chlorpromazine or haloperidol are efficacious against positive symptoms of schizophrenia such as delusion, paranoia or hallucinations. Their therapeutic benefit is assumed to be related to the blockade of $D_{2}$ receptors in the ventral striatum (nucleus accumbens). On the other hand, these compounds are not efficacious against the negative symptoms which may even aggravate (Millan et al., 2014; Remington et al., 2016). These drugs also induce several serious side-effects, either due to their off-targets including $\mathrm{H}_{1}, \alpha_{2}$, muscarinic2 $\left(\mathrm{M}_{2}\right)$ receptor antagonist properties, or to chronic central $\mathrm{D}_{2}$ receptor blockade. Notably the extrapyramidal side-effects (EPS) include parkinsonism, akathisia, dystonia and tardive dyskinesia (Ebadi and Srinivasan, 1995).

Although clozapine is more efficacious against negative and cognitive symptoms than other antipsychotic drugs and has fewer EPS (Ashby and Wang, 1996), its clinical use was discontinued due to its propensity to induce agranulocytosis. However, it was subsequently reintroduced if carefully monitored (Deutch et al., 1991; Ashby and Wang, 1996). The peculiar clinical responses gave rise to the concept of the typical and atypical antipsychotic drugs, the latter inducing less EPS and vegetative effects (Meltzer, $1993,1999)$. Studies of the pharmacological behavior of drugs like clozapine or risperidone led to the proposal that the atypical profile corresponds to a higher affinity of the drug toward 5$\mathrm{HT}_{2}$ (i.e., $5-\mathrm{HT}_{2 \mathrm{~A}}$ ) vs. $\mathrm{D}_{2}$ receptor subtypes (Meltzer et al., 1989a,b). This pharmacological constraint has been added to the $\mathrm{D}_{2}$ receptor target in the selection of drugs possibly exhibiting an atypical antipsychotic profile. Drugs like olanzapine, quetiapine, ziprasidone and more recently brexpiprazole are representatives of this class (Table 1). These newer antipsychotic drugs have lower propensity to induce EPS, but another concern emerges regarding the development of metabolic side effects such as weight excess. It is possible that their antagonist/inverse agonist profile at $5-\mathrm{HT}_{2} \mathrm{C}$ receptors in addition to the $\mathrm{H}_{1}$ receptor antagonism participate to the development of increased body weight and obesity side effect (see below) (Table 1).

The superiority of clozapine in terms of low incidence of EPS has been also related to its low affinity at $\mathrm{D}_{2}$ receptors, implying a fast dissociation from the receptor and avoiding unsurmountable $\mathrm{D}_{2}$ receptor blockade, either acutely or chronically (Kapur and Seeman, 2001). This property has not been verified for all antipsychotics but it introduces the notion that antipsychotic drugs could correct rather than block central DA transmission. Aripiprazole brexpiprazole or cariprazine display partial agonist activities at some signaling pathways connected to $\mathrm{D}_{2}$ receptors (Kiss et al., 2010; Citrome, 2013, 2015). In spite of the high occupancy of $\mathrm{D}_{2}$ receptors in vivo presumably overwhelming the $80 \%$ threshold occupancy, these partial or biased agonists do not induce catalepsy in rats and induce fewer EPS in humans compared to typical neuroleptics (Citrome, 2015).

\section{Questions and Directions}

There are several outstanding questions for neuropharmacology. In spite of the availability of antipsychotic drugs minimizing the occurrence of EPS, abnormal motor responses are still present with some of these medications.

(i) The reason why $5-\mathrm{HT}_{2 \mathrm{~A}}$ receptor antagonism has beneficial effects is still not fully understood with respect to the lower EPS and the involvement of motor part of the basal ganglia. There are reasonable amounts of data showing that the impact of $\mathrm{D}_{2}$ receptor blockade in the presence of $5-\mathrm{HT}_{2 \mathrm{~A}}$ receptor antagonism would be reinforced in the mesolimbic system and conversely dampened in the mesocortical system (Meltzer and Huang, 2008). Indeed, 5- $\mathrm{HT}_{2 \mathrm{~A}}$ receptor antagonists enhance DA release induced by $\mathrm{D}_{2}$ receptor blockade in the cortex. A similar property has been observed with $5-\mathrm{HT}_{1 \mathrm{~A}}$ receptor agonism (Meltzer and Massey, 2011; Hensler et al., 2013; Schreiber and Newman-Tancredi, 2014). This may explain the fact that antipsychotic drugs like cariprazine, with low affinity for 5$\mathrm{HT}_{2 \mathrm{~A}}$ receptor and moderate to high affinity for $5-\mathrm{HT}_{1 \mathrm{~A}}$ receptors, display atypical antipsychotic drug profiles in the clinic (Kiss et al., 2010; De Deurwaerdère, 2016). The favorable profile regarding motor parts of the basal ganglia is not likely to be related to a putative disinhibitory action of $5-\mathrm{HT}_{2}$ receptor blockade on DA neuron activity, as had been previously speculated (Kapur and Remington, 1996; De Deurwaerdère and Di Giovanni, 2016). Rather, their cortical effects could have beneficial effects on cognitive symptoms of the disease that are, in part, independent from $\mathrm{D}_{2}$ receptor blockade. The categorization in typical vs. atypical antipsychotics is not always clear in considering only the binding profiles (Table 1).

(ii) The negative symptoms remain one of the most difficult challenges in the treatment of schizophrenia (Millan et al., 2014; Remington et al., 2016). Interestingly, neuropsychopharmacological analysis tends to dissociate various symptoms of schizophrenia which could have distinct etiology (Buckley et al., 2009). Acting on these distinct dimensions implies a combination of selective drugs or the use of multi-target medicines (Butini et al., 2016), and animal models adapted for the different symptoms (Millan et al., 2014). This implies, in turn, an extensive preclinical evaluation for testing the suitability of any new compound (Millan et al., 2015b; De Deurwaerdère, 2016; Di Giovanni and De Deurwaerdère, 2016). Some of the most advanced treatments focus on the following targets (Table 1): $\mathrm{D}_{2}$ receptor antagonism regarding the positive symptoms, $5-\mathrm{HT}_{1 \mathrm{~A}}$ receptor agonism $/ 5-\mathrm{HT}_{2 \mathrm{~A}}$ receptor antagonism and/or increase in cortical acetylcholine release for the 
TABLE 1 | Receptor-binding affinities of typical and atypical antipsychotic drugs.

\begin{tabular}{|c|c|c|c|c|c|}
\hline Antipsychotics & $\mathbf{D}_{2}$ & $\mathbf{D}_{3}$ & $5-\mathrm{HT}_{1 \mathrm{~A}}$ & $5-\mathrm{HT}_{2 \mathrm{~A}}$ & Other targets* \\
\hline \multicolumn{6}{|c|}{ TYPICAL ANTIPSYCHOTICS } \\
\hline Haloperidol & 8.84 & 8.56 & 6.29 & 7.28 & $\mathrm{D}_{4}(8.83) ; \alpha_{1 \mathrm{~A}}(7.9) ; \sigma_{1}(8.52)$ \\
\hline flupentixol & 9.46 & 8.76 & 5.1 & 7.06 & $\mathrm{D}_{1}(8.46) ; \mathrm{H}_{1}(9.07)$ \\
\hline Thioridazine & 9.4 & 8.82 & 6.84 & 7.56 & $\alpha_{1 \mathrm{~A}}(8.5) ; \alpha_{1 \mathrm{~B}}(8.62) ; M_{1}(7.89) ; M_{5}(7.9) ; H_{1}$ (7.78) \\
\hline Pimozide & 9.48 & 9.6 & 6.19 & 7.32 & $5-\mathrm{HT}_{7}$ (9.3); $\mathrm{D}_{4}(8.74)$ \\
\hline Perphenazine & 8.47 & 9.89 & 6.38 & 8.25 & $5-\mathrm{HT}_{6}(7.77) ; 5-\mathrm{HT}_{7}$ (7.64); $\mathrm{D}_{1}$ (7.52); $\mathrm{D}_{4}(7.77) ; \alpha_{1 \mathrm{~A}}(8) ; \mathrm{H} 1$ (8.1); $\sigma_{1}(7.73)$ \\
\hline Loxapine & 7.96 & 7.71 & 5.61 & 8.18 & $\begin{array}{l}5-\mathrm{HT}_{2 \mathrm{C}}(7.88) ; 5-\mathrm{HT}_{6}(7.51) ; 5-\mathrm{HT}_{7} \text { (7.06); } \mathrm{D}_{1}(7.27) ; \mathrm{D}_{4}(8.08) ; \mathrm{D}_{5}(7.12) ; \alpha_{1 \mathrm{~A}}(7.51) ; \alpha_{1 \mathrm{~B}} \\
(7.28) ; \alpha_{2 \mathrm{~A}}(6.82) ; \alpha_{2 \mathrm{~B}}(6.97) ; \alpha_{2 \mathrm{C}}(7.1) ; \mathrm{M}_{1}(6.92) ; \mathrm{H}_{1} \text { (8.3) }\end{array}$ \\
\hline \multicolumn{6}{|c|}{ ATYPICAL ANTIPSYCHOTICS } \\
\hline Clozapine & 6.87 & 6.66 & 7.06 & 8.39 & 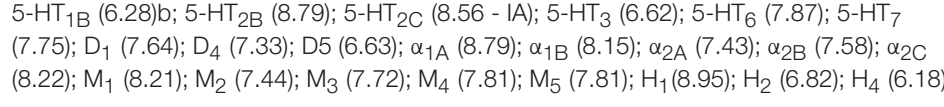 \\
\hline Risperidone & 8.21 & 8.16 & 6.75 & 9.69 & $\begin{array}{l}5-\mathrm{HT}_{1 \mathrm{~B}}(7.83) ; 5-\mathrm{HT}_{1 \mathrm{D}}(7.07) ; 5-\mathrm{HT}_{2 \mathrm{~B}}(7.8) ; 5-\mathrm{HT}_{2 \mathrm{C}}(8.17) ; 5-\mathrm{HT}_{7} \text { (8.18); } \mathrm{D}_{4}(8.21) ; \mathrm{D}_{5} \\
\text { (7.8); } \alpha_{1 \mathrm{~A}}(8.3) ; \alpha_{1 \mathrm{~B}}(8.04) ; \alpha_{2 \mathrm{~A}}(7.78) ; \alpha_{2 \mathrm{C}}(8.89) ; \mathrm{H}_{1}(7.7)\end{array}$ \\
\hline Olanzapine & 7.67 & 7.46 & 5.82 & 8.88 & $\begin{array}{l}5-\mathrm{HT}_{2 \mathrm{~B}}(8.41) ; 5-\mathrm{HT}_{2 \mathrm{C}}(8.41) ; 5-\mathrm{HT}_{3}(6.69) ; 5-\mathrm{HT}_{6}(8.09) ; 5-\mathrm{HT}_{7}(6.98) ; \mathrm{D}_{4} \text { (7.75); } \mathrm{D}_{5} \\
\text { (7.04); } \alpha_{1 \mathrm{~A}}(6.95) ; \alpha_{1 \mathrm{~B}}(6.58) ; \alpha_{2 \mathrm{~A}}(6.5) ; \alpha_{2 \mathrm{~B}}(7.09) ; \alpha_{2 \mathrm{C}} \text { (7.54); } \mathrm{M}_{1}(7.58) ; \mathrm{M}_{2}(7.2) ; \mathrm{M}_{3} \\
\text { (7.28); } \mathrm{M}_{4} \text { (7.61); } \mathrm{M}_{5} \text { (8.12); } \mathrm{H}_{1} \text { (8.66); } \mathrm{H}_{2} \text { (7.36) }\end{array}$ \\
\hline Ziprasidone & 8.09 & 8.35 & 9.01 & 9.51 & $\begin{array}{l}5-\mathrm{HT}_{1 \mathrm{~B}}(8.4) ; 5-\mathrm{HT}_{1 \mathrm{D}}(8.64) ; 5-\mathrm{HT}_{2 \mathrm{~B}} \text { (9.08); 5-HT} 2 \mathrm{C} \text { (9.01); 5- } \mathrm{HT}_{6}(7.21) ; 5-\mathrm{HT}_{7}(8.22) ; \\
\mathrm{D}_{1} \text { (8.45); } \mathrm{D}_{4} \text { (7.33); } \alpha_{1 \mathrm{~A}}(7.74) ; \mathrm{H}_{1} \text { (7.2); SERT (7.26); NET (7.32) }\end{array}$ \\
\hline Quetiapine & 6.38 & 6.41 & 6.78 & 6.81 & $\begin{array}{l}5-\mathrm{HT}_{2 \mathrm{~B}}(7.33) ; 5-\mathrm{HT}_{2 \mathrm{C}}(5.98) ; 5-\mathrm{HT}_{6}(6.02) ; 5-\mathrm{HT}_{7}(6.51) ; \mathrm{D}_{1}(6.71) ; \mathrm{D}_{4}(5.85) ; \mathrm{D}_{5}(7.8) ; \\
\alpha_{1 \mathrm{~A}}(7.66) ; \alpha_{1 \mathrm{~B}}(7.84) ; \alpha_{2 \mathrm{~A}}(5.44) ; \alpha_{2 \mathrm{C}}(7.65) ; \mathrm{H}_{1}(8.16) ; \mathrm{H}_{2}(7.38) ; \mathrm{M}_{1}(489) ; \mathrm{M}_{3}(5.79)\end{array}$ \\
\hline Brexpiprazole & 9.48 & 8.9 & 9.21 & 9.67 & $\alpha_{1 \mathrm{~A}}(8.42) ; \alpha_{1 \mathrm{~B}}(9.23) ; \alpha_{1 D}(8.58) ; \alpha_{2 \mathrm{C}}$ (9.77); 5-HT2B (8.72); 5- $\mathrm{HT}_{7}$ (8.43) \\
\hline Aripiprazole & 8.9 & 8.85 & 8.57 & 8.02 & $5-\mathrm{HT}_{2 \mathrm{~B}}(9.59)$ \\
\hline Cariprazine & 9.31 & 10.07 & 8.59 & 7.73 & $5-\mathrm{HT}_{2 \mathrm{~B}}(9.24)$ \\
\hline Amisulpiride & 8.89 & 8.62 & 5.8 & 5.08 & 5-HT2B (7.89); 5-HT7 (7.94) \\
\hline Blonaserin & 9.84 & 9.3 & 6.09 & 9.09 & \\
\hline
\end{tabular}

The $p K_{i}$ values shown are taken from several sources, including mean values from the PDSP $K_{i}$ database (Roth and Driscol, 2016). The values for the receptors: $D_{2}$, $D_{3}$, 5-HT 1 , 5-HT $2 A, 5-H T_{2 B}, 5-H T_{2 C}$ with atypical antipsychotics were from Leggio et al. (2016) or Citrome (2015). The colors indicate: Blue, drugs with higher affinity for $\mathrm{D}_{2}$ receptors; Orange,

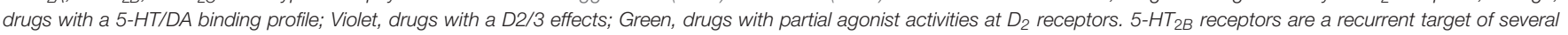

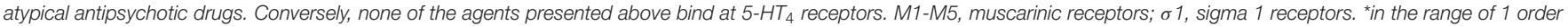
of magnitude compared to the affinity at $D_{2}$ receptors.

cognitive symptoms, and perhaps $\mathrm{D}_{3}$ receptor antagonism for the negative symptoms (Figure 3).

(iii) The pharmacological analysis of the newer antipsychotic drugs has led to consideration of other targets including 5- $\mathrm{HT}_{6}, 5-\mathrm{HT}_{7}$ receptors (Meltzer and Huang, 2008; Mauri et al., 2014) or the intriguing $5-\mathrm{HT}_{2 \mathrm{~B}}$ receptors (Devroye et al., 2016) (Table 1). Since the interaction between neurotransmitter systems is extremely complex, actions directed to some targets (e.g., $\mathrm{D}_{2}$ receptors) might unmask a deleterious involvement of other circuits. For instance, while the $5-\mathrm{HT}_{2} \mathrm{C}$ receptor blockade has not been shown to be primarily involved in the antipsychotic drug action, its blockade might be necessary to limit the occurrence of EPS induced by typical neuroleptics (Richtand et al., 2008). The neurobiological process underlying a deleterious involvement of $5-\mathrm{HT}_{2} \mathrm{C}$ receptors that follows $\mathrm{D}_{2}$ receptor blockade is not well understood (De Deurwaerdère et al., 2013). Because of the frequency of co-morbid diseases including mania, anxiety or depression in schizophrenic patients, this analysis further indicated the prescription of other medicines in addition to antipsychotic drugs (Buckley et al., 2009). Most available antipsychotic drugs have a complex pharmacological profile including adrenergic, muscarinic and histaminergic sites and most of them, especially the newer ones, are also developed for the treatment of bipolar disorder and major depression.

(iv) Very few strategies have tried to avoid the $D_{2}$ receptor target because most, if not all trials targeting a single site other than $\mathrm{D}_{2}$ receptors failed to reach clinical significance (Deutch et al., 1991; Ashby and Wang, 1996; Meltzer and Massey, 2011). Recently, the $5-\mathrm{HT}_{2} \mathrm{C}$ receptor agonist vabicanserin has been tested as a monotherapy in the treatment of schizophrenia. This was justified as the 5$\mathrm{HT}_{2} \mathrm{C}$ receptor inhibits DA release, at least in the nucleus accumbens, and its preferential agonists are efficacious in several preclinical models of schizophrenia (RosenzweigLipson et al., 2012). Although the strategy of stimulating 5$\mathrm{HT}_{2 \mathrm{C}}$ receptors should be taken with caution (Di Giovanni and De Deurwaerdère, 2016), it protects at least from the development of obesity due to its anorexigenic property and would be less prone to promoting EPS. Although having an antipsychotic profile, vabicanserin was not more efficacious than risperidone at primary end point, and its development was discontinued (Shen et al., 2014). 


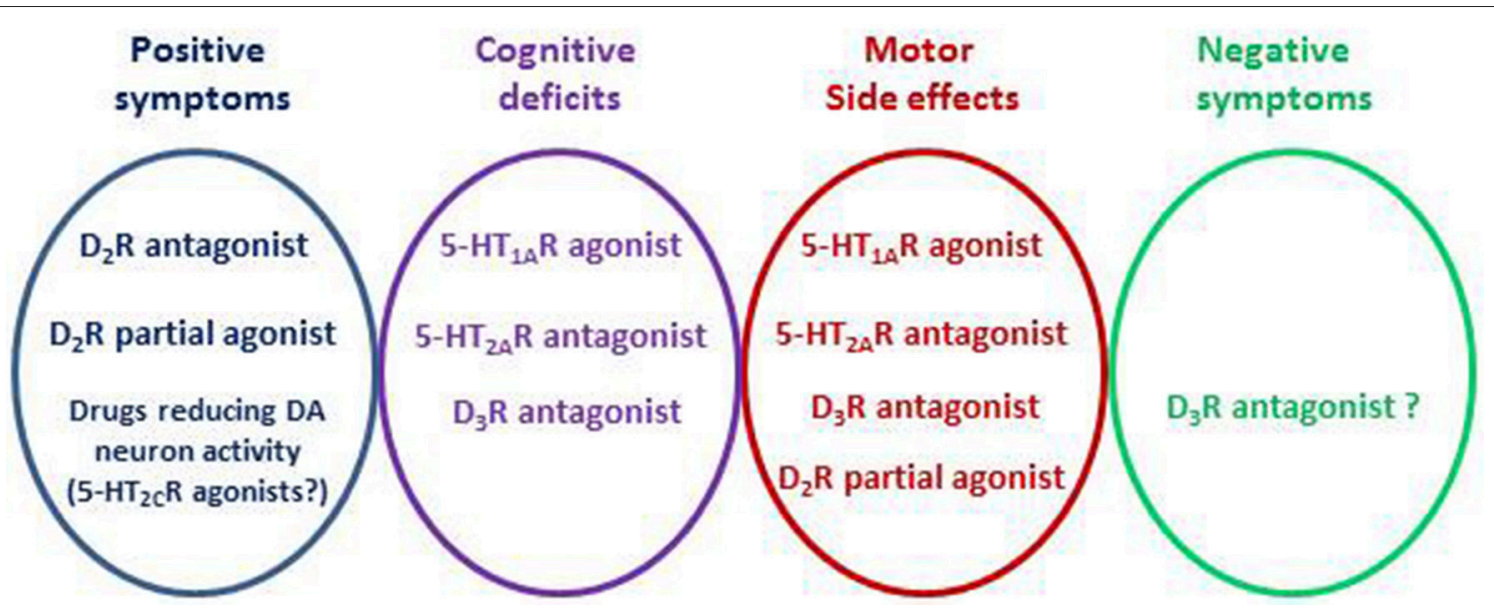

FIGURE 3 | Design of antipsychotic drugs. The elaboration of antipsychotic drugs pays attention to the positive symptoms, negative symptoms, cognitive deficits and extrapyramidal side effects. The $\mathrm{D}_{2}$ receptor subtype is the main target for the positive symptoms. The $5-\mathrm{HT}_{2 \mathrm{C}}$ receptor is an example of preclinical research target offering another possibility based on the reduction of DA neuron activity. Different targets are proposed to limit the other deficits or to avoid motor side-effects including the $5-\mathrm{HT}_{2} \mathrm{~A}, 5-\mathrm{HT}_{1 \mathrm{~A}}$ or $\mathrm{D}_{3}$ receptor subtypes. Nowadays, one of the main difficulties is to address the negative symptoms and some preclinical studies suggest beneficial effects of targeting the $\mathrm{D}_{3}$ receptor subtypes.

Nonetheless, vabicanserin might represent a change of strategy regarding the development of newer antipsychotics, focusing on the activity of the monoaminergic systems rather than on a single site.

\section{Conclusion}

After having isolated one target of antipsychotic drugs, namely the $\mathrm{D}_{2}$ receptor subtype, the search for additional targets is essential for better intervention of the full spectrum of symptoms in schizophrenia. This cannot be achieved by acting on a single target, necessitating the use of a cocktail of drugs or multitargeted compounds (Figure 3). The methodological approach to developing antipsychotic drugs is still conditioned by molecular pharmacology, although new developments in connectomics should prove valuable in the future (Fornito and Bullmore, 2015).

\section{Treatments of Depression}

\section{Historical Perspectives of Antidepressant Drugs}

Major depression is a severe, highly disabling, psychiatric disorder which is becoming a leading cause of global disease burden, with a growing prevalence of $3-17 \%$ in adults and 2.8-5.6\% in adolescents (Gururajan et al., 2016; Rantamaki and Yalcin, 2016). Its multifaceted, but poorly understood etiology involves complex interactions between different biological (genetic, epigenetic, neuroendocrine and neuroimmune), psychosocial (personality traits), developmental and environmental (exposure to early life stress) factors.

In the 1950s began a new era in the field of psychopharmacology with the clinical introduction of two antidepressants: iproniazid and imipramine (López-Muñoz and Alamo, 2009). Iproniazid, originally developed for antituberculous purposes, was characterized as MAO inhibitor (MAO-I) by Zeller and Barsky (1952). Its administration improved mood in patients and it was shown to lead to an increase in the brain levels of 5-HT in rodents (Udenfriend et al., 1957). The discovery of the antidepressant effects of iproniazid laid the path for development of more effective MAOIs such as phenelzine, tranylcypromine, isocarboxazid, and other hydrazine and indole derivates (Ban, 2001). The compound, now known as imipramine, was presented by Kuhn in 1957 as the first representative of the tricyclic antidepressants (TCAs) (Brown and Rosdolsky, 2015). In the period between 1960 and 1979, many different TCAs were developed, including amitriptyline, nortriptyline, desipramine, trimipramine, protryptyline, iprindol, dothiepin and clomipramine (Fangmann et al., 2008; López-Muñoz and Alamo, 2009). First tricyclic antidepressants were shown to inhibit the uptake of NA. The modification of the basic dibenzazepine structure of imipramine resulted in the discovery of new cyclic antidepressants during 1970s, including maprotiline and mianserine. The significant therapeutic effects of MAO-Is and TCAs, stimulated an increased interest in the role of monoaminergic system in the etiology of depression.

Fluoxetine, the first selective serotonin reuptake inhibitor (SSRI), came out in 1975 (Wong et al., 1975) and was introduced in 1987. Its unique properties and appropriate clinical efficacy established the SERT as an important target in the treatment of depression (Perez-Caballero et al., 2014). Fluoxetine is, in fact, not highly selective toward the SERT whereas citalopram, escitalopram, fluvoxamine, paroxetine or sertraline block the SERT more selectively (Thomas et al., 1987; Jacquot et al., 2007). Their efficacy is similar to TCAs but SSRIs generally have lower toxicity in comparison with MAO-Is and TCAs.

\section{Mechanisms of Action of Antidepressant Drugs}

The neurobiological basis of depression is not fully understood although the monoaminergic theory of depression stipulates 5-HT and NA extracellular deficits in different brain regions. This remains far from to be clear however, except in 
major depression with suicidal behavior where the levels of tissue 5-HT were found lower compared to levels in agematched controls (Delgado and Moreno, 2000). In animals, the destruction of either 5-HT or NA systems, or both, does not trigger depressive-like symptoms in some behavioral tests (Page et al., 1999; Cryan et al., 2002, 2005; Delaville et al., 2012). On the other hand, the enhancement of 5-HT and NA neurotransmission with some antidepressant medication results in the improvement of the common symptoms of the disease.

Studies with SSRI and other blockers of monoaminergic reuptake sites indicate that the efficacy of antidepressant drugs entails at least three sequential steps. (1) The blockade of SERT at the level of 5-HT cell bodies enhances somatodendritic 5-HT extracellular levels (Bel and Artigas, 1992; Invernizzi et al., 1992), thereby activating $5-\mathrm{HT}_{1 \mathrm{~A}}$ autoreceptors and reducing the firing rate of 5-HT neurons (Blier and de Montigny, 1990; Adell et al., 1993; Guiard et al., 2005). The blockade of SERT at terminals of 5HT neurons enhances extracellular levels of 5-HT but this effect is considerably dampened by the decrease in 5-HT neuron firing rate and the stimulation of $5-\mathrm{HT}_{1 \mathrm{~B}}$ autoreceptors located at 5HT terminals (Invernizzi et al., 1992; Gardier et al., 2003). (2) The desensitization of somatodendritic $5-\mathrm{HT}_{1 \mathrm{~A}}$ receptors in the raphe nuclei upon subchronic administration of SSRI, with the main consequence of magnifying the effects of the SERT blockade on the extracellular levels of 5-HT (Invernizzi et al., 1996; Piñeyro and Blier, 1999). (3) The final step involves modification of 5$\mathrm{HT}$ receptors at 5-HT receptive cells including $5-\mathrm{HT}_{1 \mathrm{~A}}, 5-\mathrm{HT}_{2 \mathrm{~A}}$ or 5- $\mathrm{HT}_{2 \mathrm{C}}$ receptors (Artigas et al., 2002; Artigas, 2013). These sequential steps take time which may account for the delay between start of treatment with antidepressant drug and clinical effect.

The interaction between 5-HT and NA systems is evident in the mechanism of action of TCAs because most TCAs have a better affinity for the NET compared to the SERT. Numerous studies have provided evidence that $\alpha_{1}$ and $\alpha_{2}$ receptors exerted complex interactions on 5-HT neurons, $\alpha_{1}$ receptor being excitatory. Conversely, 5-HT at least via 5$\mathrm{HT}_{2 \mathrm{~A}}$ receptors inhibits the activity of NA neurons whereas the desensitization of $5-\mathrm{HT}_{2 \mathrm{~A}}$ receptors, also occurring after SSRI, allows for an increase in central NA tone (Piñeyro and Blier, 1999; Hamon and Blier, 2013). Thus, the interaction between the 5-HT and the NA has a pivotal role in the mechanism of action of drugs targeting monoaminergic neurons terminal activity including TCAs, SSRI and MAO-I. Other antidepressant drugs target 5-HT and/or NA receptors (see below), but their mechanisms of action are less well understood. Through the interaction between monoaminergic systems (Hamon and Blier, 2013), DA changes are indirectly involved in the mechanism of action of antidepressants. The DA system is usually not directly targeted in the treatment of depression (nonetheless, see below with the introduction of antipsychotics in major depression).

\section{Amelioration of Antidepressant Drugs Actions}

In the last 20 years two main problems with antidepressant treatment have emerged, including a poor or partial response, i.e., a large proportion of patients not responding well to the therapy (Gumnick and Nemeroff, 2000), and the delay of action of antidepressant drugs usually reached after 23 weeks of treatment. The partial response of antidepressant drugs has led to the introduction of new and more effective antidepressants like venlafaxine, which inhibits the reuptake of 5-HT and NA (NSRI), and mirtazapine, which acts primarily as an antagonist of presynaptic $\alpha_{2}$-adrenoreceptors (Artigas et al., 2002). A meta-analysis assessed the effects of 12 new-generation antidepressants and showed that mirtazapine, venlafaxine and two SSRIs, escitalopram and sertraline, were more efficacious than other SSRIs (fluoxetine, fluvoxamine and paroxetine), the NSRI duloxetine and the selective NA reuptake inhibitor (SNRI) reboxetine (Cipriani et al., 2009).

The antidepressant effect of MAO-Is is dependent on inhibition of MAO-A but irreversible inhibition of that isoenzyme resulted in adverse hypertensive reactions with foods containing tyramine called "the cheese effect." To avoid this adverse event, a new strategy for the treatment of depression was presented in the form of reversible inhibitors of MAO-A (RIMA), such as moclobemide (Haefely et al., 1992), brofaromine (Davidson, 2003), and befloxatone (Curet et al., 1998). However, the use of MAO-Is today is mostly limited for treating patients with atypical depression, bipolar depression, treatment-resistant depression, or hyperserotonergic responses with SSRIs. In 2009, agomelatine, the first antidepressant that mediates its activity via the melatonergic pathway was approved (San and Arranz, 2008; Millan et al., 2010; Racagni et al., 2011). This antidepressant acts as an antagonist at $5-\mathrm{HT}_{2} \mathrm{C}$ receptors and agonist at melatonergic $\mathrm{MT}_{1}$ and $\mathrm{MT}_{2}$ receptors (Millan et al., 2010). In comparison with other standard SSRIs and SNRIs, agomelatine showed similar or even favorable efficacy and tolerability (Kasper et al., 2013). In addition to agomelatine, several other $5-\mathrm{HT}_{2 \mathrm{C}}$ agents have been reported to display strong anxiolytic/antidepressant properties in animal models and clinical studies (Millan, 2005, 2006; Millan et al., 2005; Di Giovanni and De Deurwaerdère, 2016). A summary of these evolutions has been indicated in the Table 2.

The second problem associated with antidepressant treatment is the delay of action of the drugs. Knowledge of the mechanism of action of SSRIs resulted in the proposal to reduce the delay of action by blocking $5-\mathrm{HT}_{1 \mathrm{~A} / 1 \mathrm{~B}}$ autoreceptors, thereby lessening the time period needed to produce the massive increase in 5-HT levels at the synaptic cleft (Artigas et al., 1996). However, since the efficacy of SSRI is also associated with postsynaptic 5- $\mathrm{HT}_{1 \mathrm{~A}}$ receptors (Blier et al., 1990), which are not desensitized and are required for the benefit of SSRIs, such a blockade might be expected to be counterproductive. Similar augmentation can be achieved by concomitantly blocking 5$\mathrm{HT}_{2 \mathrm{C}}$ receptors, which indirectly inhibit 5-HT neuronal activity (Cremers et al., 2004, 2007). Clinical trials involving this approach are underway (see Di Giovanni and De Deurwaerdère, 2016). Another monoaminergic possibility to obtain a fast onset of the antidepressant effect is the use of $5-\mathrm{HT}_{4}$ receptor agonists. These compounds act directly on 5-HT receptive fields in the hippocampus or the cortex and indirectly stimulate 5-HT release. Their pro-cognitive and anxiolytic effects have raised some 
TABLE 2 | Pharmacological targets of lead and newer antidepressant drugs from lead compounds.

\begin{tabular}{|c|c|c|c|}
\hline Lead compounds & Mechanisms of action & New compounds in clinic & Main targets \\
\hline Imipramine, Fluoxetine & $\begin{array}{l}\text { 5-HT/NA interaction mostly via blockade } \\
\text { of SERT and/or NET } \\
+ \\
\text { Alteration of monoamine targets and } \\
\text { function }\end{array}$ & $\begin{array}{l}\text { SSRI (Escitalopram, Citalopram, Paroxetine...) } \\
\text { NSRI (Duoxetine, Venlafaxine) } \\
\text { SNRI (Reboxetine) } \\
\text { Multi-target drugs (Vortioxetine) }\end{array}$ & $\begin{array}{l}\text { SERT } \\
\text { SERT and NET } \\
\text { NET } \\
\text { SERT/5-HT receptors }\end{array}$ \\
\hline Iproniazid & $\begin{array}{l}\text { 5-HT/NA interaction mostly via inhibition of } \\
\text { MAO-A/B (irreversible) }\end{array}$ & $\begin{array}{l}\text { Moclobemide } \\
\text { Agomelatine }\end{array}$ & $\begin{array}{l}\text { MAO-A (reversible inhibitor) } \\
\text { MT1/MT2 agonist/5- } \mathrm{HT}_{2 \mathrm{C}} \text { antagonist }\end{array}$ \\
\hline
\end{tabular}

Lead antidepressant drugs and their proposed mechanisms of action as well as newer drugs in clinical use that retain some of their targets. Agomelatine is included, although its 5 -H $T_{2 C}$ receptor antagonist action was not directly based on a lead drug (Di Giovanni and De Deurwaerdère, 2016).

interest for the treatment of depression (Lucas and Debonnel, 2002; Lucas et al., 2007; Mendez-David et al., 2014).

\section{Future Directions}

Newer antidepressants have been developed with more complex pharmacological profile such as vortioxetine (Sanchez et al., 2015). This compound blocks the SERT as well multiple 5-HT receptors (Sanchez et al., 2015; Sagud et al., 2016). This effect is in line with studies reporting that the combination of antidepressants with atypical antipsychotic drugs (olanzapine, risperidone, quetiapine, aripiprazole, paliperidone, ziprazidone, and amisulpride), can boost the effectiveness of depression treatment (Berman et al., 2007; Thase et al., 2007; Bauer et al., 2009; Han et al., 2013). Thus, the monoaminergic system remains an important field for producing newer antidepressant drugs involving refined strategies (Hamon and Blier, 2013; Artigas, 2015). Recently, there has been a growing interest in neuronal plasticity, cholinergic, GABAergic and glutamate neurotransmission, stress and HPA axis, reward system and neuroinflammation as potential underlying mechanisms of depression that go somehow beyond monoaminergic strategies (Artigas, 2015; Dale et al., 2015; Millan et al., 2015a). However, the complexity of the system is such that monoaminergic antidepressant drugs may act on different neurobiological circuits and molecular mechanisms, which might be more important targets.

\section{Obesity and Energy Balance Historical Perspective}

The neurobiological networks involved in food intake and energy balance have been the subjects of many recent studies, in view of the growing evidence for a worldwide problem of obesity. The first anti-obesity drug targeting amine neurotransmitter signaling was amphetamine. Amphetamine, $\alpha$ methylphenethylamine, member of $\beta$-phenylethylamine group of drugs, was synthesized to substitute for ephedrine. Animal and human studies showed that this compound can produce arousal and insomnia. Racemic $\alpha$-methylphenethylamine, registered by SK\&F under the name Benzedrine ${ }^{\circledR}$, was introduced in 1935 to treat narcolepsy and was also employed for mild depression, post-encephalitic parkinsonism, schizophrenia, alcoholism and other disorders (see (Bett, 1946)). In 1937, SK\&F marketed Dexedrine (d-amphetamine), the more potent of the two isomers which produced euphoria, excitability, hyperactivity and restlessness with hyperthermia. The quick loss of weight in obese subjects treated against narcolepsy with Benzedrine aroused the interest in the use of the sympathomimetics as anti-obese medicines. A clinical study on 162 patients treated with d-amphetamine, which had been performed on a smaller number of subjects, supported its usefulness as appetite depressant (Hawirko and Sprague, 1946). However, damphetamine produces addiction (Kiloh and Brandon, 1962). To decrease addictive potential, substituted amphetamines such as phenyl-tertiary-butylamine, phentermine, and fenfluramine (3-trifluoromethyl-N-ethylamphetamine) were synthesized and were approved by FDA between 1959 and 1973 for weight loss.

\section{Mechanism of Action}

The hypothalamus is a key structure involved in food intake regulation and energy balance. It receives monoaminergic terminals from several different sources and the roles of the monoamines appear to be different: 5-HT and histamine participate as a satiety factors; DA acts as the main signaling molecule in a reward system, and NA tends to enhance energy expenditure. Animal studies have shown that phenyl-tertiarybutylamine, phentermine, and fenfluramine cause the release of amines from the nerve terminals as well as inhibiting their uptake. While d-amphetamine has higher affinities for DAT and NET than SERT, fenfluramine has a higher affinity for SERT (Garattini, 1995; Kuczenski et al., 1995). In rat, both peripheral and central mechanisms of fenfluramine action have been implicated (Carruba et al., 1986).

Studies with selective ligands of 5-HT receptors in vivo have shown that hypophagic effect triggered by d-fenfluramine and its metabolite d-norfenfluramine was mediated by 5-HT acting on 5- $\mathrm{HT}_{2 \mathrm{C}}$ receptors (Vickers et al., 2001) (Table 3). Combination of phentermine and fenfluramine, i.e., "Phen-Fen," enables the therapeutically effective dose of appetite suppressants to be decreased. However, the heart valve disease related to a $5-\mathrm{HT}_{2 \mathrm{~B}}$ receptor agonism action and pulmonary hypertension (Vivero et al., 1998; Palmieri et al., 2002) caused the withdrawal of fenfluramine and dexfenfluramine from the U.S. market in 1997. Later meta-analysis of the observational studies indicated that fenfluramine-associated valvular regurgitation was less common that assumed, but still present in 1 out of 8 patients treated for $>90$ days (Sachdev et al., 2002). The next anti-obesity drug 
TABLE 3 | Anti-obesity drugs and mechanisms.



Lead compounds in the field of anti-obesity drugs and their proposed mechanisms of action are shown, together with newer drugs with similar actions. Amphetamine enhances catecholamines release through its action on DAT and NET, which led to the development of drugs that enhanced NA release. D-fenfluramine, chemically derived from amphetamine, Ioses affinities for DAT and NET in relation to SERT. Conversely, antipsychotic drugs induced weigh gain that has been corrected in newer compounds.

sibutramine (Luque and Rey, 1999), originally developed as an antidepressant, is a potent SERT and NET inhibitor in vivo (Luscombe et al., 1990). Animal studies on its mechanisms of action pointed to the activation of $\beta_{1}$-adrenoceptors, 5$\mathrm{HT}_{2 \mathrm{~A} / 2 \mathrm{C}}$ receptors and $\alpha_{1}$-adrenoceptors (Jackson et al., 1997). The compound has been shown in clinical trial to be an efficient therapeutic, although the patients who stopped using the drug quickly regained weight (James et al., 2000), as observed for the substituted amphetamines (Vivero et al., 1998). Sibutramine, having antiatherogenic activities (improvement of insulin resistance, glucose metabolism, dyslipidemia, and inflammation) concomitantly induces a moderate increase in heart rate, a slight increase in blood pressure and may also prolong the QT interval, inducing arrhythmias (Scheen, 2010). Because the hazard ratio for cardiovascular events was significantly increased in sibutramine treated patients, the drug was withdrawn from markets in 2010 (Haslam, 2016).

In 2012, a novel drug, lorcaserin, was approved by FDA for the treatment of obesity. It is a $5-\mathrm{HT}_{2} \mathrm{C}$ receptor agonist that is appetite suppressing while free of cardiovascular effects (Gustafson et al., 2013). It has about 15 and 100 times higher affinity for $5-\mathrm{HT}_{2 \mathrm{C}}$ than for $5-\mathrm{HT}_{2 \mathrm{~A}}$ and $5-\mathrm{HT}_{2 \mathrm{~B}}$ receptor subtypes. This drug stimulates the $5-\mathrm{HT}_{2} \mathrm{C}$ receptors located on proopiomelanocortin neurons in the arcuate nucleus resulting in the release of $\alpha$-melanocortin-stimulating hormone, which suppresses appetite by acting on melanocortin-4-receptors in the paraventricular nucleus (Voigt and Fink, 2015). It probably has other actions in the brain including the decrease in DA release in the nucleus accumbens, dampening goal-directed behavior (Higgins and Fletcher, 2015; Di Giovanni and De Deurwaerdère, 2016).

\section{Histamine and Obesity}

The $\mathrm{H}_{1}$ receptor antagonist component of various medications including antipsychotics is suspected to increase body weight (Kroeze et al., 2003; Ratliff et al., 2010). In addition, recent work indicates also that cerebral histaminergic system mediates the anorexic effects of oleoylethanol amide, an endogenous agonist at peroxisome proliferator-activated receptor alpha (PPAR- $\alpha$ ) (Provensi et al., 2014). Experimental and preclinical studies employing different animal models have convincingly shown that $\mathrm{H}_{1}$ and $\mathrm{H}_{3}$ receptors play an important role in energy balance and body weight gain, $\mathrm{H}_{1}$ receptor agonists and $\mathrm{H}_{3}$ receptor antagonist/inverse agonists being anorexic drugs (Clineschmidt and Lotti, 1973;
Lecklin et al., 1998; Masaki et al., 2004; Provensi et al., 2014, 2016).

Although much attempt has been done in developing histaminergic agents as anti-obesity treatment, no recent drug with a histaminergic profile reached clinics (Esbenshade et al., 2006; Provensi et al., 2016). Betahistine, registered in Europe in 1970 for the management of vertigo and vestibular pathologies, could be used to achieve anti-obesity action in some conditions (Provensi et al., 2016). This drug, combining weak agonism at $\mathrm{H}_{1}$ receptor and inverse agonism at $\mathrm{H}_{3}$ receptor, stimulates histamine synthesis and release in tuberomammillary nuclei of the posterior hypothalamus (Arrang et al., 1985; Tighilet et al., 2002; Gbahou et al., 2010). On the one hand, only $10 \%$ of 281 obese participating to a multicenter randomized placebo controlled trial positively responded to the 12 weeks therapy with betahistine (Barak et al., 2008). On the other hand, betahistine was shown to limit the excess body weight induced by the antipsychotic drug olanzapine (Table 1) in a randomized, double blind placebo controlled pilot study involving 36 patients with either schizophrenia or schizoaffective disorders (Barak et al., 2016). In an earlier double blind placebo-controlled study that involved similar number of enrolled patients, betahistine potentiated the anorexic effect of the NET blocker reboxetine in patients receiving olanzapine (Poyurovsky et al., 2013).

\section{Conclusions Regarding Monoamines and Obesity}

The study of the mechanism of action of d-fenfluramine led to completely new drugs which is an interesting achievement. Additional data are warranted in the field of the control of energy balance and monoaminergic targets. The reduction of BMI in obese patients with lorcaserin is estimated in the range of 5$10 \%$. This is less compared to the actions of previous drugs amphetamine, d-fenfluramine or sibutramine, but probably safer. Regarding antipsychotic drugs, newer antipsychotics (aripiprazole, cariprazine) display a lower affinity at $\mathrm{H}_{1}$ receptor to prevent weight gain as recommended earlier (Kroeze et al., 2003). A summary has been indicated in Table 3.

\section{FROM PATHOPHYSIOLOGY TO TREATMENTS}

\section{Parkinson's Disease Historical Perspectives}

$\mathrm{PD}$ is a neurological condition characterized by motor impairments including bradykinesia, tremor and rigidity 
(Olanow et al., 2009). The symptoms are a consequence of the degeneration of the nigrostriatal DA tract and appear approximately when $30 \%$ of DA cells in the SNc are destroyed and/or when striatal tissue DA is reduced by $70 \%$ (Burke and O'Malley, 2013). Comorbid diseases are noticed with prevalence ranging from 30 to $45 \%$ in the case of anxiety or depression (McDonald et al., 2003). The etiology of the comorbid diseases is still unknown although other neuronal changes have been identified including alterations in 5-HT and NA neurons (Jellinger, 1991; Galati and Di Giovanni, 2010; Delaville et al., 2011). More generally, PD is a synucleopathy characterized histopathologically by the presence of Lewy bodies in multiple brain regions including the $\mathrm{SNc}$ and the LC. The lesions of LC NA neurons occur earlier than SNc DA neurons, and can reach a higher extent (Del Tredici et al., 2002; Rommelfanger and Weinshenker, 2007; Delaville et al., 2011). The loss of NA input to the nigrostriatal DA system could be detrimental for the function of DA neurons (Benarroch, 2009), conferring to NA system both a protective role on DA neurons and, consequently a positive influence regarding the outcome of treatments. However, available treatments mostly target DA and not NA-related mechanisms (Table 4).

The treatments of PD depend on the stage of the disease. LDOPA was the first treatment aimed at restoring DA transmission in the brain. This amino acid can cross the blood brain barrier $(\mathrm{BBB})$ and reach the striatum before conversion to DA by AADC. The first trials started in 1961 and L-DOPA still represents the main pharmacological treatment of PD (Lees et al., 2015). Years later it was followed by the administration of DA receptor agonists, and both treatments correspond to the so-called DA replacement therapy. Deep brain stimulation of the subthalamic nucleus is a second therapeutic option in advanced stages of the disease, where patients respond poorly to medication with motor complications and have no psychiatric antecedent (Bronstein et al., 2011). A commonly used option at the onset of the disease, which appears to have few unwanted side-effects, consists in administration of MAO-B inhibitors such as L-deprenyl or rasagiline (Rascol et al., 2011; Hauser et al., 2016).

While the side-effects are still debated in the case of deep brain stimulation of the subthalamic nucleus (Bronstein et al., 2011), long-term pharmacological treatments are associated with severe motor and psychiatric side effects (Bastide et al., 2015).

\section{Mechanisms of Action of Antiparkinsonian Drugs}

The therapeutic benefit of L-DOPA and DA receptor agonists has been related to their indirect and direct actions, respectively, at DA receptors. L-DOPA has been shown to enhance extracellular levels of DA in animal models of the disease, using in vivo methods or in humans indirectly measured by the displacement of PET ligands binding at DA receptors (de la Fuente-Fernández, 2013; De Deurwaerdère et al., 2016). Since the enzyme AADC is present in most tissues as well as in brain, much of the administered L-DOPA was converted at the periphery to DA, which does not cross the BBB. This problem was ameliorated by the introduction of benserazide or carbidopa, two peripheral AADC inhibitors that do not penetrate the brain
(Cotzias, 1968; Cotzias et al., 1969). The introduction of COMT inhibitors may also increase the efficacy of L-DOPA by limiting its transformation into 3-O-methyl-DOPA, and, perhaps, by limiting the inactivation of central DA (Ries et al., 2010). One of the main side effects of L-DOPA therapy, namely L-DOPAinduced dyskinesia, has been related to the variation of plasma L-DOPA concentrations inherent to its oral administration. The pharmacokinetic challenge is to find a means of smoothing its plasma concentrations. Similarly, a continuous stimulation of DA receptors with agonists is an important criterion, and selective agonists with long-lasting action have been recently synthesized (Butini et al., 2016).

No real progress has been made regarding the pharmacodynamics of L-DOPA: researchers attempted either to boost the ability of L-DOPA to release DA in the striatum during the 1980's and the 90's, or, more recently, to limit the excess of striatal DA release thereby reducing the occurrence of dyskinesia. The danger behind these strategies, which focused on a putative restoration of striatal DA release, magnified by the implantation of grafts aimed at releasing DA into the caudateputamen of patients, is that nobody knows the extent to which striatal DA release is involved in the benefit and side-effects of peripheral L-DOPA (De Deurwaerdère et al., 2016). We now know that L-DOPA-induced dyskinesia and motor benefit can occur without a measurable enhancement of striatal DA release in animals (Porras et al., 2014), which confirmed earlier data raising doubt about the role of striatal DA in the mechanism of action of L-DOPA (Nakazato and Akiyama, 1989; Fisher et al., 2000).

In humans, the displacement of raclopride binding was observed after the intravenous administration of $3 \mathrm{mg} / \mathrm{kg} \mathrm{L}$ DOPA (de la Fuente-Fernández et al., 2004). The authors reported the displacement of ${ }^{11} \mathrm{C}$-raclopride binding, but indicated also that the presumed levels of extracellular DA produced by the i.v. administration of L-DOPA were lower in patients compared to healthy individuals (de la FuenteFernández, 2013). A similar situation occurs in rodent models at comparative, but behaviorally efficacious dosage (Navailles et al., 2010). The conclusion is that the role of striatal DA release may have been overestimated in the benefit and possibly in some side-effects elicited by L-DOPA (De Deurwaerdère et al., 2016).

The overall picture is complicated by the fact that $5-\mathrm{HT}$ neurons are mainly responsible for the release of DA induced by L-DOPA in animal models of the disease. The output of DA is dependent on the integrity of 5-HT neurons (Tanaka et al., 1999; Navailles et al., 2010). Due to the widespread innervation of 5 -HT neurons in the brain, the first consequence is that L-DOPAstimulated DA release occurs widely in the brain (Navailles et al., 2011b; Navailles and De Deurwaerdere, 2012a) (Figure 4), and this creates a new balance of central DA chemistry (Navailles and De Deurwaerdère, 2012b). The second consequence is that striatal DA released by L-DOPA is extremely low for at least three reasons: (i) the density of striatal 5-HT fibers is 10 to 20 times lower compared to the natural density of DA fibers; (ii) 5-HT neurons fire around $1 \mathrm{~Hz}$ or below and L-DOPA does not enhance the firing rate of 5-HT neurons (Miguelez et al., 2016b); DA neurons normally fire above $4 \mathrm{~Hz}$ (Bunney 
TABLE 4 | Antiparkinsonian drug treatments and pharmacological target.

\begin{tabular}{|c|c|c|c|}
\hline Pathophysiology & Drug in the market & Mechanism of action & Efficacy at pharmacological target \\
\hline $\begin{array}{l}\text { Degeneration of SNc DA neurons and } \\
\text { striatal DA loss }\end{array}$ & $\begin{array}{l}\text { L-DOPA } \\
\text { DA receptor agonists }\end{array}$ & $\begin{array}{l}\text { In part related to DA increase in the brain, } \\
\text { possibly outside the striatum } \\
\text { Stimulation of } D_{2 / 3} \text { receptors }\end{array}$ & $\begin{array}{l}\text { Unresolved } \\
\text { Unresolved }\end{array}$ \\
\hline Degeneration of LC NA neurons & None & & \\
\hline $\begin{array}{l}\text { Degeneration of neurons-oxidative } \\
\text { stress }\end{array}$ & $\begin{array}{l}\text { MAO-B inhibitors } \\
\text { (Rasagiline) }\end{array}$ & Unclear & Unresolved \\
\hline
\end{tabular}

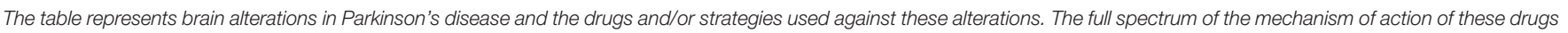
may have been misunderstood as no clear efficacy at pharmacological target has been achieved.

et al., 1973; Harden and Grace, 1995); (iii) the intraneuronal and neurochemical organization of striatal DA neurons (low metabolism, high rate of translocation into exocytotic vesicles) is specific to the DA terminals of the striatum and is not encountered in 5-HT terminals (De Deurwaerdère et al., 2016). The apparent higher magnitude of response to L-DOPA in the striatum compared to other brain regions simply corresponds to the stronger loss of clearance in the striatum due to the loss of DAT while the clearance of extracellular DA in extrastriatal regions is in part related to the NET (Navailles et al., 2014) (Figure 4).

The mechanism of action of L-DOPA is thus unclear and is likely different from DA agonists. Indeed, the efficacious agonists in the treatment of $P D$ preferentially target the $D_{2 / 3}$ receptors whereas L-DOPA favors $\mathrm{D}_{1}$ receptor-mediated mechanisms (Millan, 2010; Butini et al., 2016).

\section{Amelioration of L-DOPA Therapy}

There remains scope for improvement in several aspects of LDOPA therapy in terms of motor side effects, mood disorders, psychiatric side-effects and the evolution of the disease.

It has been proposed that excessive swings of extracellular DA are involved in the dyskinesia induced by L-DOPA (Carta et al., 2007), although this might not occur in the striatum as previously claimed. This possibility is supported by the finding that drugs or conditions that are able to decrease 5-HT neuronal activity reduced L-DOPA-induced dyskinesia (Bastide et al., 2015; De Deurwaerdère et al., 2016). Indeed, the mixed 5$\mathrm{HT}_{1 \mathrm{~A} / 1 \mathrm{~B}}$ receptor agonist, $5-\mathrm{HT}_{2} \mathrm{C}$ ligand, eltoprazine has been shown to reduce L-DOPA-induced dyskinesia in humans and animal models of the disease (Bezard et al., 2013; Svenningsson et al., 2015; Tronci et al., 2015). The efficacy of eltoprazine is not superior to existing treatment such as amantadine (Bezard and Carta, 2015). In terms of new strategies, particular attention has been given to $5-\mathrm{HT}_{1 \mathrm{~A}}$ receptor biased agonists, such as NLX112 , which acts preferentially at somatodendritic, rather than post-synaptic, 5- $\mathrm{HT}_{1 \mathrm{~A}}$ receptors (Iderberg et al., 2015; McCreary et al., 2016). It has also been proposed that SSRIs lower LDOPA-induced dyskinesia, as a result of their ability to indirectly reduce the firing rate of 5-HT neurons in the DRN (see above for the mechanism of action). The efficacy of SSRIs against LDOPA-induced dyskinesia in humans is modest (Durif et al., 1995; Mazzucchi et al., 2015), and this is also found in animal models of PD (Fidalgo et al., 2015; Miguelez et al., 2016a).
Indeed, higher doses of SSRIs are required, compared to those effective in normal individuals. This may be due to the action of L-DOPA inside the 5-HT neurons, impairing their normal biochemical processes and altering 5-HT release (Miguelez et al., 2016b), thereby dampening the reactivity of 5-HT neurons to SSRIs administration (Miguelez et al., 2016a). Other strategies that have been tested include $\mathrm{D}_{3}$ receptor antagonists or partial agonists (Bézard et al., 2003; Visanji et al., 2009). In addition to L-DOPA-induced dyskinesia, the $\mathrm{D}_{3}$ receptor subtype remains an important target in the treatment of $\mathrm{PD}$ with $\mathrm{D}_{2 / 3}$ receptor agonists (pramipexol, piribedil, ropinirole) (Millan, 2010; Leggio et al., 2016; Perez-Lloret and Rascol, 2016) being assessed in the management of impulsive-control disorder consequent to L-DOPA/DA receptor agonist administration (Seeman, 2015). Noradrenergic compounds have also been proposed to limit the occurrence of dyskinesia but the data are unclear (Delaville et al., 2011; Fox, 2013; Bhide et al., 2015; De Deurwaerdère et al., 2016).

The mechanism of action of L-DOPA toward 5-HT neurons also informs the therapeutic strategies for the mood disorders in $\mathrm{PD}$, whose prevalence is higher compared to depressed individuals without PD (McDonald et al., 2003). Nowadays, the use of SSRIs remains a first line treatment in PD but, due to the specific action of L-DOPA on 5-HT neuron activity, the use of SSRIs might not be the best approach (Liu et al., 2013; De Deurwaerdère and Ding, 2016). Other strategies, based on the blockade of post-synaptic 5-HT or NA receptors, MAO-Is, SNRIs or DA receptor agonists, are available. An entire field of research has to be devoted to addressing this question, and also considering that the etiology of mood disorders in Parkinson's disease could be different from classical depression.

The psychotic side effects of DA agonists and L-DOPA have a high prevalence in advanced stage of the disease (Melamed et al., 1996). Historically, these effects have been associated with an excessive DA tone produced by L-DOPA or DA agonists. Interestingly, the $5-\mathrm{HT}_{2} \mathrm{~A}$ receptor inverse agonist primavanserin has been shown to be effective in reducing LDOPA-induced psychosis (Meltzer et al., 2010; Markham, 2016). It might replace the use of atypical antipsychotics quetiapine or clozapine (Friedman and Factor, 2000; Chang and Fox, 2016). The mechanisms behind the efficacy of primavanserin are, as yet, unclear.

Finally, MAO-B inhibitors L-deprenyl, safinamide, zonisamide or rasagiline have been shown to be efficacious in the treatment of PD either as unique treatment in the early 

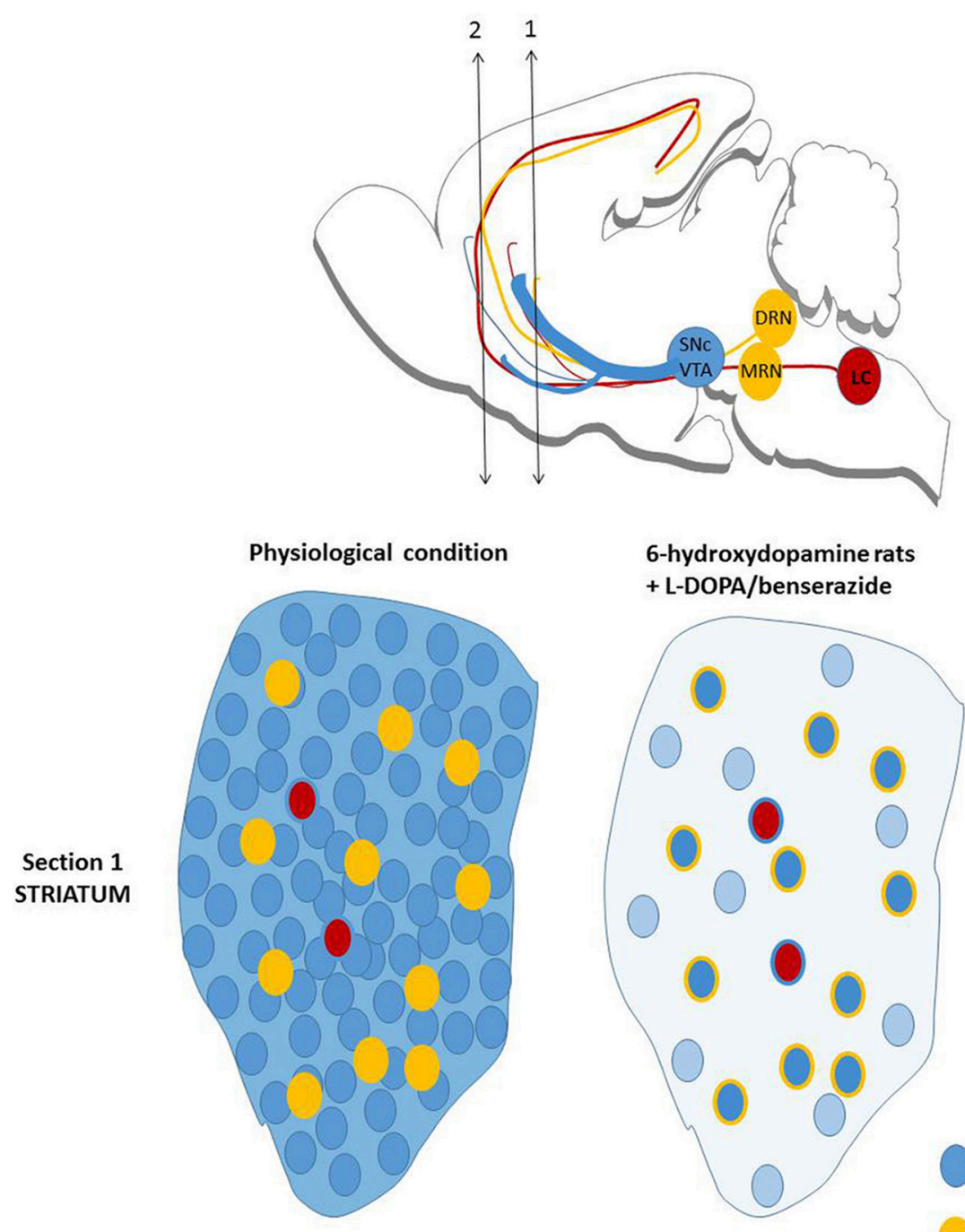

DA terminals

\section{5-HT terminals}
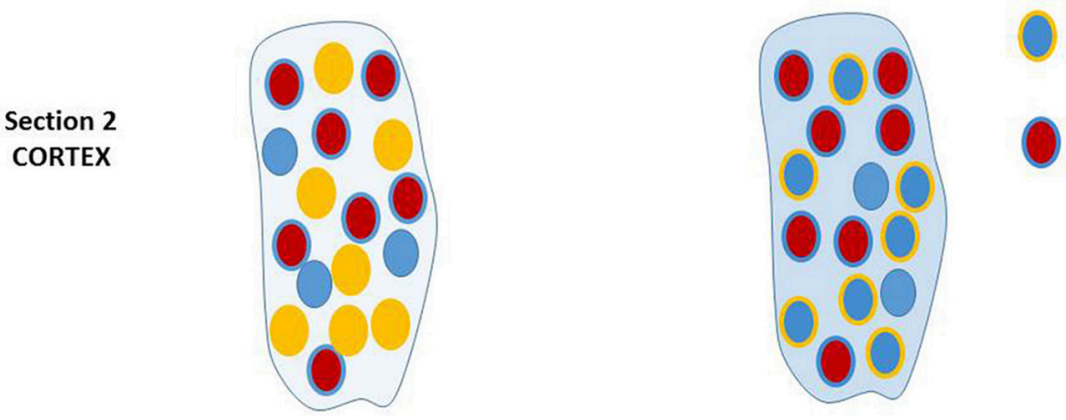

5-HT terminals containing DA

NA terminals (taking up DA)

FIGURE 4 | Mechanisms of action of L-DOPA on brain DA release. The upper illustration recalls the origin of ascending fibers for monoamines. The lower displays the normal dopaminergic transmission in the striatum (very dense) and the prefrontal cortex (very low). It includes serotonergic and noradrenergic terminals with their relative density compared to DA terminals. In the 6-hydroxydopamine rat model of PD, the density of dopaminergic fibers drop to less than $10 \%$ of the normal situation and the increase in DA release induced by L-DOPA is mostly due to serotonergic terminals. DA reuptake by noradrenergic fibers is low in the striatum due to their poor density. The overall output of striatal DA induced by L-DOPA, identified in the figure by the blue background, is very low compared to the physiological situation without L-DOPA. In the prefrontal cortex, the overall output of DA induced by L-DOPA is higher compared to the physiological situation because the density of serotonergic terminals is higher than the natural density of dopaminergic terminals. The reuptake of DA by NA fibers is magnified in L-DOPA-treated animals. The situation described in the prefrontal cortex is also observed in the hippocampus or the substantia nigra pars reticulata (not shown here) and virtually in most brain regions (De Deurwaerdère and Di Giovanni, 2016; De Deurwaerdère et al., 2016). 
stages of the disease or in conjunction with L-DOPA (Youdim et al., 2006; Riederer and Laux, 2011; Fox, 2013; Finberg, 2014). Since MAO-B is not primarily involved in the presynaptic inactivation of DA, it is possible that these compounds act at the glial level during L-DOPA therapy. In this context, L-DOPA has been shown to destroy 5-HT neurons upon chronic exposure in rodents (Navailles et al., 2011a; Stansley and Yamamoto, 2013, 2014), an effect related to an increase in metabolic stress which is blocked by antioxidant drugs including MAO-B inhibitors (Stansley and Yamamoto, 2014). The reduction of oxidative stress by MAO-B inhibitors might also reduce the destruction of DA neurons. MAO-B inhibitors of this type have also been shown to have antiapoptotic actions in a number of model systems (see (Youdim et al., 2006). Thus, the effects of these compounds in PD may be multifactorial.

\section{Conclusion}

The mechanisms behind the DA replacement therapy are unclear, because the mechanism of action of L-DOPA is still not understood in terms of its neurochemical effects, which differ from those of DA receptor agonists or MAO-B inhibitors (Table 4 for a summary). Therefore, the antiparkinsonian agents do not work as it was initially thought and this could explain why no major progress in terms of pharmacodynamics has been made. In the case of L-DOPA, it will be necessary to determine the roles of DA and the brain location of its effects, in order to regionally control DA tone from 5-HT neurons (Navailles and De Deurwaerdère, 2012b; Navailles et al., 2015).

Several models using transgene animals or injection of viral constructs targeting proteins involved in the familial forms of the disease have been raised during recent years (Bezard and Przedborski, 2011). Although these models are still under pathophysiological examination, they might open new ways of treatments, even beyond monoamines.

\section{Drug Addiction}

\section{Historical Perspective}

The addictive properties of numerous drugs including alcohol and tobacco, the opiates (opium, morphine, heroin) and the psychostimulant drugs amphetamine and cocaine, were recognized before the existence and significance of the DA reward system in the brain was known. Studies of drug addiction received an increased impetus when the primary physiological target in the brain was thought to be determined, namely the DA neurons from the VTA innervating the nucleus accumbens. All drugs of abuse share similar neurobiological property, since they increase DA release in the nucleus accumbens that parallels the reinforcing properties of the drugs (Di Chiara and Imperato, 1988; Di Chiara, 1992; Koob, 1992). While the action of drug of abuse on DA neurons can be viewed as an initiating step, the addiction is a much more complex behavioral disturbance. It involves alterations of neurobiological and humoral mechanisms in sequential steps (Le Moal and Simon, 1991; Koob and Le Moal, 1997, 2008; Koob et al., 2014), and is marked by inter-individual differences, spreading drug addiction as a disease (DerocheGamonet et al., 2004; Ahmed, 2010). In spite of the numerous studies focusing on the activity of DA neurons as a possibility to avoid relapse and to reduce drug intake, it is possible that DA transmission is no longer an appropriate target once addiction is established. At present, no DA drug is given to drug addicts although some substituted drugs targeting the DAT are developed (Hiranita et al., 2014) by analogy with methadone for opiates abuse.

\section{Mechanism of Action}

The mechanisms of action of drugs of abuse toward DA neuronal activity differ according to the drug of abuse, and most of them, classically, enhance DA outflow through an increase in impulse flow, whereas psychostimulants promote DA outflow independently from DA neuronal impulse. Gaetano Di Chiara's team has first demonstrated that this distinction was probably fundamental, in view of the control of DA neuronal activity and subsequent behavioral outcomes that can be expected from various targets, particularly $5-\mathrm{HT}_{3}$ receptors (Carboni et al., 1989). 5- $\mathrm{HT}_{3}$ receptor antagonists counteracted place preference and the enhancement of DA release induced by drugs enhancing DA neuron firing rate. After that discovery (see De Deurwaerdère and Di Giovanni, 2016), 5- $\mathrm{HT}_{2 \mathrm{~A}}$ receptor antagonists were shown to counteract the non-exocytotic release of DA induced by amphetamine or 3,4-Methylenedioxymethamphetamine (ecstasy), whereas 5$\mathrm{HT}_{2 \mathrm{C}}$ receptor agonists inhibited the impulse-dependent release of DA. In parallel, behavioral data have shown that $5-\mathrm{HT}_{2} \mathrm{C}$ receptor agonists and $5-\mathrm{HT}_{2 \mathrm{~A}}$ receptor antagonists were capable of dampening the reinforcing properties, the craving and relapse, produced by drugs of abuse, in particular cocaine (Fletcher and Higgins, 2011; Higgins and Fletcher, 2015; Howell and Cunningham, 2015). However, the involvement of DA mechanisms in the benefit of these 5-HT compounds is far from clear, suggesting that the measurement of DA neuronal activity or release is not the most appropriate neurobiological marker of the anti-addictive behavior of therapeutic approaches (De Deurwaerdère and Di Giovanni, 2016).

Other monoaminergic approaches gave promising preclinical results, especially $\mathrm{D}_{3}$ receptor antagonists (Leggio et al., 2016). A better determination of the involvement of other systems in addiction might lead to complete new treatment strategies.

\section{DISEASES WITHOUT CURRENT MONOAMINERGIC TREATMENTS}

\section{Epilepsy}

Epilepsy is characterized by seizures whose magnitude varies from almost undetectable to intense shaking. Sudden and unprovoked synchrony of bursts of neuronal hyperactivity can be "focal" if it remains confined to the area of origin, or "generalized." The origin of this condition is unknown even though genetic predisposition factors have been identified in some cases. Although it manifests as abnormal neuronal activity, it is possible that glial cells play a substantial role in triggering or maintaining this abnormality (Devinsky et al., 2013). Abnormal astrocytic function has been found in models of epilepsy, including the inability to maintain an appropriate extracellular 
milieu through different mechanisms (Coulter and Steinhäuser, 2015).

Monoaminergic drugs are not in the armamentarium of antiepileptic drugs, although they have been the object of numerous articles. The monoamine enhancing antidepressant drugs were contraindicated in patients with epilepsy (Jobe and Browning, 2005). Nevertheless, antidepressants such as SNRIs or SSRIs were commonly prescribed to patients to reduce symptoms of comorbid depression and/or anxiety (Cardamone et al., 2013). Against the initial assumption, preclinical and human studies tend to indicate that SSRIs or SNRIs have an anticonvulsant profile, which can improve seizure outcomes (Cardamone et al., 2013). Moreover, SNRIs and SSRIs could limit the occurrence of seizures in depressed patients rather than increase them (Alper et al., 2007). Additional studies are warranted to evaluate the benefit of monoamine-based antidepressant drugs in clinical praxis (see Strac et al., 2016).

SSRIs and SNRIs, as discussed above, can promote numerous mechanisms other than a simple increase in extracellular monoamine levels (Dale et al., 2015). Indeed, one "pseudomonoaminergic treatment," namely zonisamide, has received approval for the treatment of epilepsy (Bialer, 2012). Zonisamide interacts with human MAO-B, but not MAO-A (Binda et al., 2011). Similarly, L-deprenyl, the prototypical irreversible MAO-B inhibitor (Ramsay, 2013), has anticonvulsant and antiepileptogenic properties. The mechanisms triggered by these drugs are complex and likely not only related to MAO-B inhibition (Strac et al., 2016).

The roles of individual monoamines and their receptors have been the subject of many studies. To date, no specific target or a combination of specific targets has been approved for epilepsy. In the accompanying paper (Strac et al., 2016), we consider the potential interest of agonistic activity at $5-\mathrm{HT}_{2} \mathrm{C} / \mathrm{D}_{2} / \alpha_{2}$ adrenergic receptors and antagonistic activity at $\mathrm{H}_{3}$ receptors. It is intriguing that, after years of research, the favorable targets indicated from preclinical studies are those involved in tonic control of neurobiological networks and neuronal activity in the mammalian brain.

\section{Alzheimer's Disease}

The oldest of the various hypotheses, proposed in order to explain AD pathogenesis involves the cholinergic system (Sims et al., 1980). Others include the most comprehensive amyloid- $\beta$ cascade (Karran et al., 2011), glutamate/calcium neurotoxicity (Karran et al., 2011), and hyperphosphorylated tau protein (Li et al., 2007). Recent studies have revealed an association of oxidative imbalance and stress with neuron degeneration (Guidi et al., 2006), and implicated nitric oxide and other reactive nitrogen species (McCann et al., 2005). Accordingly, in addition to the four clinically approved compounds (donepezil, rivastigmine, galantamine, and memantine), that target cholinergic and glutamatergic systems (Parsons et al., 2013), new approaches, focused on the prevention or decline of amyloid cascade events, formation of tangles, oxidative injury, and inflammation, have been proposed for the $\mathrm{AD}$ treatment (Ittner and Götz, 2011). It has been suggested that AD patients might benefit from multi-target medication, such as treatment with acetylcholinesterase inhibitors (AChEIs) in combination with memantine (Lopez et al., 2009).

As neuronal degeneration in $\mathrm{AD}$ also affects monoaminergic systems (Trillo et al., 2013), dopaminergic and serotonergic dysfunction has been also proposed to be involved (Martorana and Koch, 2014; Claeysen et al., 2015; Šimić et al., 2016), suggesting additional therapeutic targets for AD. Newly synthetized molecules with neuroprotective and multimodal mechanisms of action, currently in different phases of preclinical or clinical investigations (Dias and Viegas, 2014), act not only as AChEI and modulators of $\mathrm{A} \beta$-aggregation (Tonelli et al., 2015), but also at voltage-dependent calcium channels (León and Marco-Contelles, 2011), MAO activity (Bautista-Aguilera et al., 2014), 5- $\mathrm{HT}_{3}$ receptors (Fakhfouri et al., 2012) and N-methyl-D-aspartate (NMDA) receptors (Simoni et al., 2012).

Reduced DA levels in the brain (Storga et al., 1996), cerebrospinal fluid (CSF) (Tohgi et al., 1992) and urine (Liu et al., 2011), as well as lower brain levels of L-DOPA and DOPAC have been found in AD patients (Storga et al., 1996). Individuals with $\mathrm{AD}$ also exhibit reduced expression of DA receptors (Kumar and Patel, 2007), DAT, and TH (Joyce et al., 1997) in different brain regions. The COMT Val158Met polymorphism, which affects the COMT activity, has been associated with the risk of $\mathrm{AD}$ (Yan et al., 2016). The role of dopaminergic system in AD was confirmed by findings showing that L-DOPA (Martorana et al., 2009), the MAO-B inhibitor l-deprenyl (Filip and Kolibás, 1999), and the $\mathrm{D}_{2}$ agonist rotigotine (Koch et al., 2014), have beneficial effects on cognitive functions in $\mathrm{AD}$ patients. The $\mathrm{A} \beta$ accumulation seems to be involved in dopaminergic dysfunction, contributing to the extrapyramidal deficits and rapid cognitive decline in AD patients (Preda et al., 2008). Inhibitors of COMT, like tolcapone, reduce $A \beta$ aggregation by stabilizing its monomeric state (Di Giovanni et al., 2010), while the DA receptor agonist apomorphine promotes $A \beta$ degradation and improves memory (Himeno et al., 2011). While most treatments in clinical trials tend to increase DA function, the antipsychotic drugs haloperidol and risperidone have reached the phase IV of clinical trials (Šimić et al., 2016).

Degeneration of NA neurons, observed in the early stages of $\mathrm{AD}$, in mild cognitive impairment, and even in younger individuals with still normal cognitive function, indicates that alterations in noradrenergic system might precede $A \beta$ deposition (Arai et al., 1992; Grudzien et al., 2007; Braak and Del Tredici, 2011). Lower levels of NA in CSF (Liu et al., 1991), TH in the brain, and $\mathrm{DBH}$ in the brain and plasma (Iversen et al., 1983; Mustapic et al., 2013) as well as decreased binding of $\alpha_{2}$ adrenergic receptors (which inhibit the release of NA) in the brain are found in $\mathrm{AD}$ patients (Kalaria and Andorn, 1991; Pascual et al., 1992). However, some studies proposed compensatory mechanisms in $\mathrm{AD}$ resulting in increased levels of NA (Elrod et al., 1997; Peskind et al., 2005) and TH (Szot et al., 2006).

NA pharmacotherapy has been used primarily to treat different behavioral and psychological symptoms of dementia (BPSD). Propranolol was proposed for the treatment of aggression or agitation (Greendyke et al., 1986; Shankle et al., 1995), and imipramine for treatment of depression in $\mathrm{AD}$ 
(Reifler et al., 1989). However, NA-enhancing therapy could be also used to treat cognitive impairments in patients with dementia. Combination of the NA prodrug L-DOPS and the NET inhibitor atomoxetine was shown to elevate NA levels, increase expression of brain-derived neurotrophic factor and different enzymes involved in $A \beta$ degradation, resulting in improved spatial memory (Kalinin et al., 2012). Reboxetine is currently tested in clinic (Šimić et al., 2016).

Studies suggest that NA deficiency induces inflammatory response by elevating $A \beta$ deposition and reducing microglial $A \beta$ phagocytosis (Heneka et al., 2002, 2010), thus contributing to $\mathrm{AD}$ progression. Moreover, it appears that low $\mathrm{DBH}$ activity, associated with $-1021 \mathrm{C} / \mathrm{T} \mathrm{DBH}$ regulatory polymorphism, increases the risk for $\mathrm{AD}$ in combination with interleukin 1 alpha polymorphisms (Mateo et al., 2006; Combarros et al., 2010). These findings suggest the potential of NA to slow down the neurodegeneration process by stimulating anti-inflammatory responses, microglial migration and phagocytosis, thereby contributing to $A \beta$ clearance. Future studies should evaluate proposed anti-inflammatory and neuroprotective mechanisms of NA pharmacotherapy as therapeutic strategy in $\mathrm{AD}$ patients.

Lower number/activity of 5-HT neurons (Aletrino et al., 1992; Meltzer et al., 1998), as well as decreased concentration of 5HT and its metabolites in the brain (Garcia-Alloza et al., 2005), CSF (Tohgi et al., 1992) and blood platelets (Muck-Seler et al., 2009) suggested a role of the serotonergic system in AD (Terry et al., 2008; Ramirez et al., 2014). A progressive decline in the density of different brain 5-HT receptors was observed in AD patients (Reynolds et al., 1995; Lai et al., 2003; Garcia-Alloza et al., 2004; Kepe et al., 2006; Lorke et al., 2006; Marner et al., 2012), sometimes correlating with the severity of cognitive impairment (Versijpt et al., 2003; Lai et al., 2005). Such changes in the serotonergic system could be also associated with BPSD (Lanari et al., 2006).

The association of 5-HT signaling with accumulation of A $\beta$ plaques (Holm et al., 2010; Cirrito et al., 2011), and improvement in cognitive performance after treatment with 5-HT modulators (Payton et al., 2003; Geldenhuys and Van der Schyf, 2011; Ramirez et al., 2014), point to serotonergic system as a potential target for AD therapy. Both in vivo and in vitro studies demonstrated the potential of different agonists and/or antagonists of various 5-HT receptors for treating $\mathrm{AD}$, including those affecting $5-\mathrm{HT}_{1 \mathrm{~A}}, 5-\mathrm{HT}_{4}$, and $5-\mathrm{HT}_{6}$ receptors (Meneses, 2013; Ramirez et al., 2014; Šimić et al., 2016; Werner and Covenas, 2016). The development of serotonergic medications which interact with multiple targets (Rezvani et al., 2009; Fakhfouri et al., 2015; Leiser et al., 2015; Stahl, 2015), could be a promising approach for $\mathrm{AD}$ treatment. The most advanced clinical trials focus on the $5-\mathrm{HT}_{1 \mathrm{~A}}$ receptor agonists, tandospirone or buspirone, as well as citalopram (Šimić et al., 2016).

Multitarget drug design is also used, targeting enzymes involved in oxidative stress and inflammation, and these strategies are likely to interfere with monoamine tone. This research is presented in the next section.

\section{Ischemic Stroke/Oxidative Stress}

Stroke is a vascular disorder that constitutes the second leading cause of death worldwide with higher incidence in elderly people. Inflammation and oxidative stress, accumulated during human aging, negatively influence the vascular damage following a stroke incident (DiNapoli et al., 2008), and the immune system may contribute to the infarct progression (Iadecola and Anrather, 2011). Human brain is highly demanding of oxygen. It accounts for the $20 \%$ of the body oxygen consumption. This high demand of energy makes the brain highly dependent on cerebral blood supply and an organ especially susceptible to the deleterious effect of hypoxia. Two different types of stroke occur. Ischemic stroke that occurs in the blood vessels of the brain as a consequence of the formed clots, preventing oxygen arrival to the brain cells and inducing a hypoxic condition. About $80 \%$ of all strokes are ischemic. On the other hand, the hemorrhagic stroke occurs when a blood vessel in the brain breaks or ruptures as a consequence of high blood pressure or brain aneurysms, resulting in the blood seeping into the cerebral tissue, causing damage to the brain cells. Actually, the fact that a high percentage of patients having suffered stroke subsequently developed $\mathrm{AD}$, indicates a strong link between these two pathologies. In this context, hypoxia and ischemic injury induce the up-regulation of beta secretase 1 (BACE-1) that increases the $\beta$-amyloid formation (Guglielmotto et al., 2009). Increasing evidence suggest that the neurovasculature plays an important role in the onset and progression of neurological disorders like AD (Zlokovic, 2008; Grammas, 2011; Marchesi, 2014). This has led to the concept of "neurovascular unit," integrated by neurons, astrocytes and vascular cells, which constitutes a functional unit able to maintain the homeostasis of the brain's microenvironment (Iadecola, 2010). Different amine oxidases are present in this "neurovascular unit" and they could play an important role under physiological and pathological conditions.

As discussed above, MAOs are involved in the metabolism of biogenic amines. MAO-Is provide additional benefits in neurologic disorders by reducing the formation of neurotoxic products such as hydrogen peroxide and aldehydes, which are derived from MAO activities. In neurodegeneration, MAO-I, especially those containing a propargylamine group, have been reported to possess multiple beneficial activities including neuroprotective, anti-apoptotic and antioxidant properties (Jenner, 2004; Sanz et al., 2004, 2008; Bar-Am et al., 2005).

Another amine oxidase present in cerebrovascular tissue, mainly in endothelial cells constituting the BBB, also plays a role in neurological disorders. Vascular adhesion protein 1 (VAP-1) is a homodimer glycoprotein with enzymatic function that binds leukocytes through its semicarbazide sensitive amine oxidase (SSAO) activity inducing inflammation (Smith et al., 1998; Jalkanen and Salmi, 2008). SSAO/VAP-1 metabolizes only primary amines producing aldehydes, hydrogen peroxide and ammonia, which are able to induce oxidative stress and cellular damage when overproduced (Yu and Deng, 1998). SSAO/VAP-1 is localized at the cell membrane and is released into blood as soluble form that is altered in several human 
pathologies (Kurkijärvi et al., 1998; Boomsma et al., 2003), including AD (Ferrer et al., 2002; del Mar Hernandez et al., 2005) and cerebral ischemia (Airas et al., 2008). The mediators that induce these alterations in the SSAO/VAP-1 levels are still unknown, but it is believed that increased SSAO/VAP-1 levels may contribute to the physiopathology of these diseases, thus constituting a potential therapeutic target (Conklin et al., 1998; Solé et al., 2008). Actually, human plasma SSAO activity is a strong predictor of parenchymal hemorrhages after tissue plasminogen activator (tPA) treatment in ischemic stroke patients (Hernandez-Guillamon et al., 2010), and plasma SSAO activity, which is also elevated in hemorrhagic stroke patients, predicts their neurological outcome (Hernandez-Guillamon et al., 2012). Considering all these data, SSAO/VAP-1 could mediate the link between stroke and the progression to $\mathrm{AD}$ through the alteration of the cerebrovascular function.

In spite of the different cellular localization of both MAO isoforms as well as SSAO/VAP-1, and their different substrate specificities, a cross-talk between these oxidases occurs. It has been described that MAO modulates the behavior of SSAO/VAP-1 (Fitzgerald and Tipton, 2002) and SSAO/VAP-1 may compensate in some extent the deficit in the oxidative deaminating capacity in situations where MAO activity is dysfunctional (Murphy et al., 1991).

Dynamic communication between cells of the neurovascular unit is required for normal brain functioning. The neurovascular unit consists of all major cellular components of the brain including neurons, astrocytes, brain endothelium, pericytes, vascular smooth muscle cells, microglia, and perivascular macrophages. In a situation of hemorrhagic stroke, an alteration of the homeostasis between all components of the neurovascular unit occurs, and the role of amine oxidases, especially the SSAO/VAP-1 activity is increased, contributing through its catalytic activity to the oxidative stress and inflammation (Hernandez-Guillamon et al., 2012). The neurovascular unit disruption may also alter the neuronal monoaminergic transmission. In this context, a pharmacological approach that is able to interact simultaneously with different amine oxidases might be a novel and more effective therapeutic approach (Solé et al., 2015; Sun et al., 2015). The close relationship between $\mathrm{AD}$ and stroke and the involvement of SSAO/VAP-1 in both diseases suggests that the synthesis and design of the new multitarget drugs, able to interact with different types of amine oxidases (MAO-A, MAO-B, and SSAO/VAP-1), could provide a useful therapeutic approach that is able to modulate the monoaminergic transmission, to protect the $\mathrm{BBB}$, and hence avoid the progression of both neurological disorders. It should be noted that oxidative stress is recurring feature of several theories of the etiology of neurodegenerative diseases, which might be addressed by reducing hydrogen peroxide formation.

\section{Concluding Remarks}

Despite the progress made on the influence of monoamines in the three above-mentioned diseases, no monoamine-based treatments are available at present. In most cases, one emerging strategy would be the use of SSRI or MAO-Is, two approaches that are altering monoaminergic transmission throughout the brain rather than a specific monoaminergic drug targeting the injured tissue. In fact, there are two interconnecting issues: one addressing the regional origin of the disease, and the other addressing the functional consequences away from the dysfunctional site. Assuming that the benefit of antidepressant drugs like SSRI or MAO-I is related to the ultimate reorganization of neurobiological networks, their possible benefit could be related to actions away from the injured sites.

\section{GENERAL CONCLUDING REMARKS}

Monoaminergic drugs affect different processes in the brain that control the tone of neurotransmission or/and tissue excitability, and therefore should be studied as future targets for novel therapeutic approaches, not only for depression, but also for schizophrenia, addiction, obesity, PD, epilepsy, $\mathrm{AD}$ and stroke. This analysis acknowledges the Neuroscience based Nomenclature proposed by the IUPHAR which is based on the pharmacological profiles of psychotropic drugs rather than the clinical indication (Zohar et al., 2015). Common approaches involve the use of agents acting on monoaminergic transporters, $\mathrm{D}_{2}, \mathrm{D}_{3}, 5-\mathrm{HT}_{2 \mathrm{~B} / 2 \mathrm{C}}, 5-\mathrm{HT}_{1 \mathrm{~A}}, 5-\mathrm{HT}_{2 \mathrm{~A}}, \mathrm{H}_{3}$, or $\alpha_{2}$ receptors. All these targets, apart the $5-\mathrm{HT}_{2 \mathrm{~A}}$ receptor, exert widespread influences in the brain and alter multiple brain functions simultaneously. Thus, compounds affecting monoaminergic transmission have numerous consequences for the brain and its neurobiological networks. While researchers are aware that the symptomatic treatment of a disease results from multiple actions on the brain function, the linkages enabling a favorable reorganization of brain function after monoaminebased treatments are still not fully understood.

The search for effective targets in the treatment of brain diseases was facilitated by the serendipitous discoveries of compounds that were efficacious in schizophrenia, depression and obesity. Several new compounds have been developed that retain the original pharmacological targets involved in those therapeutic benefits combined with actions on new targets, identified from subsequent research, whilst aiming to minimize undesirable "off-target" actions. Knowledge of the monoaminergic mechanisms underlying drug efficacy led to the development of drugs with more specific mechanisms of action; lorcaserin, agomelatine, and vortioxetine are interesting achievements in this context. The identification of pathophysiological causes to tailor appropriate therapeutic approaches has been less successful. It has shown some success with PD but not with addiction to drug of abuse. Nonetheless, the failure to improve on current antiparkinsonian therapies confirms that the efficacy of these treatments is not simply related to a compensation of the loss of striatal DA. To some extent, the remarkable clinical success of L-DOPA was serendipitous. It is difficult to implement new monoaminergic treatment strategies in the clinic unless they depend on those currently accepted. This is exemplified by the third group of diseases where the progress regarding the involvement of monoamines in these diseases has not yet resulted in new monoamine-based treatments.

Current attempts to address the full spectrum of action of existing drugs can be improved. It is to be hoped that novel approaches, such as connectomics with polyomic 
research addressing brain functions, neurobiological networks, monoaminergic systems and their mutual interactions, might offer new perspectives and enhance the current state-of-theart biological research in these psychiatric and neurological disorders.

\section{AUTHOR CONTRIBUTIONS}

All authors contributed to the conception and interpretation of the work and to its critical revision. All authors

\section{REFERENCES}

Adell, A., Carceller, A., and Artigas, F. (1993). In vivo brain dialysis study of the somatodendritic release of serotonin in the Raphe nuclei of the rat: effects of 8hydroxy-2-(di-n-propylamino)tetralin. J. Neurochem. 60, 1673-1681. doi: 10. 1111/j.1471-4159.1993.tb13390.x

Ahles, A., and Engelhardt, S. (2014). Polymorphic variants of adrenoceptors: pharmacology, physiology, and role in disease. Pharmacol. Rev. 66, 598-637. doi: 10.1124/pr.113.008219

Ahmed, S. H. (2010). Validation crisis in animal models of drug addiction: beyond non-disordered drug use toward drug addiction. Neurosci. Biobehav. Rev. 35, 172-184. doi: 10.1016/j.neubiorev.2010.04.005

Airas, L., Lindsberg, P. J., Karjalainen-Lindsberg, M. L., Mononen, I., Kotisaari, K., Smith, D. J., et al. (2008). Vascular adhesion protein-1 in human ischaemic stroke. Neuropathol. Appl. Neurobiol. 34, 394-402. doi: 10.1111/j.1365-2990. 2007.00911.x

Aletrino, M. A., Vogels, O. J., Van Domburg, P. H., and Ten Donkelaar, H. J. (1992). Cell loss in the nucleus raphes dorsalis in Alzheimer's disease. Neurobiol. Aging 13, 461-468. doi: 10.1016/0197-4580(92)90073-7

Alper, K., Schwartz, K. A., Kolts, R. L., and Khan, A. (2007). Seizure incidence in psychopharmacological clinical trials: an analysis of Food and Drug Administration (FDA) summary basis of approval reports. Biol. Psychiatry 62, 345-354. doi: 10.1016/j.biopsych.2006.09.023

Andersson, K. E. (1980). Adrenoceptors-classification, activation and blockade by drugs. Postgrad. Med. J. 56(Suppl. 2), 7-16.

Arai, H., Ichimiya, Y., Kosaka, K., Moroji, T., and Iizuka, R. (1992). Neurotransmitter changes in early- and late-onset Alzheimer-type dementia. Prog. Neuropsychopharmacol. Biol. Psychiatry 16, 883-890. doi: 10.1016/02785846(92)90106-O

Arrang, J. M., Garbarg, M., Quach, T. T., Dam Trung Tuong, M., Yeramian, E., and Schwartz, J. C. (1985). Actions of betahistine at histamine receptors in the brain. Eur. J. Pharmacol. 111, 73-84. doi: 10.1016/0014-2999(85) 90115-3

Artigas, F. (2013). Serotonin receptors involved in antidepressant effects. Pharmacol. Ther. 137, 119-131. doi: 10.1016/j.pharmthera.2012.09.006

Artigas, F. (2015). Developments in the field of antidepressants, where do we go now? Eur. Neuropsychopharmacol. 25, 657-670. doi: 10.1016/j.euroneuro.2013. 04.013

Artigas, F., Nutt, D. J., and Shelton, R. (2002). Mechanism of action of antidepressants. Psychopharmacol. Bull. 36(Suppl. 2), 123-132.

Artigas, F., Romero, L., de Montigny, C., and Blier, P. (1996). Acceleration of the effect of selected antidepressant drugs in major depression by 5 HT1A antagonists. Trends Neurosci. 19, 378-383. doi: 10.1016/S0166-2236(96) 10037-0

Ashby, C. R. Jr., and Wang, R. Y. (1996). Pharmacological actions of the atypical antipsychotic drug clozapine: a review. Synapse 24, 349-394.

Ban, T. A. (2001). Pharmacotherapy of depression: a historical analysis. J. Neural Transm. (Vienna) 108, 707-716. doi: 10.1007/s007020170047

Barak, N., Beck, Y., and Albeck, J. H. (2016). A randomized, double-blind, placebo-controlled pilot study of betahistine to counteract olanzapineassociated weight gain. J. Clin. Psychopharmacol. 36, 253-256. doi: 10.1097/JCP. 0000000000000489

Barak, N., Greenway, F. L., Fujioka, K., Aronne, L. J., and Kushner, R. F. (2008). Effect of histaminergic manipulation on weight in obese adults: a randomized have approved the final version and may be held accountable for the integrity of this review of current literature.

\section{ACKNOWLEDGMENTS}

Support was kindly provided by the EU COST Action CM1103. GD kindly acknowledges MCST R\&I 2013-014. PD acknowledges the "Fondation de France" and the Centre National de la Recherche Scientifique."

placebo controlled trial. Int. J. Obes. (Lond). 32, 1559-1565. doi: 10.1038/ijo. 2008.135

Bar-Am, O., Weinreb, O., Amit, T., and Youdim, M. B. (2005). Regulation of Bcl-2 family proteins, neurotrophic factors, and APP processing in the neurorescue activity of propargylamine. FASEB J. 19, 1899-1901. doi: 10.1096/fj.05-3794fje

Barnes, N. M., and Sharp, T. (1999). A review of central 5-HT receptors and their function. Neuropharmacology 38, 1083-1152. doi: 10.1016/S00283908(99)00010-6

Bastide, M. F., Meissner, W. G., Picconi, B., Fasano, S., Fernagut, P. O., Feyder, M., et al. (2015). Pathophysiology of L-dopa-induced motor and non-motor complications in Parkinson's disease. Prog. Neurobiol. 132, 96-168. doi: 10. 1016/j.pneurobio.2015.07.002

Bauer, M., Pretorius, H. W., Constant, E. L., Earley, W. R., Szamosi, J., and Brecher, M. (2009). Extended-release quetiapine as adjunct to an antidepressant in patients with major depressive disorder: results of a randomized, placebocontrolled, double-blind study. J. Clin. Psychiatry 70, 540-549. doi: 10.4088/ JCP.08m04629

Bautista-Aguilera, O. M., Esteban, G., Chioua, M., Nikolic, K., Agbaba, D., Moraleda, I., et al. (2014). Multipotent cholinesterase/monoamine oxidase inhibitors for the treatment of Alzheimer's disease: design, synthesis, biochemical evaluation, ADMET, molecular modeling, and QSAR analysis of novel donepezil-pyridyl hybrids. Drug Des. Devel. Ther. 8, 1893-1910. doi: 10. 2147/DDDT.S69258

Beaulieu, J. M., and Gainetdinov, R. R. (2011). The physiology, signaling, and pharmacology of dopamine receptors. Pharmacol. Rev. 63, 182-217. doi: 10. 1124/pr.110.002642

Bel, N., and Artigas, F. (1992). Fluvoxamine preferentially increases extracellular 5-hydroxytryptamine in the raphe nuclei: an in vivo microdialysis study. Eur. J. Pharmacol. 229, 101-103. doi: 10.1016/0014-2999(92)90292-C

Benarroch, E. E. (2009). The locus ceruleus norepinephrine system: functional organization and potential clinical significance. Neurology 73, 1699-1704. doi: 10.1212/WNL.0b013e3181c2937c

Berman, R. M., Marcus, R. N., Swanink, R., McQuade, R. D., Carson, W. H., CoreyLisle, P. K., et al. (2007). The efficacy and safety of aripiprazole as adjunctive therapy in major depressive disorder: a multicenter, randomized, double-blind, placebo-controlled study. J. Clin. Psychiatry 68, 843-853. doi: 10.4088/JCP. v68n0604

Bett, W. R. (1946). Benzedrine sulphate in clinical medicine; a survey of the literature. Postgrad. Med. J. 22, 205-218. doi: 10.1136/pgmj.22.250.205

Bezard, E., and Carta, M. (2015). Could the serotonin theory give rise to a treatment for levodopa-induced dyskinesia in Parkinson's disease? Brain 138(Pt 4), 829-830. doi: 10.1093/brain/awu407

Bézard, E., Ferry, S., Mach, U., Stark, H., Leriche, L., Boraud, T., et al. (2003). Attenuation of levodopa-induced dyskinesia by normalizing dopamine D3 receptor function. Nat. Med. 9, 762-767. doi: 10.1038/nm875

Bezard, E., and Przedborski, S. (2011). A tale on animal models of Parkinson's disease. Mov. Disord. 26, 993-1002. doi: 10.1002/mds.23696

Bezard, E., Tronci, E., Pioli, E. Y., Li, Q., Porras, G., Björklund, A., et al. (2013). Study of the antidyskinetic effect of eltoprazine in animal models of levodopainduced dyskinesia. Mov. Disord. 28, 1088-1096. doi: 10.1002/mds.25366

Bhide, N., Lindenbach, D., Barnum, C. J., George, J. A., Surrena, M. A., and Bishop, C. (2015). Effects of the beta-adrenergic receptor antagonist Propranolol on dyskinesia and L-DOPA-induced striatal DA efflux in the hemi-parkinsonian rat. J. Neurochem. 134, 222-232. doi: 10.1111/jnc.13125 
Bialer, M. (2012). Chemical properties of antiepileptic drugs (AEDs). Adv. Drug Deliv. Rev. 64, 887-895. doi: 10.1016/j.addr.2011.11.006

Binda, C., Aldeco, M., Mattevi, A., and Edmondson, D. E. (2011). Interactions of monoamine oxidases with the antiepileptic drug zonisamide: specificity of inhibition and structure of the human monoamine oxidase B complex. J. Med. Chem. 54, 909-912. doi: 10.1021/jm101359c

Blier, P., and de Montigny, C. (1990). Electrophysiological investigation of the adaptive response of the 5-HT system to the administration of 5-HT1A receptor agonists. J. Cardiovasc. Pharmacol. 15(Suppl. 7), S42-S48. doi: 10. 1097/00005344-199001001-00006

Blier, P., de Montigny, C., and Chaput, Y. (1990). A role for the serotonin system in the mechanism of action of antidepressant treatments: preclinical evidence. J. Clin. Psychiatry 51(Suppl), 14-20. discussion: 21.

Boomsma, F., Bhaggoe, U. M., van der Houwen, A. M., and van den Meiracker, A. H. (2003). Plasma semicarbazide-sensitive amine oxidase in human (patho)physiology. Biochim. Biophys. Acta 1647, 48-54. doi: 10.1016/S15709639(03)00047-5

Braak, H., and Del Tredici, K. (2011). The pathological process underlying Alzheimer's disease in individuals under thirty. Acta Neuropathol. 121, 171-181. doi: 10.1007/s00401-010-0789-4

Bronstein, J. M., Tagliati, M., Alterman, R. L., Lozano, A. M., Volkmann, J., Stefani, A., et al. (2011). Deep brain stimulation for Parkinson disease: an expert consensus and review of key issues. Arch. Neurol. 68, 165. doi: 10.1001/ archneurol.2010.260

Brown, W. A., and Rosdolsky, M. (2015). The clinical discovery of imipramine. Am. J. Psychiatry 172, 426-429. doi: 10.1176/appi.ajp.2015.14101336

Buckley, P. F., Miller, B. J., Lehrer, D. S., and Castle, D. J. (2009). Psychiatric comorbidities and schizophrenia. Schizophr. Bull. 35, 383-402. doi: 10.1093/ schbul/sbn 135

Bunney, B. S., Aghajanian, G. K., and Roth, R. H. (1973). Comparison of effects of L-dopa, amphetamine and apomorphine on firing rate of rat dopaminergic neurones. Nat. New Biol. 245, 123-125. doi: 10.1038/newbio245123a0

Burke, R. E., and O'Malley, K. (2013). Axon degeneration in Parkinson's disease. Exp. Neurol. 246, 72-83. doi: 10.1016/j.expneurol.2012.01.011

Butini, S., Nikolic, K., Kassel, S., Brückmann, H., Filipic, S., Agbaba, D., et al. (2016). Polypharmacology of dopamine receptor ligands. Prog. Neurobiol. 142, 68-103. doi: 10.1016/j.pneurobio.2016.03.011

Carboni, E., Acquas, E., Frau, R., and Di Chiara, G. (1989). Differential inhibitory effects of a 5-HT3 antagonist on drug-induced stimulation of dopamine release. Eur. J. Pharmacol. 164, 515-519. doi: 10.1016/0014-2999(89)90259-8

Cardamone, L., Salzberg, M. R., O’Brien, T. J., and Jones, N. C. (2013). Antidepressant therapy in epilepsy: can treating the comorbidities affect the underlying disorder? Br. J. Pharmacol. 168, 1531-1554. doi: 10.1111/bph.12052

Carlsson, A., and Lindqvist, M. (1963). Effect of chlorpromazine or haloperidol on formation of 3-methoxytyramine and normetanephrine in mouse brain. Acta Pharmacol. Toxicol. (Copenh). 20, 140-144. doi: 10.1111/j.1600-0773. 1963.tb01730.x

Carruba, M. O., Mantegazza, P., Memo, M., Missale, C., Pizzi, M., and Spano, P. F. (1986). Peripheral and central mechanisms of action of serotoninergic anorectic drugs. Appetite 7(Suppl.), 105-113. doi: 10.1016/S0195-6663(86)80056-3

Carta, M., Carlsson, T., Kirik, D., and Björklund, A. (2007). Dopamine released from 5-HT terminals is the cause of L-DOPA-induced dyskinesia in parkinsonian rats. Brain 130(Pt 7), 1819-1833. doi: 10.1093/brain/awm082

Chang, A., and Fox, S. H. (2016). Psychosis in Parkinson's disease: epidemiology, pathophysiology, and management. Drugs 76, 1093-1118. doi: 10.1007/s40265016-0600-5

Cipriani, A., Furukawa, T. A., Salanti, G., Geddes, J. R., Higgins, J. P., Churchill, R., et al. (2009). Comparative efficacy and acceptability of 12 new-generation antidepressants: a multiple-treatments meta-analysis. Lancet 373, 746-758. doi: 10.1016/S0140-6736(09)60046-5

Cirrito, J. R., Disabato, B. M., Restivo, J. L., Verges, D. K., Goebel, W. D., Sathyan, A., et al. (2011). Serotonin signaling is associated with lower amyloid-beta levels and plaques in transgenic mice and humans. Proc. Natl. Acad. Sci. U.S.A. 108, 14968-14973. doi: 10.1073/pnas.1107411108

Citrome, L. (2013). Cariprazine: chemistry, pharmacodynamics, pharmacokinetics, and metabolism, clinical efficacy, safety, and tolerability. Expert Opin. Drug Metab. Toxicol. 9, 193-206. doi: 10.1517/17425255.2013. 759211
Citrome, L. (2015). The ABC's of dopamine receptor partial agonists - aripiprazole, brexpiprazole and cariprazine: the 15-min challenge to sort these agents out. Int. J. Clin. Pract. 69, 1211-1220. doi: 10.1111/ijcp.12752

Claeysen, S., Bockaert, J., and Giannoni, P. (2015). Serotonin: a new hope in Alzheimer's disease? ACS Chem. Neurosci. 6, 940-943. doi: 10.1021/ acschemneuro. 5 b00135

Clineschmidt, B. V., and Lotti, V. J. (1973). Histamine: intraventricular injection suppresses ingestive behavior of the cat. Arch. Int. Pharmacodyn. Ther. 206, 288-298.

Combarros, O., Warden, D. R., Hammond, N., Cortina-Borja, M., Belbin, O., Lehmann, M. G., et al. (2010). The dopamine beta-hydroxylase -1021C/T polymorphism is associated with the risk of Alzheimer's disease in the Epistasis Project. BMC Med. Genet. 11:162. doi: 10.1186/1471-2350-11-162

Conklin, D. J., Langford, S. D., and Boor, P. J. (1998). Contribution of serum and cellular semicarbazide-sensitive amine oxidase to amine metabolism and cardiovascular toxicity. Toxicol. Sci. 46, 386-392. doi: 10.1093/toxsci/46.2.386

Cooper, J. R., Bloom, F. E., and Roth, R. H. (2003). The Biochemical Basis of Neuropharmacology. New York, NY: Oxford University Press.

Cotzias, G. C. (1968). L-Dopa for Parkinsonism. N. Engl. J. Med. 278, 630. doi: 10. 1056/NEJM196803142781127

Cotzias, G. C., Papavasiliou, P. S., and Gellene, R. (1969). Modification of Parkinsonism-chronic treatment with L-dopa. N. Engl. J. Med. 280, 337-345. doi: 10.1056/NEJM196902132800701

Coulter, D. A., and Steinhäuser, C. (2015). Role of astrocytes in epilepsy. Cold Spring Harb. Perspect. Med. 5:a022434. doi: 10.1101/cshperspect.a022434

Cremers, T. I., Giorgetti, M., Bosker, F. J., Hogg, S., Arnt, J., Mørk, A., et al. (2004). Inactivation of 5-HT(2C) receptors potentiates consequences of serotonin reuptake blockade. Neuropsychopharmacology 29, 1782-1789. doi: 10.1038/sj. npp. 1300474

Cremers, T. I., Rea, K., Bosker, F. J., Wikström, H. V., Hogg, S., Mørk, A., et al. (2007). Augmentation of SSRI effects on serotonin by 5-HT2C antagonists: mechanistic studies. Neuropsychopharmacology 32, 1550-1557. doi: 10.1038/sj. npp. 1301287

Cryan, J. F., Page, M. E., and Lucki, I. (2002). Noradrenergic lesions differentially alter the antidepressant-like effects of reboxetine in a modified forced swim test. Eur. J. Pharmacol. 436, 197-205. doi: 10.1016/S0014-2999(01)01628-4

Cryan, J. F., Valentino, R. J., and Lucki, I. (2005). Assessing substrates underlying the behavioral effects of antidepressants using the modified rat forced swimming test. Neurosci. Biobehav. Rev. 29, 547-569. doi: 10.1016/j.neubiorev. 2005.03.008

Curet, O., Damoiseau-Ovens, G., Sauvage, C., Sontag, N., Avenet, P., Depoortere, H., et al. (1998). Preclinical profile of befloxatone, a new reversible MAOA inhibitor. J. Affect. Disord. 51, 287-303. doi: 10.1016/S0165-0327(98) 00225-0

Dale, E., Bang-Andersen, B., and Sánchez, C. (2015). Emerging mechanisms and treatments for depression beyond SSRIs and SNRIs. Biochem. Pharmacol. 95, 81-97. doi: 10.1016/j.bcp.2015.03.011

Davidson, J. R. T. (2003). Pharmacotherapy of social phobia. Acta. Psychiatr. Scand. Suppl. 108, 65-71. doi: 10.1034/j.1600-0447.108.s417.7.x

Daws, L. C. (2009). Unfaithful neurotransmitter transporters: focus on serotonin uptake and implications for antidepressant efficacy. Pharmacol. Ther. 121, 89-99. doi: 10.1016/j.pharmthera.2008.10.004

De Deurwaerdère, P. (2016). Cariprazine: new dopamine biased agonist for neuropsychiatric disorders. Drugs Today 52, 97-110. doi: 10.1358/dot.2016.52. 2.2461868

De Deurwaerdère, P., and Di Giovanni, G. (2016). Serotonergic modulation of the activity of mesencephalic dopaminergic systems: therapeutic implications. Prog. Neurobiol. doi: 10.1016/j.pneurobio.2016.03.004. [Epub ahead of print].

De Deurwaerdère, P., Di Giovanni, G., and Millan, M. J. (2016). Expanding the repertoire of L-DOPA's actions: a comprehensive review of its functional neurochemistry. Prog. Neurobiol. doi: 10.1016/j.pneurobio.2016.07.002. [Epub ahead of print].

De Deurwaerdère, P., and Ding, Y. (2016). Antiparkinsonian treatment for depression in Parkinson's disease: are selective serotonin reuptake inhibitors recommended? Transl. Neurosci. Clin. 2, 138-149. doi: 10.18679/CN11-6030/ R.2016.019

De Deurwaerdère, P., Lagière, M., Bosc, M., and Navailles, S. (2013). Multiple controls exerted by 5 -HT2C receptors upon basal ganglia function: from 
physiology to pathophysiology. Exp. Brain Res. 230, 477-511. doi: 10.1007/ s00221-013-3508-2

de la Fuente-Fernández, R. (2013). Imaging of dopamine in PD and implications for motor and neuropsychiatric manifestations of PD. Front. Neurol. 4:90. doi: $10.3389 /$ fneur.2013.00090

de la Fuente-Fernández, R., Schulzer, M., Mak, E., Calne, D. B., and Stoessl, A. J. (2004). Presynaptic mechanisms of motor fluctuations in Parkinson's disease: a probabilistic model. Brain 127(Pt 4), 888-899. doi: 10.1093/brain/awh102

Delaville, C., Chetrit, J., Abdallah, K., Morin, S., Cardoit, L., De Deurwaerdère, P., et al. (2012). Emerging dysfunctions consequent to combined monoaminergic depletions in Parkinsonism. Neurobiol. Dis. 45, 763-773. doi: 10.1016/j.nbd. 2011.10.023

Delaville, C., Deurwaerdère, P. D., and Benazzouz, A. (2011). Noradrenaline and Parkinson's disease. Front. Syst. Neurosci. 5:31. doi: 10.3389/fnsys.2011.00031

Delgado, P. L., and Moreno, F. A. (2000). Role of norepinephrine in depression. J. Clin. Psychiatry 61(Suppl. 1), 5-12.

del Mar Hernandez, M., Esteban, M., Szabo, P., Boada, M., and Unzeta, M. (2005). Human plasma semicarbazide sensitive amine oxidase (SSAO), beta-amyloid protein and aging. Neurosci. Lett. 384, 183-187. doi: 10.1016/j.neulet.2005.04. 074

Del Tredici, K., Rüb, U., De Vos, R. A., Bohl, J. R., and Braak, H. (2002). Where does parkinson disease pathology begin in the brain? J. Neuropathol. Exp. Neurol. 61, 413-426. doi: 10.1093/jnen/61.5.413

Deroche-Gamonet, V., Belin, D., and Piazza, P. V. (2004). Evidence for addictionlike behavior in the rat. Science 305, 1014-1017. doi: 10.1126/science.10 99020

Deutch, A. Y., Moghaddam, B., Innis, R. B., Krystal, J. H., Aghajanian, G. K., Bunney, B. S., et al. (1991). Mechanisms of action of atypical antipsychotic drugs. Implications for novel therapeutic strategies for schizophrenia. Schizophr. Res 4, 121-156. doi: 10.1016/0920-9964(91)90030-U

Devinsky, O., Vezzani, A., Najjar, S., De Lanerolle, N. C., and Rogawski, M. A. (2013). Glia and epilepsy: excitability and inflammation. Trends Neurosci. 36, 174-184. doi: 10.1016/j.tins.2012.11.008

Devroye, C., Cathala, A., Haddjeri, N., Rovera, R., Vallée, M., Drago, F., et al. (2016). Differential control of dopamine ascending pathways by serotonin2B receptor antagonists: new opportunities for the treatment of schizophrenia. Neuropharmacology 109, 59-68. doi: 10.1016/j.neuropharm.2016. 05.024

Dias, K. S., and Viegas, C. Jr. (2014). Multi-target directed drugs: a modern approach for design of new drugs for the treatment of alzheimer's disease. Curr. Neuropharmacol. 12, 239-255. doi: 10.2174/1570159X1203140511153200

Di Chiara, G. (1992). Reinforcing drug seeking. Trends Pharmacol. Sci. 13, 428-429. doi: 10.1016/0165-6147(92)90135-S

Di Chiara, G., and Imperato, A. (1988). Drugs abused by humans preferentially increase synaptic dopamine concentrations in the mesolimbic system of freely moving rats. Proc. Natl. Acad. Sci. U.S.A. 85, 5274-5278. doi: 10.1073/pnas.85. 14.5274

Di Chiara, G., Tanda, G. L., Frau, R., and Carboni, E. (1992). Heterologous monoamine reuptake: lack of transmitter specificity of neuron-specific carriers. Neurochem. Int. 20(Suppl.), 231s-235s.

Di Giovanni, G., and De Deurwaerdère, P. (2016). New therapeutic opportunities for 5-HT2C receptor ligands in neuropsychiatric disorders. Pharmacol. Ther. 157, 125-162. doi: 10.1016/j.pharmthera.2015.11.009

Di Giovanni, S., Eleuteri, S., Paleologou, K. E., Yin, G., Zweckstetter, M., Carrupt, P. A., et al. (2010). Entacapone and tolcapone, two catechol O-methyltransferase inhibitors, block fibril formation of alpha-synuclein and beta-amyloid and protect against amyloid-induced toxicity. J. Biol. Chem. 285, 14941-14954. doi: 10.1074/jbc.M109.080390

DiNapoli, V. A., Huber, J. D., Houser, K., Li, X., and Rosen, C. L. (2008). Early disruptions of the blood-brain barrier may contribute to exacerbated neuronal damage and prolonged functional recovery following stroke in aged rats. Neurobiol. Aging 29, 753-764. doi: 10.1016/j.neurobiolaging.2006.12.007

Durif, F., Vidailhet, M., Bonnet, A. M., Blin, J., and Agid, Y. (1995). Levodopainduced dyskinesias are improved by fluoxetine. Neurology 45, 1855-1858. doi: 10.1212/WNL.45.10.1855

Ebadi, M., and Srinivasan, S. K. (1995). Pathogenesis, prevention, and treatment of neuroleptic-induced movement disorders. Pharmacol. Rev. 47, 575-604.
Eisenhofer, G., Kopin, I. J., and Goldstein, D. S. (2004). Catecholamine metabolism: a contemporary view with implications for physiology and medicine. Pharmacol. Rev. 56, 331-349. doi: 10.1124/pr.56.3.1

Elrod, R., Peskind, E. R., DiGiacomo, L., Brodkin, K. I., Veith, R. C., and Raskind, M. A. (1997). Effects of Alzheimer's disease severity on cerebrospinal fluid norepinephrine concentration. Am. J. Psychiatry 154, 25-30. doi: 10.1176/ajp. 154.1.25

Emilien, G., Maloteaux, J. M., Geurts, M., Hoogenberg, K., and Cragg, S. (1999). Dopamine receptors-physiological understanding to therapeutic intervention potential. Pharmacol. Ther. 84, 133-156. doi: 10.1016/S0163-7258(99)00029-7

Esbenshade, T. A., Fox, G. B., and Cowart, M. D. (2006). Histamine H3 receptor antagonists: preclinical promise for treating obesity and cognitive disorders. Mol. Interv. 6, 77-88, 59. doi: 10.1124/mi.6.2.5

Fakhfouri, G., Mousavizadeh, K., Mehr, S. E., Dehpour, A. R., Zirak, M. R., Ghia, J. E., et al. (2015). From chemotherapy-induced emesis to neuroprotection: therapeutic opportunities for 5-HT3 receptor antagonists. Mol. Neurobiol. 52, 1670-1679. doi: 10.1007/s12035-014-8957-5

Fakhfouri, G., Rahimian, R., Ghia, J. E., Khan, W. I., and Dehpour, A. R. (2012). Impact of 5-HT(3) receptor antagonists on peripheral and central diseases. Drug Discov. Today 17, 741-747. doi: 10.1016/j.drudis.2012.02.009

Fangmann, P., Assion, H. J., Juckel, G., González, C. A., and López-Muñoz, F. (2008). Half a century of antidepressant drugs: on the clinical introduction of monoamine oxidase inhibitors, tricyclics, and tetracyclics. Part II: tricyclics and tetracyclics. J. Clin. Psychopharmacol. 28, 1-4. doi: 10.1097/jcp. 0b013e3181627b60

Ferrer, I., Lizcano, J. M., Hernández, M., and Unzeta, M. (2002). Overexpression of semicarbazide sensitive amine oxidase in the cerebral blood vessels in patients with Alzheimer's disease and cerebral autosomal dominant arteriopathy with subcortical infarcts and leukoencephalopathy. Neurosci. Lett. 321, 21-24. doi: 10.1016/S0304-3940(01)02465-X

Fidalgo, C., Ko, W. K., Tronci, E., Li, Q., Stancampiano, R., Chuan, Q., et al. (2015). Effect of serotonin transporter blockade on L-DOPA-induced dyskinesia in animal models of Parkinson's disease. Neuroscience 298, 389-396. doi: 10.1016/ j.neuroscience.2015.04.027

Filip, V., and Kolibás, E. (1999). Selegiline in the treatment of Alzheimer's disease: a long-term randomized placebo-controlled trial. Czech and Slovak Senile Dementia of Alzheimer type study group. J. Psychiatry Neurosci. 24, 234-243.

Finberg, J. P. (2014). Update on the pharmacology of selective inhibitors of MAO$\mathrm{A}$ and MAO-B: focus on modulation of CNS monoamine neurotransmitter release. Pharmacol. Ther. 143, 133-152. doi: 10.1016/j.pharmthera.2014. 02.010

Fisher, A., Biggs, C. S., Eradiri, O., and Starr, M. S. (2000). Dual effects of L-3,4dihydroxyphenylalanine on aromatic L-amino acid decarboxylase, dopamine release and motor stimulation in the reserpine-treated rat: evidence that behaviour is dopamine independent. Neuroscience 95, 97-111. doi: 10.1016/ S0306-4522(99)00406-6

Fitoussi, A., Dellu-Hagedorn, F., and De Deurwaerdère, P. (2013). Monoamines tissue content analysis reveals restricted and site-specific correlations in brain regions involved in cognition. Neuroscience 255, 233-245. doi: 10.1016/j. neuroscience.2013.09.059

Fitzgerald, D. H., and Tipton, K. F. (2002). Inhibition of monoamine oxidase modulates the behaviour of semicarbazide-sensitive amine oxidase (SSAO). J. Neural Transm. (Vienna) 109, 251-265. doi: 10.1007/s007020200021

Fletcher, P. J., and Higgins, G. A. (2011). "Serotonin and reward-related behaviour: focus on 5-HT2C receptors," in 5-HT2C Receptors in the Pathophysiology of CNS Disease, eds G. Di Giovanni, E. Esposito, and V. Di Matteo (New York, NY: Springer), 293-324. doi: 10.1007/978-1-60761-941-3_15

Fornito, A., and Bullmore, E. T. (2015). Connectomics: a new paradigm for understanding brain disease. Eur. Neuropsychopharmacol. 25, 733-748. doi: 10. 1016/j.euroneuro.2014.02.011

Fowler, J. S., MacGregor, R. R., Wolf, A. P., Arnett, C. D., Dewey, S. L., Schlyer, D., et al. (1987). Mapping human brain monoamine oxidase A and B with 11C-labeled suicide inactivators and PET. Science 235, 481-485. doi: 10.1126/ science.3099392

Fox, S. H. (2013). Non-dopaminergic treatments for motor control in Parkinson's disease. Drugs 73, 1405-1415. doi: 10.1007/s40265-013-0105-4 
Friedman, J. H., and Factor, S. A. (2000). Atypical antipsychotics in the treatment of drug-induced psychosis in Parkinson's disease. Mov. Disord. 15, 201-211. doi: 10.1002/1531-8257(200003)15:2<201::AID-MDS1001>3.0.CO;2-D

Gagnon, C., Schatz, R., Otten, U., and Thoenen, H. (1976). Synthesis, subcellular distribution and turnover of dopamine beta-hydroxylase in organ cultures of sympathetic ganglia and adrenal medullae. J. Neurochem. 27, 1083-1089. doi: 10.1111/j.1471-4159.1976.tb00312.x

Galati, S., and Di Giovanni, G. (2010). Neuroprotection in Parkinson's disease: a realistic goal? CNS Neurosci. Ther. 16, 327-329. doi: 10.1111/j.1755-5949.2010. 00206.x

Garattini, S. (1995). Biological actions of drugs affecting serotonin and eating. Obes. Res. 3(Suppl. 4), 463s-470s. doi: 10.1002/j.1550-8528.1995.tb00213.x

Garcia-Alloza, M., Gil-Bea, F. J., Diez-Ariza, M., Chen, C. P., Francis, P. T., Lasheras, B., et al. (2005). Cholinergic-serotonergic imbalance contributes to cognitive and behavioral symptoms in Alzheimer's disease. Neuropsychologia 43, 442-449. doi: 10.1016/j.neuropsychologia.2004.06.007

Garcia-Alloza, M., Hirst, W. D., Chen, C. P., Lasheras, B., Francis, P. T., and Ramírez, M. J. (2004). Differential involvement of 5-HT(1B/1D) and 5-HT6 receptors in cognitive and non-cognitive symptoms in Alzheimer's disease. Neuropsychopharmacology 29, 410-416. doi: 10.1038/sj.npp.1300330

Gardier, A. M., David, D. J., Jego, G., Przybylski, C., Jacquot, C., Durier, S., et al. (2003). Effects of chronic paroxetine treatment on dialysate serotonin in 5HT1B receptor knockout mice. J. Neurochem. 86, 13-24. doi: 10.1046/j.14714159.2003.01827.x

Gbahou, F., Davenas, E., Morisset, S., and Arrang, J. M. (2010). Effects of betahistine at histamine $\mathrm{H} 3$ receptors: mixed inverse agonism/agonism in vitro and partial inverse agonism in vivo. J. Pharmacol. Exp. Ther. 334, 945-954. doi: 10.1124/jpet.110.168633

Geldenhuys, W. J., and Van der Schyf, C. J. (2011). Role of serotonin in Alzheimer's disease: a new therapeutic target? CNS Drugs 25, 765-781. doi: 10.2165/ 11590190-000000000-00000

Ghanemi, A., and Hu, X. (2015). Elements toward novel therapeutic targeting of the adrenergic system. Neuropeptides 49, 25-35. doi: 10.1016/j.npep.2014.11. 003

Grammas, P. (2011). Neurovascular dysfunction, inflammation and endothelial activation: implications for the pathogenesis of Alzheimer's disease. J. Neuroinflammation 8:26. doi: 10.1186/1742-2094-8-26

Greendyke, R. M., Kanter, D. R., Schuster, D. B., Verstreate, S., and Wootton, J. (1986). Propranolol treatment of assaultive patients with organic brain disease. A double-blind crossover, placebo-controlled study. J. Nerv. Ment. Dis. 174, 290-294. doi: 10.1097/00005053-198605000-00005

Grudzien, A., Shaw, P., Weintraub, S., Bigio, E., Mash, D. C., and Mesulam, M. M. (2007). Locus coeruleus neurofibrillary degeneration in aging, mild cognitive impairment and early Alzheimer's disease. Neurobiol. Aging 28, 327-335. doi: 10.1016/j.neurobiolaging.2006.02.007

Guglielmotto, M., Aragno, M., Autelli, R., Giliberto, L., Novo, E., Colombatto, S., et al. (2009). The up-regulation of BACE1 mediated by hypoxia and ischemic injury: role of oxidative stress and HIF1alpha. J. Neurochem. 108, 1045-1056. doi: 10.1111/j.1471-4159.2008.05858.x

Guiard, B. P., Froger, N., Hamon, M., Gardier, A. M., and Lanfumey, L. (2005). Sustained pharmacological blockade of NK1 substance $\mathrm{P}$ receptors causes functional desensitization of dorsal raphe 5-HT 1A autoreceptors in mice. J. Neurochem. 95, 1713-1723. doi: 10.1111/j.1471-4159.2005.03488.x

Guidi, I., Galimberti, D., Lonati, S., Novembrino, C., Bamonti, F., Tiriticco, M., et al. (2006). Oxidative imbalance in patients with mild cognitive impairment and Alzheimer's disease. Neurobiol. Aging 27, 262-269. doi: 10. 1016/j.neurobiolaging.2005.01.001

Gumnick, J. F., and Nemeroff, C. B. (2000). Problems with currently available antidepressants. J. Clin. Psychiatry 61(Suppl. 10), 5-15.

Gururajan, A., Clarke, G., Dinan, T. G., and Cryan, J. F. (2016). Molecular biomarkers of depression. Neurosci. Biobehav. Rev. 64, 101-133. doi: 10.1016/j. neubiorev.2016.02.011

Gustafson, A., King, C., and Rey, J. A. (2013). Lorcaserin (Belviq): A selective serotonin 5-HT2C agonist in the treatment of obesity. P T 38, 525-534.

Haefely, W., Burkard, W. P., Cesura, A. M., Kettler, R., Lorez, H. P., Martin, J. R., et al. (1992). Biochemistry and pharmacology of moclobemide, a prototype RIMA. Psychopharmacology (Berl). 106(Suppl.), S6-S14. doi: 10. 1007/BF02246225
Hale, M. W., and Lowry, C. A. (2011). Functional topography of midbrain and pontine serotonergic systems: implications for synaptic regulation of serotonergic circuits. Psychopharmacology (Berl). 213, 243-264. doi: 10.1007/ s00213-010-2089-Z

Hamon, M., and Blier, P. (2013). Monoamine neurocircuitry in depression and strategies for new treatments. Prog. Neuropsychopharmacol. Biol. Psychiatry 45, 54-63. doi: 10.1016/j.pnpbp.2013.04.009

Han, C., Wang, S. M., Kato, M., Lee, S. J., Patkar, A. A., Masand, P. S., et al. (2013). Second-generation antipsychotics in the treatment of major depressive disorder: current evidence. Expert Rev. Neurother. 13, 851-870. doi: 10.1586/ 14737175.2013 .811901

Harden, D. G., and Grace, A. A. (1995). Activation of dopamine cell firing by repeated L-DOPA administration to dopamine-depleted rats: its potential role in mediating the therapeutic response to L-DOPA treatment. J. Neurosci. 15, $6157-6166$.

Haslam, D. (2016). Weight management in obesity - past and present. Int. J. Clin. Pract. 70, 206-217. doi: 10.1111/ijcp.12771

Hauser, R. A., Abler, V., Eyal, E., and Eliaz, R. E. (2016). Efficacy of rasagiline in early Parkinson's disease: a meta-analysis of data from the TEMPO and ADAGIO studies. Int. J. Neurosci. 126, 942-946. doi: 10.3109/00207454.2016. 1154552

Hawirko, L., and Sprague, P. H. (1946). Appetite-depressing drugs in obesity. Can. Med. Assoc. J. 54, 26-29.

Heneka, M. T., Galea, E., Gavriluyk, V., Dumitrescu-Ozimek, L., Daeschner, J., O’Banion, M. K., et al. (2002). Noradrenergic depletion potentiates beta amyloid-induced cortical inflammation: implications for Alzheimer's disease. J. Neurosci. 22, 2434-2442.

Heneka, M. T., Nadrigny, F., Regen, T., Martinez-Hernandez, A., DumitrescuOzimek, L., Terwel, D., et al. (2010). Locus ceruleus controls Alzheimer's disease pathology by modulating microglial functions through norepinephrine. Proc. Natl. Acad. Sci. U.S.A. 107, 6058-6063. doi: 10.1073/pnas.0909586107

Hensler, J. G., Artigas, F., Bortolozzi, A., Daws, L. C., De Deurwaerdère, P., Milan, L., et al. (2013). Catecholamine/Serotonin interactions: systems thinking for brain function and disease. Adv. Pharmacol. 68, 167-197. doi: 10.1016/B9780-12-411512-5.00009-9

Hernandez-Guillamon, M., Garcia-Bonilla, L., Solé, M., Sosti, V., Parés, M., Campos, M., et al. (2010). Plasma VAP-1/SSAO activity predicts intracranial hemorrhages and adverse neurological outcome after tissue plasminogen activator treatment in stroke. Stroke 41, 1528-1535. doi: 10.1161/ STROKEAHA.110.584623

Hernandez-Guillamon, M., Solé, M., Delgado, P., García-Bonilla, L., Giralt, D. Boada, C., et al. (2012). VAP-1/SSAO plasma activity and brain expression in human hemorrhagic stroke. Cerebrovasc. Dis. 33, 55-63. doi: 10.1159/ 000333370

Higgins, G. A., and Fletcher, P. J. (2015). Therapeutic potential of 5-ht2c receptor agonists for addictive disorders. ACS Chem. Neurosci. 6, 1071-1088. doi: 10. 1021/acschemneuro.5b00025

Himeno, E., Ohyagi, Y., Ma, L., Nakamura, N., Miyoshi, K., Sakae, N., et al. (2011). Apomorphine treatment in Alzheimer mice promoting amyloid-beta degradation. Ann. Neurol. 69, 248-256. doi: 10.1002/ana.22319

Hiranita, T., Kohut, S. J., Soto, P. L., Tanda, G., Kopajtic, T. A., and Katz, J. L. (2014). Preclinical efficacy of N-substituted benztropine analogs as antagonists of methamphetamine self-administration in rats. J. Pharmacol. Exp. Ther. 348, 174-191. doi: 10.1124/jpet.113.208264

Holm, P., Ettrup, A., Klein, A. B., Santini, M. A., El-Sayed, M., Elvang, A. B., et al. (2010). Plaque deposition dependent decrease in 5-HT2A serotonin receptor in AbetaPPswe/PS1dE9 amyloid overexpressing mice. J. Alzheimers. Dis. 20, 1201-1213. doi: 10.3233/JAD-2010-100117

Howell, L. L., and Cunningham, K. A. (2015). Serotonin 5-HT2 receptor interactions with dopamine function: implications for therapeutics in cocaine use disorder. Pharmacol. Rev. 67, 176-197. doi: 10.1124/pr.114. 009514

Hoyer, D., Hannon, J. P., and Martin, G. R. (2002). Molecular, pharmacological and functional diversity of 5-HT receptors. Pharmacol. Biochem. Behav. 71, 533-554. doi: 10.1016/S0091-3057(01)00746-8

Iadecola, C. (2010). The overlap between neurodegenerative and vascular factors in the pathogenesis of dementia. Acta Neuropathol. 120, 287-296. doi: 10.1007/ s00401-010-0718-6 
Iadecola, C., and Anrather, J. (2011). The immunology of stroke: from mechanisms to translation. Nat. Med. 17, 796-808. doi: 10.1038/nm.2399

Iderberg, H., McCreary, A. C., Varney, M. A., Kleven, M. S., Koek, W., Bardin, L., et al. (2015). NLX-112, a novel 5-HT1A receptor agonist for the treatment of L-DOPA-induced dyskinesia: Behavioral and neurochemical profile in rat. Exp. Neurol. 271, 335-350. doi: 10.1016/j.expneurol.2015.05.021

Invernizzi, R., Belli, S., and Samanin, R. (1992). Citalopram's ability to increase the extracellular concentrations of serotonin in the dorsal raphe prevents the drug's effect in the frontal cortex. Brain Res. 584, 322-324. doi: 10.1016/00068993(92)90914-U

Invernizzi, R., Bramante, M., and Samanin, R. (1996). Role of 5-HT1A receptors in the effects of acute chronic fluoxetine on extracellular serotonin in the frontal cortex. Pharmacol. Biochem. Behav. 54, 143-147. doi: 10.1016/00913057(95)02159-0

Ittner, L. M., and Götz, J. (2011). Amyloid-beta and tau-a toxic pas de deux in Alzheimer's disease. Nat. Rev. Neurosci. 12, 65-72. doi: 10.1038/nrn2967

Iversen, L. L., Rossor, M. N., Reynolds, G. P., Hills, R., Roth, M., Mountjoy, C. Q., et al. (1983). Loss of pigmented dopamine-beta-hydroxylase positive cells from locus coeruleus in senile dementia of Alzheimer's type. Neurosci. Lett. 39, 95-100. doi: 10.1016/0304-3940(83)90171-4

Jackson, H. C., Bearham, M. C., Hutchins, L. J., Mazurkiewicz, S. E., Needham, A. M., and Heal, D. J. (1997). Investigation of the mechanisms underlying the hypophagic effects of the 5-HT and noradrenaline reuptake inhibitor, sibutramine, in the rat. Br. J. Pharmacol. 121, 1613-1618. doi: 10.1038/sj.bjp. 0701311

Jacquot, C., David, D. J., Gardier, A. M., and Sánchez, C. (2007). [Escitalopram and citalopram: the unexpected role of the R-enantiomer]. Encephale 33, 179-187. doi: 10.1016/S0013-7006(07)91548-1

Jalkanen, S., and Salmi, M. (2008). VAP-1 and CD73, endothelial cell surface enzymes in leukocyte extravasation. Arterioscler. Thromb. Vasc. Biol. 28, 18-26. doi: 10.1161/ATVBAHA.107.153130

James, W. P., Astrup, A., Finer, N., Hilsted, J., Kopelman, P., Rössner, S., et al. (2000). Effect of sibutramine on weight maintenance after weight loss: a randomised trial. STORM Study Group. Sibutramine trial of obesity reduction and maintenance. Lancet 356, 2119-2125. doi: 10.1016/S0140-6736(00)034917

Jellinger, K. A. (1991). Pathology of Parkinson's disease. Changes other than the nigrostriatal pathway. Mol. Chem. Neuropathol. 14, 153-197. doi: 10.1007/ BF03159935

Jenner, P. (2004). Preclinical evidence for neuroprotection with monoamine oxidase-B inhibitors in Parkinson's disease. Neurology 63(7 Suppl 2), S13-S22. doi: 10.1212/wnl.63.7_suppl_2.s13

Jobe, P. C., and Browning, R. A. (2005). The serotonergic and noradrenergic effects of antidepressant drugs are anticonvulsant, not proconvulsant. Epilepsy Behav. 7, 602-619. doi: 10.1016/j.yebeh.2005.07.014

Joyce, J. N., Smutzer, G., Whitty, C. J., Myers, A., and Bannon, M. J. (1997). Differential modification of dopamine transporter and tyrosine hydroxylase mRNAs in midbrain of subjects with Parkinson's, Alzheimer's with parkinsonism, and Alzheimer's disease. Mov. Disord. 12, 885-897. doi: 10.1002/ mds.870120609

Kalaria, R. N., and Andorn, A. C. (1991). Adrenergic receptors in aging and Alzheimer's disease: decreased alpha 2-receptors demonstrated by [3H]paminoclonidine binding in prefrontal cortex. Neurobiol. Aging 12, 131-136. doi: 10.1016/0197-4580(91)90051-K

Kalinin, S., Polak, P. E., Lin, S. X., Sakharkar, A. J., Pandey, S. C., and Feinstein, D. L. (2012). The noradrenaline precursor L-DOPS reduces pathology in a mouse model of Alzheimer's disease. Neurobiol. Aging 33, 1651-1663. doi: 10.1016/j. neurobiolaging.2011.04.012

Kapur, S., and Remington, G. (1996). Serotonin-dopamine interaction and its relevance to schizophrenia. Am. J. Psychiatry 153, 466-476. doi: 10.1176/ajp. 153.4.466

Kapur, S., and Seeman, P. (2001). Does fast dissociation from the dopamine d(2) receptor explain the action of atypical antipsychotics?: A new hypothesis. Am. J. Psychiatry 158, 360-369. doi: 10.1176/appi.ajp.158.3.360

Karran, E., Mercken, M., and De Strooper, B. (2011). The amyloid cascade hypothesis for Alzheimer's disease: an appraisal for the development of therapeutics. Nat. Rev. Drug Discov. 10, 698-712. doi: 10.1038/nrd3505
Kasper, S., Corruble, E., Hale, A., Lemoine, P., Montgomery, S. A., and Quera-Salva, M. A. (2013). Antidepressant efficacy of agomelatine versus SSRI/SNRI: results from a pooled analysis of head-to-head studies without a placebo control. Int. Clin. Psychopharmacol. 28, 12-19. doi: 10.1097/YIC. 0b013e328359768e

Kepe, V., Barrio, J. R., Huang, S. C., Ercoli, L., Siddarth, P., Shoghi-Jadid, K., et al. (2006). Serotonin 1A receptors in the living brain of Alzheimer's disease patients. Proc. Natl. Acad. Sci. U.S.A. 103, 702-707. doi: 10.1073/pnas. 0510237103

Kiloh, L. G., and Brandon, S. (1962). Habituation and addiction to amphetamines. Br. Med. J. 2, 40-43. doi: 10.1136/bmj.2.5296.40

Kiss, B., Horváth, A., Némethy, Z., Schmidt, E., Laszlovszky, I., Bugovics, G., et al. (2010). Cariprazine (RGH-188), a dopamine $\mathrm{D}(3)$ receptor-preferring, $\mathrm{D}(3) / \mathrm{D}(2)$ dopamine receptor antagonist-partial agonist antipsychotic candidate: in vitro and neurochemical profile. J. Pharmacol. Exp. Ther. 333, 328-340. doi: 10.1124/jpet.109.160432

Koch, G., Di Lorenzo, F., Bonnì, S., Giacobbe, V., Bozzali, M., Caltagirone, C., et al. (2014). Dopaminergic modulation of cortical plasticity in Alzheimer's disease patients. Neuropsychopharmacology 39, 2654-2661. doi: 10.1038/npp.2014.119

Koob, G. F. (1992). Drugs of abuse: anatomy, pharmacology and function of reward pathways. Trends Pharmacol. Sci. 13, 177-184. doi: 10.1016/01656147(92)90060-J

Koob, G. F., Buck, C. L., Cohen, A., Edwards, S., Park, P. E., Schlosburg, J. E., et al. (2014). Addiction as a stress surfeit disorder. Neuropharmacology 76(Pt B), 370-382. doi: 10.1016/j.neuropharm.2013.05.024

Koob, G. F., and Le Moal, M. (1997). Drug abuse: hedonic homeostatic dysregulation. Science 278, 52-58. doi: 10.1126/science.278.5335.52

Koob, G. F., and Le Moal, M. (2008). Review. Neurobiological mechanisms for opponent motivational processes in addiction. Philos. Trans. R. Soc. Lond. B. Biol. Sci. 363, 3113-3123. doi: 10.1098/rstb.2008.0094

Kroeze, W. K., Hufeisen, S. J., Popadak, B. A., Renock, S. M., Steinberg, S., Ernsberger, P., et al. (2003). H1-histamine receptor affinity predicts short-term weight gain for typical and atypical antipsychotic drugs. Neuropsychopharmacology 28, 519-526. doi: 10.1038/sj.npp.1300027

Kuczenski, R., Segal, D. S., Cho, A. K., and Melega, W. (1995). Hippocampus norepinephrine, caudate dopamine and serotonin, and behavioral responses to the stereoisomers of amphetamine and methamphetamine. J. Neurosci. 15, 1308-1317.

Kumar, U., and Patel, S. C. (2007). Immunohistochemical localization of dopamine receptor subtypes (D1R-D5R) in Alzheimer's disease brain. Brain Res. 1131, 187-196. doi: 10.1016/j.brainres.2006.10.049

Kurkijärvi, R., Adams, D. H., Leino, R., Möttönen, T., Jalkanen, S., and Salmi, M. (1998). Circulating form of human vascular adhesion protein-1 (VAP1): increased serum levels in inflammatory liver diseases. J. Immunol. 161, $1549-1557$.

Lai, M. K., Tsang, S. W., Alder, J. T., Keene, J., Hope, T., Esiri, M. M., et al. (2005). Loss of serotonin 5-HT2A receptors in the postmortem temporal cortex correlates with rate of cognitive decline in Alzheimer's disease. Psychopharmacology (Berl). 179, 673-677. doi: 10.1007/s00213-004-2077-2

Lai, M. K., Tsang, S. W., Francis, P. T., Esiri, M. M., Hope, T., Lai, O. F., et al. (2003). $\left[{ }^{3} \mathrm{H}\right] \mathrm{GR} 113808$ binding to serotonin $5-\mathrm{HT}_{4}$ receptors in the postmortem neocortex of Alzheimer disease: a clinicopathological study. J. Neural Transm. (Vienna) 110, 779-788. doi: 10.1007/s00702-003-0825-9

Lanari, A., Amenta, F., Silvestrelli, G., Tomassoni, D., and Parnetti, L. (2006). Neurotransmitter deficits in behavioural and psychological symptoms of Alzheimer's disease. Mech. Ageing Dev. 127, 158-165. doi: 10.1016/j.mad.2005. 09.016

Lecklin, A., Etu-Seppälä, P., Stark, H., and Tuomisto, L. (1998). Effects of intracerebroventricularly infused histamine and selective $\mathrm{H} 1, \mathrm{H} 2$ and $\mathrm{H} 3$ agonists on food and water intake and urine flow in Wistar rats. Brain Res. 793, 279-288. doi: 10.1016/S0006-8993(98)00186-3

Lees, A. J., Tolosa, E., and Olanow, C. W. (2015). Four pioneers of L-dopa treatment: Arvid Carlsson, Oleh Hornykiewicz, George Cotzias, and Melvin Yahr. Mov. Disord. 30, 19-36. doi: 10.1002/mds.26120

Leggio, G. M., Bucolo, C., Platania, C. B. M., Salomone, S., and Drago, F. (2016). Current drug treatments targeting dopamine D3 receptor. Pharmacol. Ther. 165, 164-177. doi: 10.1016/j.pharmthera.2016.06.007 
Leiser, S. C., Li, Y., Pehrson, A. L., Dale, E., Smagin, G., and Sanchez, C. (2015). Serotonergic regulation of prefrontal cortical circuitries involved in cognitive processing: a review of individual 5-HT receptor mechanisms and concerted effects of 5-HT receptors exemplified by the multimodal antidepressant vortioxetine. ACS Chem. Neurosci. 6, 970-986. doi: 10.1021/cn500340j

Le Moal, M., and Simon, H. (1991). Mesocorticolimbic dopaminergic network: functional and regulatory roles. Physiol. Rev. 71, 155-234.

León, R., and Marco-Contelles, J. (2011). A step further towards multitarget drugs for Alzheimer and neuronal vascular diseases: targeting the cholinergic system, amyloid-beta aggregation and $\mathrm{Ca}(2+)$ dyshomeostasis. Curr. Med. Chem. 18, 552-576. doi: 10.2174/092986711794480186

Li, G., Sokal, I., Quinn, J. F., Leverenz, J. B., Brodey, M., Schellenberg, G. D., et al. (2007). CSF tau/Abeta42 ratio for increased risk of mild cognitive impairment: a follow-up study. Neurology 69, 631-639. doi: 10.1212/01.wnl.0000267428. 62582.aa

Liu, H. C., Yang, J. C., Chang, Y. F., Liu, T. Y., and Chi, C. W. (1991). Analysis of monoamines in the cerebrospinal fluid of Chinese patients with Alzheimer's disease. Ann. N. Y. Acad. Sci. 640, 215-218. doi: 10.1111/j.1749-6632.1991. tb00220.x

Liu, J., Dong, J., Wang, L., Su, Y., Yan, P., and Sun, S. (2013). Comparative efficacy and acceptability of antidepressants in Parkinson's disease: a network meta-analysis. PLoS ONE 8:e76651. doi: 10.1371/journal.pone.0076651

Liu, L., Li, Q., Li, N., Ling, J., Liu, R., Wang, Y., et al. (2011). Simultaneous determination of catecholamines and their metabolites related to Alzheimer's disease in human urine. J. Sep. Sci. 34, 1198-1204. doi: 10.1002/jssc.201000799

Lopez, O. L., Becker, J. T., Wahed, A. S., Saxton, J., Sweet, R. A., Wolk, D. A., et al. (2009). Long-term effects of the concomitant use of memantine with cholinesterase inhibition in Alzheimer disease. J. Neurol. Neurosurg. Psychiatr. 80, 600-607. doi: 10.1136/jnnp.2008.158964

López-Muñoz, F., and Alamo, C. (2009). Monoaminergic neurotransmission: the history of the discovery of antidepressants from 1950s until today. Curr. Pharm. Des. 15, 1563-1586. doi: 10.2174/138161209788168001

López-Muñoz, F., Alamo, C., Cuenca, E., Shen, W. W., Clervoy, P., and Rubio, G. (2005). History of the discovery and clinical introduction of chlorpromazine. Ann. Clin. Psychiatry 17, 113-135. doi: 10.1080/10401230591002002

Lorke, D. E., Lu, G., Cho, E., and Yew, D. T. (2006). Serotonin 5-HT2A and 5-HT6 receptors in the prefrontal cortex of Alzheimer and normal aging patients. BMC Neurosci. 7:36. doi: 10.1186/1471-2202-7-36

Lucas, G., and Debonnel, G. (2002). 5-HT4 receptors exert a frequency-related facilitatory control on dorsal raphe nucleus 5-HT neuronal activity. Eur. J. Neurosci. 16, 817-822. doi: 10.1046/j.1460-9568.2002.02150.x

Lucas, G., Rymar, V. V., Du, J., Mnie-Filali, O., Bisgaard, C., Manta, S., et al. (2007). Serotonin(4) (5-HT(4)) receptor agonists are putative antidepressants with a rapid onset of action. Neuron 55, 712-725. doi: 10.1016/j.neuron.2007.07.041

Luque, C. A., and Rey, J. A. (1999). Sibutramine: a serotonin-norepinephrine reuptake-inhibitor for the treatment of obesity. Ann. Pharmacother. 33, 968-978. doi: 10.1345/aph.18319

Luscombe, G. P., Slater, N. A., Lyons, M. B., Wynne, R. D., Scheinbaum, M. L., and Buckett, W. R. (1990). Effect on radiolabelled-monoamine uptake in vitro of plasma taken from healthy volunteers administered the antidepressant sibutramine HCl. Psychopharmacology (Berl). 100, 345-349. doi: 10.1007/ BF02244604

Marchesi, V. T. (2014). Alzheimer's disease and CADASIL are heritable, adultonset dementias that both involve damaged small blood vessels. Cell. Mol. Life Sci. 71, 949-955. doi: 10.1007/s00018-013-1542-7

Markham, A. (2016). Pimavanserin: first global approval. Drugs 76, 1053-1057. doi: 10.1007/s40265-016-0597-9

Marner, L., Frokjaer, V. G., Kalbitzer, J., Lehel, S., Madsen, K., Baare, W. F., et al. (2012). Loss of serotonin 2A receptors exceeds loss of serotonergic projections in early Alzheimer's disease: a combined [11C]DASB and [18F]altanserin-PET study. Neurobiol. Aging 33, 479-487. doi: 10.1016/j.neurobiolaging.2010.03.023

Martorana, A., and Koch, G. (2014). "Is dopamine involved in Alzheimer's disease?". Front. Aging Neurosci. 6:252. doi: 10.3389/fnagi.2014. 00252

Martorana, A., Mori, F., Esposito, Z., Kusayanagi, H., Monteleone, F., Codecà, C., et al. (2009). Dopamine modulates cholinergic cortical excitability in Alzheimer's disease patients. Neuropsychopharmacology 34, 2323-2328. doi: 10. 1038/npp. 2009.60
Masaki, T., Chiba, S., Yasuda, T., Noguchi, H., Kakuma, T., Watanabe, T., et al. (2004). Involvement of hypothalamic histamine $\mathrm{H} 1$ receptor in the regulation of feeding rhythm and obesity. Diabetes 53, 2250-2260. doi: 10.2337/diabetes. 53.9.2250

Mateo, I., Infante, J., Rodríguez, E., Berciano, J., Combarros, O., and Llorca, J. (2006). Interaction between dopamine beta-hydroxylase and interleukin genes increases Alzheimer's disease risk. J. Neurol. Neurosurg. Psychiatr. 77, 278-279. doi: 10.1136/jnnp.2005.075358

Mauri, M. C., Paletta, S., Maffini, M., Colasanti, A., Dragogna, F., Di Pace, C., et al. (2014). Clinical pharmacology of atypical antipsychotics: an update. EXCLI J. $13,1163-1191$

Mazzucchi, S., Frosini, D., Ripoli, A., Nicoletti, V., Linsalata, G., Bonuccelli, U., et al. (2015). Serotonergic antidepressant drugs and L-dopa-induced dyskinesias in Parkinson's disease. Acta Neurol. Scand. 131, 191-195. doi: 10. 1111/ane.12314

McCann, S. M., Mastronardi, C., de Laurentiis, A., and Rettori, V. (2005). The nitric oxide theory of aging revisited. Ann. N. Y. Acad. Sci. 1057, 64-84. doi: 10. 1196/annals.1356.064

McCreary, A. C., Varney, M. A., and Newman-Tancredi, A. (2016). The novel $5-\mathrm{HT}_{1 \mathrm{~A}}$ receptor agonist, NLX-112 reduces L-DOPA-induced abnormal involuntary movements in rat: a chronic administration study with microdialysis measurements. Neuropharmacology 105, 651-660. doi: 10.1016/ j.neuropharm.2016.01.013

McDonald, W. M., Richard, I. H., and DeLong, M. R. (2003). Prevalence, etiology, and treatment of depression in Parkinson's disease. Biol. Psychiatry 54, 363-375. doi: 10.1016/S0006-3223(03)00530-4

Melamed, E., Zoldan, J., Friedberg, G., Ziv, I., and Weizmann, A. (1996). Involvement of serotonin in clinical features of Parkinson's disease and complications of L-DOPA therapy. Adv. Neurol. 69, 545-550.

Meltzer, C. C., Smith, G., DeKosky, S. T., Pollock, B. G., Mathis, C. A., Moore, R. Y., et al. (1998). Serotonin in aging, late-life depression, and Alzheimer's disease: the emerging role of functional imaging. Neuropsychopharmacology 18, 407-430. doi: 10.1016/S0893-133X(97)00194-2

Meltzer, H. Y. (1993). New drugs for the treatment of schizophrenia. Psychiatr. Clin. North Am. 16, 365-385.

Meltzer, H. Y. (1999). Treatment of schizophrenia and spectrum disorders: pharmacotherapy, psychosocial treatments, and neurotransmitter interactions. Biol. Psychiatry 46, 1321-1327. doi: 10.1016/S0006-3223(99)00255-3

Meltzer, H. Y., and Huang, M. (2008). In vivo actions of atypical antipsychotic drug on serotonergic and dopaminergic systems. Prog. Brain Res. 172, 177-197. doi: 10.1016/S0079-6123(08)00909-6

Meltzer, H. Y., and Massey, B. W. (2011). The role of serotonin receptors in the action of atypical antipsychotic drugs. Curr. Opin. Pharmacol. 11, 59-67. doi: 10.1016/j.coph.2011.02.007

Meltzer, H. Y., Matsubara, S., and Lee, J. C. (1989a). Classification of typical and atypical antipsychotic drugs on the basis of dopamine D-1, D-2 and serotonin2 pKi values. J. Pharmacol. Exp. Ther. 251, 238-246.

Meltzer, H. Y., Matsubara, S., and Lee, J. C. (1989b). The ratios of serotonin2 and dopamine 2 affinities differentiate atypical and typical antipsychotic drugs. Psychopharmacol. Bull. 25, 390-392.

Meltzer, H. Y., Mills, R., Revell, S., Williams, H., Johnson, A., Bahr, D., et al. (2010). Pimavanserin, a serotonin $(2 \mathrm{~A})$ receptor inverse agonist, for the treatment of parkinson's disease psychosis. Neuropsychopharmacology 35, 881-892. doi: 10 . 1038/npp.2009.176

Meltzer, H. Y., and Roth, B. L. (2013). Lorcaserin and pimavanserin: emerging selectivity of serotonin receptor subtype-targeted drugs. J. Clin. Invest. 123, 4986-4991. doi: 10.1172/JCI70678

Mendez-David, I., David, D. J., Darcet, F., Wu, M. V., Kerdine-Romer, S., Gardier, A. M., et al. (2014). Rapid anxiolytic effects of a 5-HT(4) receptor agonist are mediated by a neurogenesis-independent mechanism. Neuropsychopharmacology 39, 1366-1378. doi: 10.1038/npp.2013.332

Meneses, A. (2013). 5-HT systems: emergent targets for memory formation and memory alterations. Rev. Neurosci. 24, 629-664. doi: 10.1515/revneuro-20130026

Miguelez, C., Navailles, S., De Deurwaerdere, P., and Ugedo, L. (2016a). The acute and long-term L-DOPA effects are independent from changes in the activity of dorsal raphe serotonergic neurons in 6-OHDA lesioned rats. Br. J. Pharmacol. 173, 2135-2146. doi: 10.1111/bph.13447 
Miguelez, C., Navailles, S., Delaville, C., Marquis, L., Lagière, M., Benazzouz, A., et al. (2016b). L-DOPA elicits non-vesicular releases of serotonin and dopamine in hemiparkinsonian rats in vivo. Eur. Neuropsychopharmacol. 26, 1297-1309. doi: 10.1016/j.euroneuro.2016.05.004

Millan, M. J. (2005). Serotonin 5-HT2C receptors as a target for the treatment of depressive and anxious states: focus on novel therapeutic strategies. Therapie 60, 441-460. doi: 10.2515/therapie:2005065

Millan, M. J. (2006). Multi-target strategies for the improved treatment of depressive states: Conceptual foundations and neuronal substrates, drug discovery and therapeutic application. Pharmacol. Ther. 110, 135-370. doi: 10. 1016/j.pharmthera.2005.11.006

Millan, M. J. (2010). From the cell to the clinic: a comparative review of the partial $\mathrm{D}(2) / \mathrm{D}(3)$ receptor agonist and alpha2-adrenoceptor antagonist, piribedil, in the treatment of Parkinson's disease. Pharmacol. Ther. 128, 229-273. doi: 10. 1016/j.pharmthera.2010.06.002

Millan, M. J., Brocco, M., Gobert, A., and Dekeyne, A. (2005). Anxiolytic properties of agomelatine, an antidepressant with melatoninergic and serotonergic properties: role of 5-HT2C receptor blockade. Psychopharmacology (Berl). 177, 448-458. doi: 10.1007/s00213-004-1962-z

Millan, M. J., Fone, K., Steckler, T., and Horan, W. P. (2014). Negative symptoms of schizophrenia: clinical characteristics, pathophysiological substrates, experimental models and prospects for improved treatment. Eur. Neuropsychopharmacol. 24, 645-692. doi: 10.1016/j.euroneuro.2014.03.008

Millan, M. J., Goodwin, G. M., Meyer-Lindenberg, A., and Ögren, S. O. (2015a). 60 years of advances in neuropsychopharmacology for improving brain health, renewed hope for progress. Eur. Neuropsychopharmacol. 25, 591-598. doi: 10. 1016/j.euroneuro.2015.01.015

Millan, M. J., Goodwin, G. M., Meyer-Lindenberg, A., and Ove Ögren, S. (2015b). Learning from the past and looking to the future: emerging perspectives for improving the treatment of psychiatric disorders. Eur. Neuropsychopharmacol. 25, 599-656. doi: 10.1016/j.euroneuro.2015.01.016

Millan, M. J., Marin, P., Kamal, M., Jockers, R., Chanrion, B., Labasque, M., et al. (2010). The melatonergic agonist and clinically active antidepressant, agomelatine, is a neutral antagonist at 5-HT2C receptors. Int. J. Neuropsychopharmacol. 14, 768-783. doi: 10.1017/S1461145710001045

Morisset, S., Rouleau, A., Ligneau, X., Gbahou, F., Tardivel-Lacombe, J., Stark, H., et al. (2000). High constitutive activity of native $\mathrm{H} 3$ receptors regulates histamine neurons in brain. Nature 408, 860-864. doi: 10.1038/35048583

Muck-Seler, D., Presecki, P., Mimica, N., Mustapic, M., Pivac, N., Babic, A., et al. (2009). Platelet serotonin concentration and monoamine oxidase type B activity in female patients in early, middle and late phase of Alzheimer's disease. Prog. Neuropsychopharmacol. Biol. Psychiatry 33, 1226-1231. doi: 10.1016/j.pnpbp. 2009.07.004

Murphy, D. L., Sims, K. B., Karoum, F., Garrick, N. A., de la Chapelle, A., Sankila, E. M., et al. (1991). Plasma amine oxidase activities in Norrie disease patients with an X-chromosomal deletion affecting monoamine oxidase. J. Neural Transm. Gen. Sect. 83, 1-12. doi: 10.1007/BF01244447

Mustapic, M., Presecki, P., Pivac, N., Mimica, N., Hof, P. R., Simic, G., et al. (2013). Genotype-independent decrease in plasma dopamine beta-hydroxylase activity in Alzheimer's disease. Prog. Neuropsychopharmacol. Biol. Psychiatry 44, 94-99. doi: 10.1016/j.pnpbp.2013.02.002

Myöhänen, T. T., Schendzielorz, N., and Männistö, P. T. (2010). Distribution of catechol-O-methyltransferase (COMT) proteins and enzymatic activities in wild-type and soluble COMT deficient mice. J. Neurochem. 113, 1632-1643. doi: 10.1111/j.1471-4159.2010.06723.x

Nakazato, T., and Akiyama, A. (1989). Effect of exogenous L-dopa on behavior in the rat: an in vivo voltammetric study. Brain Res. 490, 332-338. doi: 10.1016/ 0006-8993(89)90250-3

Navailles, S., Bioulac, B., Gross, C., and De Deurwaerdère, P. (2010). Serotonergic neurons mediate ectopic release of dopamine induced by L-DOPA in a rat model of Parkinson's disease. Neurobiol. Dis. 38, 136-143. doi: 10.1016/j.nbd. 2010.01.012

Navailles, S., Bioulac, B., Gross, C., and De Deurwaerdère, P. (2011a). Chronic L-DOPA therapy alters central serotonergic function and L-DOPAinduced dopamine release in a region-dependent manner in a rat model of Parkinson's disease. Neurobiol. Dis. 41, 585-590. doi: 10.1016/j.nbd.2010. 11.007
Navailles, S., Carta, M., Guthrie, M., and De Deurwaerdère, P. (2011b). L-DOPA and serotonergic neurons: functional implication and therapeutic perspectives in Parkinson's disease. Cent. Nerv. Syst. Agents Med. Chem. 11, 305-320. doi: 10. 2174/1871524911106040305

Navailles, S., and De Deurwaerdere, P. (2012a). Contribution of serotonergic transmission to the motor and cognitive effects of high-frequency stimulation of the subthalamic nucleus or levodopa in Parkinson's disease. Mol. Neurobiol. 45, 173-185. doi: 10.1007/s12035-011-8230-0

Navailles, S., and De Deurwaerdère, P. (2012b). Imbalanced dopaminergic transmission mediated by serotonergic neurons in L-DOPA-induced dyskinesia. Parkinsons. Dis. 2012, 323686. doi: 10.1155/2012/323686

Navailles, S., Di Giovanni, G., and De Deurwaerdère, P. (2015). The 5-HT4 agonist prucalopride stimulates L-DOPA-induced dopamine release in restricted brain regions of the hemiparkinsonian rat in vivo. CNS Neurosci. Ther. 21, 745-747. doi: $10.1111 / \mathrm{cns} .12436$

Navailles, S., Milan, L., Khalki, H., Di Giovanni, G., Lagière, M., and De Deurwaerdère, P. (2014). Noradrenergic terminals regulate L-DOPA-derived dopamine extracellular levels in a region-dependent manner in Parkinsonian rats. CNS Neurosci. Ther. 20, 671-678. doi: 10.1111/cns.12275

Olanow, C. W., Stern, M. B., and Sethi, K. (2009). The scientific and clinical basis for the treatment of Parkinson disease (2009). Neurology 72(21 Suppl 4), S1-S136. doi: 10.1212/wnl.0b013e3181a1d44c

Owen, M. J., Sawa, A., and Mortensen, P. B. (2016). Schizophrenia. Lancet 388, 86-97. doi: 10.1016/S0140-6736(15)01121-6

Page, M. E., Detke, M. J., Dalvi, A., Kirby, L. G., and Lucki, I. (1999). Serotonergic mediation of the effects of fluoxetine, but not desipramine, in the rat forced swimming test. Psychopharmacology (Berl). 147, 162-167. doi: 10.1007/ s002130051156

Palmieri, V., Arnett, D. K., Roman, M. J., Liu, J. E., Bella, J. N., Oberman, A., et al. (2002). Appetite suppressants and valvular heart disease in a population-based sample: the HyperGEN study. Am. J. Med. 112, 710-715. doi: 10.1016/S00029343(02)01123-3

Panula, P., Chazot, P. L., Cowart, M., Gutzmer, R., Leurs, R., Liu, W. L., et al. (2015). International union of basic and clinical pharmacology. XCVIII. Histamine Receptors. Pharmacol Rev 67, 601-655. doi: 10.1124/pr.114.010249

Parsons, C. G., Danysz, W., Dekundy, A., and Pulte, I. (2013). Memantine and cholinesterase inhibitors: complementary mechanisms in the treatment of Alzheimer's disease. Neurotox. Res. 24, 358-369. doi: 10.1007/s12640-013-9398$\mathrm{Z}$

Pascual, J., Grijalba, B., García-Sevilla, J. A., Zarranz, J. J., and Pazos, A. (1992). Loss of high-affinity alpha 2-adrenoceptors in Alzheimer's disease: an autoradiographic study in frontal cortex and hippocampus. Neurosci. Lett. 142, 36-40. doi: 10.1016/0304-3940(92)90614-D

Payton, S., Cahill, C. M., Randall, J. D., Gullans, S. R., and Rogers, J. T. (2003). Drug discovery targeted to the Alzheimer's APP mRNA 5'-untranslated region: the action of paroxetine and dimercaptopropanol. J. Mol. Neurosci. 20, 267-275. doi: 10.1385/JMN:20:3:267

Perez-Caballero, L., Torres-Sanchez, S., Bravo, L., Mico, J. A., and Berrocoso, E. (2014). Fluoxetine: a case history of its discovery and preclinical development. Expert Opin. Drug Discov. 9, 567-578. doi: 10.1517/17460441.2014.907790

Perez-Lloret, S., and Rascol, O. (2016). Piribedil for the treatment of motor and non-motor symptoms of Parkinson disease. CNS Drugs. 30, 703-717. doi: 10. 1007/s40263-016-0360-5

Peskind, E. R., Tsuang, D. W., Bonner, L. T., Pascualy, M., Riekse, R. G., Snowden, M. B., et al. (2005). Propranolol for disruptive behaviors in nursing home residents with probable or possible Alzheimer disease: a placebocontrolled study. Alzheimer Dis. Assoc. Disord. 19, 23-28. doi: 10.1097/01.wad. $0000155067.16313 .5 \mathrm{e}$

Piñeyro, G., and Blier, P. (1999). Autoregulation of serotonin neurons: role in antidepressant drug action. Pharmacol. Rev. 51, 533-591.

Porras, G., De Deurwaerdere, P., Li, Q., Marti, M., Morgenstern, R., Sohr, R., et al. (2014). L-dopa-induced dyskinesia: beyond an excessive dopamine tone in the striatum. Sci. Rep. 4:3730. doi: 10.1038/srep03730

Poyurovsky, M., Fuchs, C., Pashinian, A., Levi, A., Weizman, R., and Weizman, A. (2013). Reducing antipsychotic-induced weight gain in schizophrenia: a double-blind placebo-controlled study of reboxetine-betahistine combination. Psychopharmacology (Berl). 226, 615-622. doi: 10.1007/s00213-012-2935-2 
Preda, S., Govoni, S., Lanni, C., Racchi, M., Mura, E., Grilli, M., et al. (2008). Acute beta-amyloid administration disrupts the cholinergic control of dopamine release in the nucleus accumbens. Neuropsychopharmacology 33, 1062-1070. doi: 10.1038/sj.npp.1301485

Provensi, G., Blandina, P., and Passani, M. B. (2016). The histaminergic system as a target for the prevention of obesity and metabolic syndrome. Neuropharmacology 106, 3-12. doi: 10.1016/j.neuropharm.2015.07.002

Provensi, G., Coccurello, R., Umehara, H., Munari, L., Giacovazzo, G., Galeotti, N., et al. (2014). Satiety factor oleoylethanolamide recruits the brain histaminergic system to inhibit food intake. Proc. Natl. Acad. Sci. U.S.A. 111, 11527-11532. doi: 10.1073/pnas.1322016111

Racagni, G., Riva, M. A., Molteni, R., Musazzi, L., Calabrese, F., Popoli, M., et al. (2011). Mode of action of agomelatine: synergy between melatonergic and 5HT2C receptors. World J. Biol. Psychiatry 12, 574-587. doi: 10.3109/15622975. 2011.595823

Ramirez, M. J., Lai, M. K., Tordera, R. M., and Francis, P. T. (2014). Serotonergic therapies for cognitive symptoms in Alzheimer's disease: rationale and current status. Drugs 74, 729-736. doi: 10.1007/s40265-014-0217-5

Ramsay, R. R. (2013). Inhibitor design for monoamine oxidases. Curr. Pharm. Des. 19, 2529-2539. doi: 10.2174/1381612811319140004

Rantamaki, T., and Yalcin, I. (2016). Antidepressant drug actionFrom rapid changes on network function to network rewiring. Prog. Neuropsychopharmacol. Biol. Psychiatry 64, 285-292. doi: 10.1016/j.pnpbp. 2015.06.001

Rascol, O., Fitzer-Attas, C. J., Hauser, R., Jankovic, J., Lang, A., Langston, J. W., et al. (2011). A double-blind, delayed-start trial of rasagiline in Parkinson's disease (the ADAGIO study): prespecified and post-hoc analyses of the need for additional therapies, changes in UPDRS scores, and non-motor outcomes. Lancet Neurol. 10, 415-423. doi: 10.1016/S1474-4422(11)70073-4

Ratliff, J. C., Barber, J. A., Palmese, L. B., Reutenauer, E. L., and Tek, C. (2010). Association of prescription $\mathrm{H} 1$ antihistamine use with obesity: results from the National Health and Nutrition Examination Survey. Obesity (Silver. Spring). 18, 2398-2400. doi: 10.1038/oby.2010.176

Reifler, B. V., Teri, L., Raskind, M., Veith, R., Barnes, R., White, E., et al. (1989). Double-blind trial of imipramine in Alzheimer's disease patients with and without depression. Am. J. Psychiatry 146, 45-49. doi: 10.1176/ajp.146.1.45

Remington, G., Foussias, G., Fervaha, G., Agid, O., Takeuchi, H., Lee, J., et al. (2016). Treating negative symptoms in schizophrenia: an update. Curr Treat Options Psychiatry 3, 133-150. doi: 10.1007/s40501-016-0075-8

Reynolds, G. P., Mason, S. L., Meldrum, A., De Keczer, S., Parnes, H., Eglen, R. M., et al. (1995). 5-Hydroxytryptamine (5-HT) 4 receptors in post mortem human brain tissue: distribution, pharmacology and effects of neurodegenerative diseases. Br. J. Pharmacol. 114, 993-998. doi: 10.1111/j.1476-5381.1995. tb13303.x

Rezvani, A. H., Kholdebarin, E., Brucato, F. H., Callahan, P. M., Lowe, D. A., and Levin, E. D. (2009). Effect of R3487/MEM3454, a novel nicotinic alpha7 receptor partial agonist and 5-HT3 antagonist on sustained attention in rats. Prog. Neuropsychopharmacol. Biol. Psychiatry 33, 269-275. doi: 10.1016/j. pnpbp.2008.11.018

Richtand, N. M., Welge, J. A., Logue, A. D., Keck, P. E. Jr., Strakowski, S. M., and McNamara, R. K. (2008). Role of serotonin and dopamine receptor binding in antipsychotic efficacy. Prog. Brain Res. 172, 155-175. doi: 10.1016/S00796123(08)00908-4

Riederer, P., and Laux, G. (2011). MAO-inhibitors in Parkinson's disease. Exp. Neurobiol. 20, 1-17. doi: 10.5607/en.2011.20.1.1

Ries, V., Selzer, R., Eichhorn, T., Oertel, W. H., and Eggert, K. (2010). Replacing a dopamine agonist by the COMT-inhibitor tolcapone as an adjunct to L-dopa in the treatment of Parkinson's disease: a randomized, multicenter, open-label, parallel-group study. Clin. Neuropharmacol. 33, 142-150. doi: 10.1097/WNF. 0b013e3181d99d6f

Rommelfanger, K. S., and Weinshenker, D. (2007). Norepinephrine: the redheaded stepchild of Parkinson's disease. Biochem. Pharmacol. 74, 177-190. doi: 10. 1016/j.bcp.2007.01.036

Rosenzweig-Lipson, S., Comery, T. A., Marquis, K. L., Gross, J., and Dunlop, J. (2012). 5- $\mathrm{HT}_{2 \mathrm{C}}$ agonists as therapeutics for the treatment of schizophrenia. Handb. Exp. Pharmacol. 213, 147-165. doi: 10.1007/978-3-64225758-2_6
Roth, B. L., and Driscol, J. (2016). Psychoactive Drug Screening Program Ki Database. Chapel Hill, NC: University of North Carolina at Chapel Hill and the United States National Institute of Mental Health.

Sachdev, M., Miller, W. C., Ryan, T., and Jollis, J. G. (2002). Effect of fenfluraminederivative diet pills on cardiac valves: a meta-analysis of observational studies. Am. Heart J. 144, 1065-1073. doi: 10.1067/mhj.2002.126733

Sagud, M., Nikolac Perkovic, M., Vuksan-Cusa, B., Maravic, A., Svob Strac, D., Mihaljevic Peles, A., et al. (2016). A prospective, longitudinal study of platelet serotonin and plasma brain-derived neurotrophic factor concentrations in major depression: effects of vortioxetine treatment. Psychopharmacology (Berl). 233, 3259-3267. doi: 10.1007/s00213-016-4364-0

San, L., and Arranz, B. (2008). Agomelatine: a novel mechanism of antidepressant action involving the melatonergic and the serotonergic system. Eur. Psychiatry 23, 396-402. doi: 10.1016/j.eurpsy.2008.04.002

Sanchez, C., Asin, K. E., and Artigas, F. (2015). Vortioxetine, a novel antidepressant with multimodal activity: review of preclinical and clinical data. Pharmacol. Ther. 145, 43-57. doi: 10.1016/j.pharmthera.2014.07.001

Sanz, E., Quintana, A., Battaglia, V., Toninello, A., Hidalgo, J., Ambrosio, S., et al (2008). Anti-apoptotic effect of Mao-B inhibitor PF9601N [N-(2-propynyl)2-(5-benzyloxy-indolyl) methylamine] is mediated by p53 pathway inhibition in MPP+-treated SH-SY5Y human dopaminergic cells. J. Neurochem. 105, 2404-2417. doi: 10.1111/j.1471-4159.2008.05326.x

Sanz, E., Romera, M., Bellik, L., Marco, J. I., and Unzeta, M. (2004). Indolalkylamines derivatives as antioxidant and neuroprotective agents in an experimental model of Parkinson's disease. Med. Sci. Monit. 10, BR477-BR484

Saura, J., Bleuel, Z., Ulrich, J., Mendelowitsch, A., Chen, K., Shih, J. C., et al. (1996). Molecular neuroanatomy of human monoamine oxidases A and B revealed by quantitative enzyme radioautography and in situ hybridization histochemistry. Neuroscience 70, 755-774. doi: 10.1016/S0306-4522(96) 83013-2

Saura, J., Kettler, R., Da Prada, M., and Richards, J. G. (1992). Quantitative enzyme radioautography with 3H-Ro 41-1049 and 3H-Ro 19-6327 in vitro: localization and abundance of MAO-A and MAO-B in rat CNS, peripheral organs, and human brain. J. Neurosci. 12, 1977-1999.

Scheen, A. J. (2010). Cardiovascular risk-benefit profile of sibutramine. Am. J. Cardiovasc. Drugs 10, 321-334. doi: 10.2165/11584800-000000000-00000

Schendzielorz, N., Oinas, J. P., Myöhänen, T. T., Reenilä, I., Raasmaja, A., and Männistö, P. T. (2013). Catechol-O-methyltransferase (COMT) protein expression and activity after dopaminergic and noradrenergic lesions of the rat brain. PLOS ONE 8:e61392. doi: 10.1371/journal.pone. 0061392

Schreiber, R., and Newman-Tancredi, A. (2014). Improving cognition in schizophrenia with antipsychotics that elicit neurogenesis through $5-\mathrm{HT}(1 \mathrm{~A})$ receptor activation. Neurobiol. Learn. Mem. 110, 72-80. doi: 10.1016/j.nlm. 2013.12.015

Seeman, P. (2015). Parkinson's disease treatment may cause impulse-control disorder via dopamine D3 receptors. Synapse 69, 183-189. doi: 10.1002/syn. 21805

Seeman, P., Chau-Wong, M., Tedesco, J., and Wong, K. (1975). Brain receptors for antipsychotic drugs and dopamine: direct binding assays. Proc. Natl. Acad. Sci. U.S.A. 72, 4376-4380. doi: 10.1073/pnas.72.11.4376

Seeman, P., Lee, T., Chau-Wong, M., and Wong, K. (1976). Antipsychotic drug doses and neuroleptic/dopamine receptors. Nature 261, 717-719. doi: 10.1038/ $261717 \mathrm{a} 0$

Shankle, W. R., Nielson, K. A., and Cotman, C. W. (1995). Low-dose propranolol reduces aggression and agitation resembling that associated with orbitofrontal dysfunction in elderly demented patients. Alzheimer Dis. Assoc. Disord. 9, 233-237. doi: 10.1097/00002093-199509040-00010

Shen, J. H., Zhao, Y., Rosenzweig-Lipson, S., Popp, D., Williams, J. B., Giller, E., et al. (2014). A 6-week randomized, double-blind, placebo-controlled, comparator referenced trial of vabicaserin in acute schizophrenia. J. Psychiatr. Res. 53, 14-22. doi: 10.1016/j.jpsychires.2014.02.012

Šimić, G., Babić Leko, M., Wray, S., Harrington, C. R., Delalle, I., Jovanov-Milošević, N., et al. (2016). Monoaminergic neuropathology in Alzheimer's disease. Prog. Neurobiol. doi: 10.1016/j.pneurobio.2016. 04.001. [Epub ahead of print]. 
Simoni, E., Daniele, S., Bottegoni, G., Pizzirani, D., Trincavelli, M. L., Goldoni, L., et al. (2012). Combining galantamine and memantine in multitargeted, new chemical entities potentially useful in Alzheimer's disease. J. Med. Chem. 55, 9708-9721. doi: 10.1021/jm3009458

Sims, N. R., Bowen, D. M., Smith, C. C., Flack, R. H., Davison, A. N., Snowden, J. S., et al. (1980). Glucose metabolism and acetylcholine synthesis in relation to neuronal activity in Alzheimer's disease. Lancet 1, 333-336. doi: 10.1016/S01406736(80)90884-3

Smith, D. J., Salmi, M., Bono, P., Hellman, J., Leu, T., and Jalkanen, S. (1998). Cloning of vascular adhesion protein 1 reveals a novel multifunctional adhesion molecule. J. Exp. Med. 188, 17-27. doi: 10.1084/jem.188.1.17

Solé, M., Hernandez-Guillamon, M., Boada, M., and Unzeta, M. (2008). p53 phosphorylation is involved in vascular cell death induced by the catalytic activity of membrane-bound SSAO/VAP-1. Biochim. Biophys. Acta 1783, 1085-1094. doi: 10.1016/j.bbamcr.2008.02.014

Solé, M., Minano-Molina, A. J., and Unzeta, M. (2015). Cross-talk between Abeta and endothelial SSAO/VAP-1 accelerates vascular damage and Abeta aggregation related to CAA-AD. Neurobiol. Aging 36, 762-775. doi: 10.1016/ j.neurobiolaging.2014.09.030

Stahl, S. M. (2015). Modes and nodes explain the mechanism of action of vortioxetine, a multimodal agent (MMA): blocking $5 \mathrm{HT} 3$ receptors enhances release of serotonin, norepinephrine, and acetylcholine. CNS Spectr. 20, 455-459. doi: 10.1017/S1092852915000346

Stansley, B. J., and Yamamoto, B. K. (2013). L-dopa-induced dopamine synthesis and oxidative stress in serotonergic cells. Neuropharmacology 67, 243-251. doi: 10.1016/j.neuropharm.2012.11.010

Stansley, B. J., and Yamamoto, B. K. (2014). Chronic L-dopa decreases serotonin neurons in a subregion of the dorsal raphe nucleus. J. Pharmacol. Exp. Ther. 351, 440-447. doi: 10.1124/jpet.114.218966

Storga, D., Vrecko, K., Birkmayer, J. G., and Reibnegger, G. (1996). Monoaminergic neurotransmitters, their precursors and metabolites in brains of Alzheimer patients. Neurosci. Lett. 203, 29-32. doi: 10.1016/0304-3940(95)12256-7

Strac, D., Pivac, N., Smolders, I. J., Fogel, W., De Deurwaerdere, P., and Di Giovanni, G. (2016). Monoaminergic mechanisms in epilepsy may offer innovative therapeutic opportunity for monoaminergic multi-target drugs. Front. Neurosci. 10:492. doi: 10.3389/fnins.2016.00492

Sun, P., Esteban, G., Inokuchi, T., Marco-Contelles, J., Weksler, B. B., Romero, I. A., et al. (2015). Protective effect of the multitarget compound DPH-4 on human SSAO/VAP-1-expressing hCMEC/D3 cells under oxygen-glucose deprivation conditions: an in vitro experimental model of cerebral ischaemia. Br. J. Pharmacol. 172, 5390-5402. doi: 10.1111/bph.13328

Svenningsson, P., Rosenblad, C., Af Edholm Arvidsson, K., Wictorin, K., Keywood, C., Shankar, B., et al. (2015). Eltoprazine counteracts 1-DOPAinduced dyskinesias in Parkinson's disease: a dose-finding study. Brain $138(\mathrm{Pt}$ 4), 963-973. doi: 10.1093/brain/awu409

Szot, P., White, S. S., Greenup, J. L., Leverenz, J. B., Peskind, E. R., and Raskind, M. A. (2006). Compensatory changes in the noradrenergic nervous system in the locus ceruleus and hippocampus of postmortem subjects with Alzheimer's disease and dementia with Lewy bodies. J. Neurosci. 26, 467-478. doi: 10.1523/ JNEUROSCI.4265-05.2006

Tammimäki, A., Käenmäki, M., Kambur, O., Kulesskaya, N., Keisala, T., Karvonen, E., et al. (2010). Effect of S-COMT deficiency on behavior and extracellular brain dopamine concentrations in mice. Psychopharmacology (Berl). 211, 389-401. doi: 10.1007/s00213-010-1944-2

Tanaka, H., Kannari, K., Maeda, T., Tomiyama, M., Suda, T., and Matsunaga, M. (1999). Role of serotonergic neurons in L-DOPA-derived extracellular dopamine in the striatum of 6-OHDA-lesioned rats. Neuroreport 10, 631-634. doi: 10.1097/00001756-199902250-00034

Taylor, K. M. (1975). "Brain histamine," in Biochemistry of Biogenic Amines, eds L. L. Iversen, S. D. Iversen, and S. H. Snyder (New York, NY: Plenum Press New Yok and London), 327-380. doi: 10.1007/978-1-4684-3171-1 6

Terry, A. V. Jr., Buccafusco, J. J., and Wilson, C. (2008). Cognitive dysfunction in neuropsychiatric disorders: selected serotonin receptor subtypes as therapeutic targets. Behav. Brain Res. 195, 30-38. doi: 10.1016/j.bbr.2007.12.006

Thase, M. E., Corya, S. A., Osuntokun, O., Case, M., Henley, D. B., Sanger, T. M., et al. (2007). A randomized, double-blind comparison of olanzapine/fluoxetine combination, olanzapine, and fluoxetine in treatmentresistant major depressive disorder. J. Clin. Psychiatry 68, 224-236. doi: 10. 4088/JCP.v68n0207
Thomas, D. R., Nelson, D. R., and Johnson, A. M. (1987). Biochemical effects of the antidepressant paroxetine, a specific 5-hydroxytryptamine uptake inhibitor. Psychopharmacology (Berl). 93, 193-200. doi: 10.1007/BF001 79933

Tighilet, B., Trottier, S., Mourre, C., Chotard, C., and Lacour, M. (2002). Betahistine dihydrochloride interaction with the histaminergic system in the cat: neurochemical and molecular mechanisms. Eur. J. Pharmacol. 446, 63-73. doi: 10.1016/S0014-2999(02)01795-8

Tohgi, H., Ueno, M., Abe, T., Takahashi, S., and Nozaki, Y. (1992). Concentrations of monoamines and their metabolites in the cerebrospinal fluid from patients with senile dementia of the Alzheimer type and vascular dementia of the Binswanger type. J. Neural Transm. Park. Dis. Dement. Sect. 4, 69-77. doi: 10. 1007/BF02257623

Tonelli, M., Catto, M., Tasso, B., Novelli, F., Canu, C., Iusco, G., et al. (2015). Multitarget therapeutic leads for Alzheimer's disease: quinolizidinyl derivatives of $\mathrm{Bi}$ - and tricyclic systems as dual inhibitors of cholinesterases and betaamyloid (Abeta) aggregation. ChemMedChem 10, 1040-1053. doi: 10.1002/ cmdc. 201500104

Torres, G. E., Gainetdinov, R. R., and Caron, M. G. (2003). Plasma membrane monoamine transporters: structure, regulation and function. Nat. Rev. Neurosci. 4, 13-25. doi: 10.1038/nrn 1008

Trillo, L., Das, D., Hsieh, W., Medina, B., Moghadam, S., Lin, B., et al (2013). Ascending monoaminergic systems alterations in Alzheimer's disease. Translating basic science into clinical care. Neurosci. Biobehav. Rev. 37, 1363-1379. doi: 10.1016/j.neubiorev.2013.05.008

Tronci, E., Fidalgo, C., Stancampiano, R., and Carta, M. (2015). Effect of selective and non-selective serotonin receptor activation on 1-DOPA-induced therapeutic efficacy and dyskinesia in parkinsonian rats. Behav. Brain Res. 292, 300-304. doi: 10.1016/j.bbr.2015.06.034

Udenfriend, S., Weissbach, H., and Bogdanski, D. F. (1957). Effect of iproniazid on serotonin metabolism in vivo. J. Pharmacol. Exp. Ther. 120, 255-260.

Versijpt, J., Van Laere, K. J., Dumont, F., Decoo, D., Vandecapelle, M., Santens, P., et al. (2003). Imaging of the 5-HT2A system: age-, gender-, and Alzheimer's disease-related findings. Neurobiol. Aging 24, 553-561. doi: 10.1016/S01974580(02)00137-9

Vickers, S. P., Dourish, C. T., and Kennett, G. A. (2001). Evidence that hypophagia induced by $\mathrm{d}$-fenfluramine and d-norfenfluramine in the rat is mediated by 5-HT2C receptors. Neuropharmacology 41, 200-209. doi: 10.1016/S00283908(01)00063-6

Visanji, N. P., Fox, S. H., Johnston, T., Reyes, G., Millan, M. J., and Brotchie, J. M. (2009). Dopamine D3 receptor stimulation underlies the development of LDOPA-induced dyskinesia in animal models of Parkinson's disease. Neurobiol. Dis. 35, 184-192. doi: 10.1016/j.nbd.2008.11.010

Vivero, L. E., Anderson, P. O., and Clark, R. F. (1998). A close look at fenfluramine and dexfenfluramine. J. Emerg. Med. 16, 197-205. doi: 10.1016/ S0736-4679(97)00289-8

Voigt, J. P., and Fink, H. (2015). Serotonin controlling feeding and satiety. Behav. Brain Res. 277, 14-31. doi: 10.1016/j.bbr.2014.08.065

Werner, F. M., and Covenas, R. (2016). Serotonergic drugs: agonists/antagonists at specific serotonergic subreceptors for the treatment of cognitive, depressant and psychotic symptoms in Alzheimer's disease. Curr. Pharm. Des. 22, 2064-2071. doi: 10.2174/1381612822666160127113524

Wimalasena, K. (2011). Vesicular monoamine transporters: structure-function, pharmacology, and medicinal chemistry. Med. Res. Rev. 31, 483-519. doi: 10. 1002/med.20187

Wong, D. T., Bymaster, F. P., Horng, J. S., and Molloy, B. B. (1975). A new selective inhibitor for uptake of serotonin into synaptosomes of rat brain: 3-(ptrifluoromethylphenoxy). N-methyl-3-phenylpropylamine. J. Pharmacol. Exp. Ther. 193, 804-811.

Yan, W., Zhao, C., Sun, L., and Tang, B. (2016). Association between polymorphism of COMT gene (Val158Met) with Alzheimer's disease: an updated analysis. J. Neurol. Sci. 361, 250-255. doi: 10.1016/j.jns.2016. 01.014

Youdim, M. B., Edmondson, D., and Tipton, K. F. (2006). The therapeutic potential of monoamine oxidase inhibitors. Nat. Rev. Neurosci. 7, 295-309. doi: 10.1038/ nrn 1883

Yu, P. H., and Deng, Y. L. (1998). Endogenous formaldehyde as a potential factor of vulnerability of atherosclerosis: involvement of semicarbazide-sensitive amine 
oxidase-mediated methylamine turnover. Atherosclerosis 140, 357-363. doi: 10. 1016/S0021-9150(98)00142-7

Zeller, E. A., and Barsky, J. (1952). In vivo inhibition of liver and brain monoamine oxidase by 1-Isonicotinyl-2-isopropyl hydrazine. Proc. Soc. Exp. Biol. Med. 81, 459-461. doi: 10.3181/00379727-81-19910

Zlokovic, B. V. (2008). New therapeutic targets in the neurovascular pathway in Alzheimer's disease. Neurotherapeutics 5, 409-414. doi: 10.1016/j.nurt.2008. 05.011

Zohar, J., Stahl, S., Moller, H. J., Blier, P., Kupfer, D., Yamawaki, S., et al. (2015). A review of the current nomenclature for psychotropic agents and an introduction to the neuroscience-based nomenclature. Eur. Neuropsychopharmacol. 25, 2318-2325. doi: 10.1016/j.euroneuro.2015.08.019
Conflict of Interest Statement: The authors declare that the research was conducted in the absence of any commercial or financial relationships that could be construed as a potential conflict of interest.

Copyright $\odot 2016$ Di Giovanni, Svob Strac, Sole, Unzeta, Tipton, Mück-Šeler, Bolea, Della Corte, Nikolac Perkovic, Pivac, Smolders, Stasiak, Fogel and De Deurwaerdère. This is an open-access article distributed under the terms of the Creative Commons Attribution License (CC BY). The use, distribution or reproduction in other forums is permitted, provided the original author(s) or licensor are credited and that the original publication in this journal is cited, in accordance with accepted academic practice. No use, distribution or reproduction is permitted which does not comply with these terms. 